UNIVERSIDADE DE SÃO PAULO

INSTITUTO DE FÍSICA DA USP

SÍNTESE CRÍTICA DE PARTE DA OBRA DE KALINE COUTINHO

\title{
Modelagem Molecular: Efeito do Meio em Propriedades Eletrônicas e Estruturais
}

\author{
KALINE RABELO COUTINHO
}

Apresentado ao Instituto de Física da Universidade de São Paulo como parte dos requisitos de inscrição para o Concurso Livre-Docente Edital IF17/2012.

Abril de 2012 


\section{FICHA CATALOGRÁFICA}

\section{Preparada pelo Serviço de Biblioteca e Informação} do Instituto de Física da Universidade de São Paulo

Coutinho, Kaline Rabelo

Modelagem molecular: efeito do meio em propriedades eletrônicas e estruturais. - São Paulo, 2012.

Tese (Livre-Docência) - Universidade de São Paulo. Instituto de Física, Depto. Física Geral

Área de Concentração: Modelagem molecular

Unitermos: 1. Modelagem molecular; 2. Estrutura eletrônica; 3. Espectroscopia eletrônica. 
ÍNDICE

1. INTRODUÇÃ

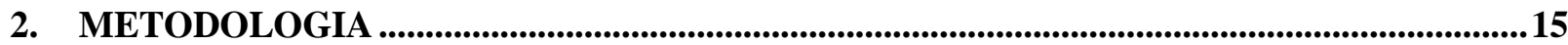

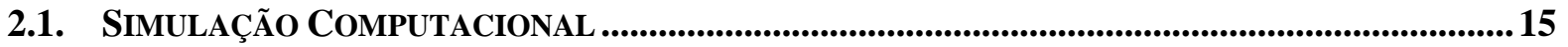

2.2. Método Monte CaRlo IMPlementado no Código DICE ...........................................17

2.3. Método Híbrido Sequencial com MeCÂNiCa QUÂNTICA E MeCÂNiCa Molecular 26

2.4. FUnÇÃo de DISTRIBUIÇÃo de MÍNIMA DISTÂNCIA...............................................................33

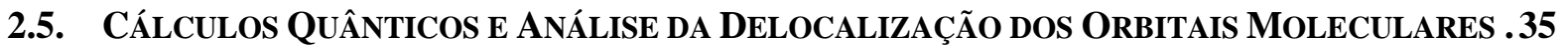

2.6. Configuração Eletrostática Média do Solvente ........................................................37

2.7. PRocedimento de PolarizaÇÃo Iterativo ..................................................................39

2.8. CÁlCUlo de VARIAÇões de ENERGIA LIVRe ......................................................................41

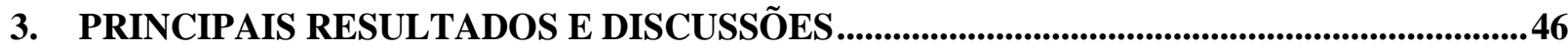

3.1. Método Híbrido SEQuencial com Mecânica QuÂnTICA E MeCÂNiCa Molecular 46

3.1.1. ADVANCES IN QUANTUM CHEMISTRY, 28, 89, (1997) ....................................................... 46

3.1.2. INTERNATIONAL JOURNAL OF QUANTUM CHEMISTRY, 66, 249 (1998) ................................ 48

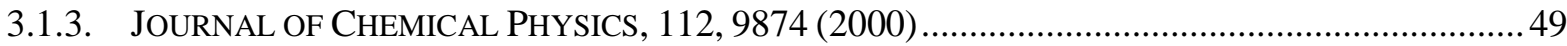

3.1.4. INTERNATIONAL JOURNAL OF QUANTUM CHEMISTRY, 77, 192 (2000) .................................51

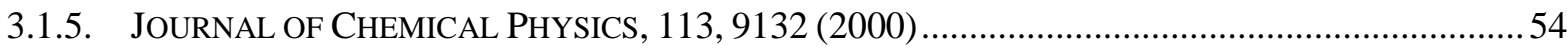

3.2. FUnÇÃo DE DiSTRIBUIÇão DE MÍNIMA DiSTÂNCIA (MDDF) ...............................................56

3.2.1. ADVANCES IN QUANTUM CHEMISTRY, 41, 161 (2002) ........................................................56

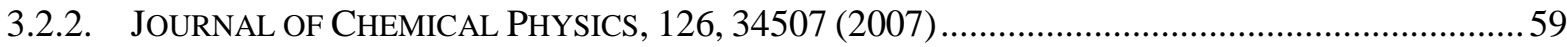

3.3. ANÁliSE DA DELOCALIZAÇÃo DOS ORBITAIS MOLECULARES .........................................62

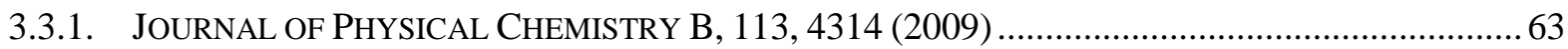

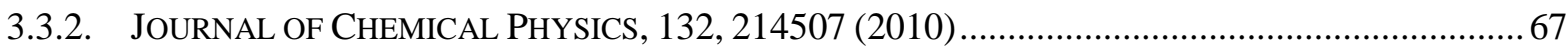

3.4. ConfiguraÇÃo Eletrostática Média do Solvente (ASEC) .........................................69

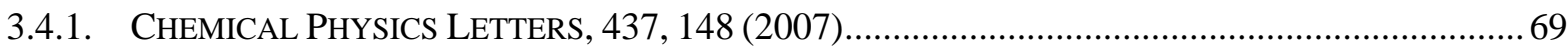

3.5. PROCEDIMENTO DE PolaRIZAÇÃo ITERATIVO .......................................................................71

3.5.1. CHEMICAL PHYSICS LETTERS, 429, 119 (2006) .................................................................... 71

3.5.2. JOURNAL OF PHYSICAL CHEMISTRY B, 116, 2713 (2012) ..................................................73 


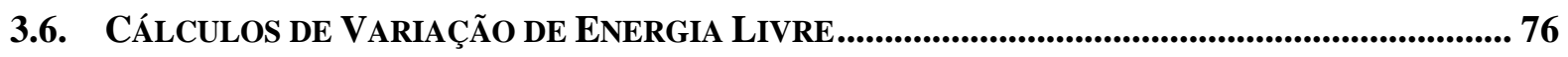

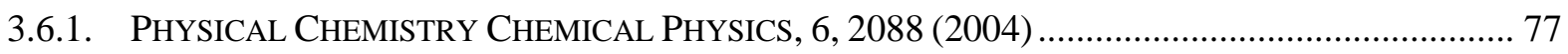

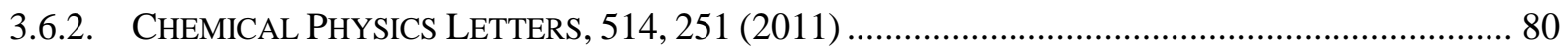

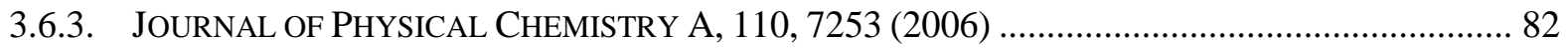

3.6.4. THEORETICAL CHEMISTRY ACCOUNTS, 131, 1214 (2012)................................................... 84

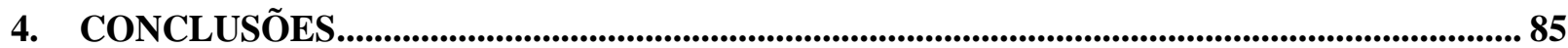

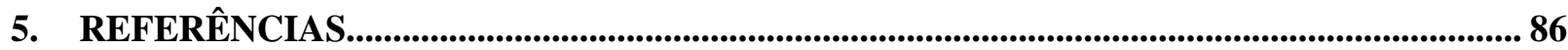

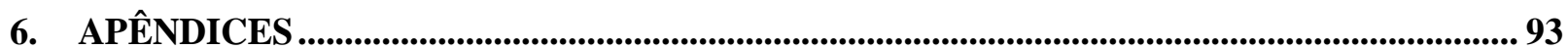




\section{ÍNDICE DE FIGURAS}

Figura 1: Exemplos de funções de distribuição radial de pares entre centros de massa para sistemas em fase líquida: pirimidina em tetracloreto de carbono (esquerda) e em água (direita). Gráficos retirados da ref. [59]...25 Figura 2: Ilustração de uma configuração molecular da pirimidina rodeada pelas moléculas de água que formam: ligações de hidrogênio (esquerda), a primeira camada de solvatação (centro) e até a segunda camada de solvatação (direita). .26

Figura 3: Exemplo de função de autocorrelação da energia potencial por molécula (círculos) e do ajuste da função exponencial de decaimento duplo (linha). Os valores ajustados e o tempo de correlação também estão apresentados. Gráfico retirado da ref. [64].

Figura 4: Exemplo de análise da ineficiência estatística, s, calculada para cadeia de valores $\{U i\}$ com diferentes tamanhos L. A linha tracejada representa o valor estimado de s. Gráfico retirado da ref. [64].

Figura 5: Exemplo de valores calculados para energia de ligação (esquerda) e a distribuição gaussiana (direita) obtida para 160 configurações estatisticamente descorrelacionadas. Gráfico retirado da ref. [60]. ....................31

Figura 6: Exemplo da convergência da média em relação à quantidade de configurações utilizadas na média. Os valores utilizados na média estão mostrados na Figura 5. Gráfico retirado da ref. [60].

Figura 7: Exemplo da dependência do deslocamento da banda de transição eletrônica com relação à quantidade de moléculas de solvente incluídas explicitamente nos cálculos quânticos. Gráfico da esquerda retirado da ref. [38]. Gráfico da direita mostra diferenças em considerar o campo eletrostático remanescente do solvente além das moléculas explícitas (dados da ref. [66]).

Figura 8: Ilustração do volume normalização da RDF no formato de casca esférica (esquerda) e da MDDF no formato de casca de paralelepípedo (direita). Figura retirada da ref. [40] .................................................34 Figura 9: Ilustração da molécula de benzofenona rodeada por 45 moléculas de água em uma configuração gerada na simulação utilizando o critério de proximidade: do centro de massa (esquerda) e da mínima distância

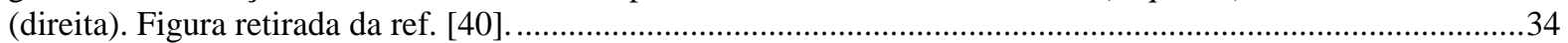
Figura 10: Ilustração da delocalização do orbital mais alto ocupado, HOMO, na solução aquosa de metilamina (esquerda) e de fluoreto (direita), ambos soluto rodeados pela primeira camada de solvatação. .......................36 Figura 11: Ilustração de uma molécula: com envolvimento eletrostático gerado a partir de uma configuração selecionada da simulação, com 250 moléculas de água descritas como cargas pontuais (esquerda), e com ASEC gerada a partir de 60 configurações estatisticamente descorrelacionadas selecionada da simulação, e cada configuração com 250 moléculas de água descritas como cargas pontuais (direita)........................................38 Figura 12: Exemplo da dependência do momento de dipolo durante o procedimento de polarização iterativo SQM/MM para benzofenona em solução aquosa. Na esquerda, cálculos com 100 configurações para solução aquosa em condições normal, o círculo branco representa o momento de dipolo obtido com o procedimento padrão dos campos de força. Na esquerda, cálculos com ASEC, os círculos brancos são obtidos para solução aquosa em condições normal e os círculos pretos em condições supercríticas. Gráficos retirados da ref. [40] (esquerda) e da ref. [91] (direita)...

Figura 13: Esquema do ciclo termodinâmico. ....................................................................................43

Figura 14: Esquema do processo de solvatação ou aniquilação. ...........................................................44

Figura 15: Exemplo da mudança do potencial Lennard-Jones no início (linha sólida) e fim (linha tracejada) da segunda etapa do processo de aniquilação. Gráfico retirado da ref. [97]. ................................................45 Figura 16: Funções de distribuição radial de pares dos carbonos do benzeno com carbonos e oxigênios de 4 solventes: (a) $\mathrm{C}_{6} \mathrm{H}_{6}$, (b) $\mathrm{H}_{2} \mathrm{O}$, (c) $\mathrm{C}_{6} \mathrm{H}_{12}$ e (d) $\mathrm{CCl}_{4}$ (esquerda) e dependência do solvatocromismo da primeira banda de absorção eletrônica do benzeno com relação ao número de moléculas do solvente explicitamente incluídos no cálculos quânticos (direita). Nesse gráfico os pontos sólidos mostram a primeira camada de solvatação. Gráficos retirados da ref. [36].

Figura 17: Ilustração das curvas de energia do estado fundamental, $g$, e primeiro estado excitado, $e$, dos processos de transição eletrônica através da absorção de luz, $v_{0}$, e emissão completamente relaxada de luz, $v_{2}$, e dos efeitos de solvente na absorção, $\Delta E_{\text {solv }}^{\text {abs }}=h\left(v_{1}-v_{0}\right)$, na emissão, $\Delta E_{\text {solv }}^{\text {emi }}=h\left(v_{3}-v_{2}\right)$, e no deslocamento de Stokes, $\Delta E_{\text {solv }}^{\text {Stokes }}=h\left[\left(v_{2}-v_{0}\right)-\left(v_{3}-v_{1}\right)\right]$. Figura retirada da ref. [38].

Figura 18: (a) Gráfico da RDF entre centros de massa do $\beta$-caroteno e das moléculas de acetona e (b) a MDDF para o mesmo sistema. Gráfico retirado da ref. [39].

Figura 19: Ilustração do $\beta$-caroteno isolado (em cima à esquerda), rodeado pela primeira e segunda camada de acetona usando o critério de proximidade do centro de massa (direita) e pela primeira camada usando o critério mínima distância (embaixo à esquerda). .58 
Figura 20: Funções de distribuição, RDF entre centros de massa e MDDF, calculado nas simulações de benzofenona em solução aquosa. Gráfico retirado da ref. [40].

Figura 21: (esquerda) Variação do momento de dipolo da benzofenona em água com o processo de polarização iterativo. O ponto branco representa o dipolo calculado da forma padrão; (direita) Variação da RDF, $G_{O o}(r)$, durante o procedimento de polarização. Gráficos retirados da ref. [40].

Figura 22: Convergência da energia média do orbital HOMO em relação ao número de configurações incluída na média. Esses dados são para a solução aquosa de metanol. Gráfico retirado da ref. [41] ................................64 Figura 23: Convergência da energia média dos orbitais HOMO e LUMO (esquerda) e dos índices de reatividade globais (direita) em relação ao número de moléculas explicitamente incluídas em configurações com envolvimento eletrostático adicional. Esses dados são para a solução aquosa de metanol. Gráficos retirados da ref. [41]. . .64

Figura 24: Energia média do orbital molecular que tem pelo menos $X \%$ de contribuição do soluto. Esses dados são para a solução aquosa de metanol. Gráfico retirado da ref. [41]................................................................65 Figura 25: Contribuição do $F^{-}$para os orbitais moleculares do sistema supermolecular $F^{-}+6 \mathrm{H}_{2} \mathrm{O}$ e o envolvimento eletrostático de 19 moléculas de água (esquerda) e a ilustração dos orbitais HOMO e HOMO-13 (direita). Gráfico e figuras retiradas da ref. [42].

Figura 26: Comparação da distribuição, ou médias acumuladas, de valores obtidos com $m$ cálculos quânticos versus o valor obtido com ASEC (linha tracejada): (esquerda) distribuição dos valores para o efeito de solvente na blindagem magnética do ${ }^{17} \mathrm{O}$ para acetona em solução aquosa e (direita) médias acumuladas do momento de dipolo polarizado e da energia da transição eletrônica $\pi-\pi^{*}$ para aminopurina em solução aquosa. Gráficos retirados da ref. [43].

Figura 27: (esquerda) Variação do momento de dipolo da acetona em água durante o procedimento de polarização iterativo. O ponto branco representa o dipolo calculado da forma padrão; (direita) Variação da RDF, $G_{O O}(r)$, durante o procedimento de polarização. Gráficos retirados da ref [44]. . .72

Figura 28: (esquerda) MDDFs e (direita) variação do momento de dipolo durante o processo de polarização da molécula de prodan em vários solventes. Gráficos retirados da ref. [108].

Figura 29: Ilustração da bicamada de DLPC hidratada (em cima esquerda), posicionamento inicial de 2 moléculas de prodan com conjuntos de cargas diferentes (em cima direita), posicionamento final do prodan com conjunto de cardas CS1 (centro esquerda) e CS3 (centro direita), gráficos do perfil de densidade eletrônica total do sistema simulado, das moléculas de água, da bicamada de DLPC e da molécula de prodan com os diferentes conjuntos de cargas (embaixo esquerda) e RDFs entre o oxigênio do prodan e moléculas de água (vermelho) e diferentes grupos funcionais dos DLPCs: colina (azul), fosfato (verde), glicerol (amarelo), carbonil (marrom), primeiros 5 grupos metil da cadeia alifática (laranja) e últimos 6 grupos metil (cinza). Os gráficos retirados da ref. [45].

Figura 30: Variação do momento de dipolo e cargas do nitrogênio e oxigênio da orto-betaina isolada (direita) e perfil da energia interna da orto-betaina isolada e da energia livre em solução (esquerda) em relação ao ângulo de torção $\varphi$ entre os anéis piridinium e fenóxido. Gráficos retirados da ref. [46].

Figura 31: Deslocamento solvatocrômico da transição $n-\pi^{*}$ da orto-betaina isolada e em solução aquosa em relação ao ângulo de torção. Gráfico retirado da ref. [46].

Figura 32: Variação do momento de dipolo não polarizado e polarizado da orto-betaina (esquerda) e perfil da energia interna (vácuo) e da energia livre com a orto-betaina não polarizada e polarizada (direita) variando com o ângulo $\varphi$. Gráficos retirados da ref. [47].

Figura 33: Perfil de energia ao longo do processo de tautomerização da mercaptopirimidina em vácuo (esquerda) e perfil de energia livre em solução aquosa (direita). As linhas tracejadas mostram os resultados em vácuo apenas para comparação. Gráficos modificados da ref. [48]. 


\section{Introdução}

Em dezembro de 1997 defendi minha tese de doutorado [1] intitulada "Modelo Discreto de Solvente. Solvatocromismo no Espectro de Absorção Molecular" sob a orientação do Prof. Mario José de Oliveira e Prof. Sylvio Canuto. Juntando as áreas de especialidades dos meus orientadores, Mecânica Estatística do Prof. M. J. de Oliveira e Física Atômica e Molecular do Prof. S. Canuto, consegui dar minha contribuição independente dentro da área de Modelagem Molecular de Efeitos de Solventes [2],[3],[4]. Essa contribuição propiciou subsídios para que o método híbrido sequencial que utiliza Mecânica Quântica/Mecânica Molecular (S-QM/MM) fosse proposto por mim e Prof. S. Canuto [2]. Adicionalmente, desenvolvi e venho atualizando periodicamente um código computacional [5], chamado DICE $^{1}$, que simula sistemas moleculares densos utilizando o método Monte Carlo com amostragem de Metropolis. Esse código é distribuído gratuitamente por mim, via solicitação por email. Atualmente, cerca de 20 grupos de pesquisa no Brasil e 18 no exterior estão cadastrados como usuários do DICE e temos cerca de 250 citações do programa. Desde então, venho trabalhando nessa área e dando contribuições no estudo dos efeitos de solventes (ou meio complexo) em propriedades moleculares.

$\mathrm{O}$ estudo das propriedades estruturais e eletrônicas de átomos e moléculas em meio condensado, principalmente em solução, é um problema que tem atraído grande interesse teórico. Em parte porque a compreensão das mudanças dessas propriedades pode servir para identificar e elucidar os principais termos das interações moleculares em diversos processos físico-químicos, bioquímicos e biofísicos [6]. Nas últimas 2 décadas tem existido um grande aumento nas possibilidades teóricas para estudar solvatação e os efeitos de solventes em geral [7]. Esta é uma consequência da melhora dos computadores e dos métodos teóricos.

Os primeiros esforços para calcular os efeitos de solventes em propriedades moleculares surgiram com o modelo contínuo de solvente, proposto pelos pioneiros Onsager [8] e Kirkwood [9], e implementado na mecânica quântica, equação de Schrödinger, através do campo de reação autoconsistente (SCRF) [10],[11]. Posteriormente, houve uma importante evolução do método que levou ao modelo contínuo polarizável (PCM) [12]. Devido à sua simplicidade o PCM é um dos métodos teóricos mais utilizados para estudar os efeitos de solventes. Entretanto, pelo mesmo motivo, esse método apresenta várias limitações e não consegue descrever efeitos produzidos por ligações específicas, como as ligações de hidrogênio e ligações metal-ligantes; delocalização e transferência de carga entre o soluto e o solvente; entre outros. Desta forma, existe uma ampla necessidade de modelos mais realistas do meio solvente.

Uma evolução natural dos modelos de solventes é a inclusão explícita de moléculas de solvente ao redor da molécula de interesse, soluto, nos cálculos quânticos. Entretanto, um ponto crucial desse procedimento é o posicionamento das moléculas de solvente ao redor do

\footnotetext{
${ }^{1}$ Palavra do inglês que significa dado.
} 
soluto, ou seja, é gerar as configurações moleculares acessíveis de sistemas soluto-solvente. Uma forma confiável, eficiente e sistemática de gerar essas configurações moleculares de sistemas densos numa condição termodinâmica específica é através das simulações computacionais [13]. Essas simulações vão utilizar modelos para descrever as interações moleculares e com base em soluções de equações dinâmicas ou amostragem de distribuições probabilísticas vão gerar milhões de configurações moleculares acessíveis ao sistema. A implementação computacional dessas simulações deu origem aos métodos de dinâmica molecular (MD) e Monte Carlo com amostragem de Metropolis (MC), respectivamente. Em princípio, utilizando o mesmo modelo para as interações moleculares, esses métodos são equivalentes para simulações infinitamente longas, mas na prática existem vários detalhes de implementação que podem tornar um dos métodos de simulação muito mais vantajoso que outro para uma dada propriedade de interesse de um sistema molecular específico. Sendo assim, a escolha do método de simulação está fortemente ligada ao problema que se deseja estudar. O ponto crucial das simulações é sem dúvida nenhuma a escolha do modelo para descrever as interações moleculares. A escolha, que descreve os sistemas moleculares de forma mais precisa, é sem dúvida baseada num hamiltoniano quântico, onde a energia total e forças atômicas são calculadas com métodos de primeiros princípios, ou ab initio [14]. Atualmente, as simulações quânticas que estão mais bem consolidadas na literatura são a dinâmica molecular de Car-Parrinello (CPMD) [15] e a dinâmica molecular de BornOppenheimer (BOMD) [16]. Em ambos os métodos, utiliza-se a estrutura eletrônica e o teorema de Hellmann-Feynman para calcular as forças nos núcleos atômicos que são movidos de acordo com as equações de movimento clássicas. Entretanto eles diferem essencialmente na forma de obter a estrutura eletrônica, ou seja, a função de onda eletrônica do sistema para cada conjunto instantâneo de posições atômicas. No primeiro método utilizase uma evolução temporal de uma função de onda eletrônica inicial, enquanto que no segundo resolve-se a equação de Schrödinger eletrônica. Mais detalhes sobre esses métodos podem ser encontrados em referências especializadas [14],[17]. Essas simulações quânticas são também conhecidas por dinâmica molecular de primeiros princípios. Uma dinâmica molecular quântica ou semiclássica para os núcleos atômicos pode ser gerada através de integrais de trajetória (Path Integrals Molecular Dynamics) [18].

As dinâmicas moleculares de primeiros princípios são hoje os métodos mais sofisticados que existem para gerar configurações moleculares acessíveis a sistemas densos em condições termodinâmicas específicas, porém são métodos que envolvem um grande custo computacional. Custo esse, relacionado não apenas a questões financeiras da aquisição dos computadores de alto desempenho com grande número de processadores e grande capacidade de memória e disco rígido, mas também ao tempo de processamento dos cálculos que é muito longo e chega a inviabilizar uma grande quantidade de estudos teóricos. Uma alternativa para as simulações quânticas são as conhecidas simulações clássicas que utilizam modelos empíricos clássicos, chamados de campo de força, para descrever as interações moleculares [13]. Existem vários campos de força disponíveis na literatura. Dentre eles os 
mais conhecidos são GROMOS [19], AMBER [20], CHARMM [21], OPLS [22], UFF [23], entre outros. Os campos de força são compostos por um conjunto de funções, que descrevem diferentes termos das interações moleculares, e um amplo conjunto de parâmetros que substituídos nas funções vão fornecer valores numéricos para as interações entre moléculas específicas ou grupamentos de átomos que compõem as moléculas. Em geral, as funções dos campos de força descrevem interações entre pares de átomos com os seguintes termos:

$$
E=E_{\text {bond }}+E_{\text {angle }}+E_{\text {torsion }}+E_{\mathrm{vdW}}+E_{\text {elect }}
$$

onde todos esses termos descrevem a energia de interação: $E_{\text {bond }}$ devido as vibrações das ligações químicas (interação entre primeiros vizinhos), $E_{\text {angle }}$ devido as vibrações angulares

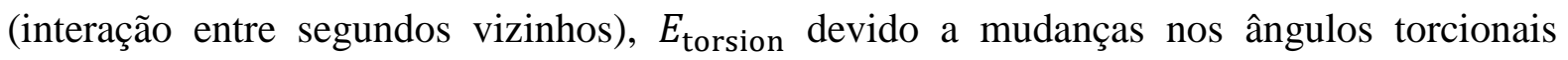
(interação entre terceiros vizinhos), $E_{\mathrm{vdW}}$ devido interações tipo van der Waals (interação entre átomos além dos terceiros vizinhos) e $E_{\text {elect }}$ devido interações eletrostáticas (interação entre átomos além dos terceiros vizinhos). Esses três primeiros termos são comumente chamados de interações de átomos ligados e necessariamente fazem parte da energia de interação intramolecular. Já os dois últimos termos são comumente chamados de interações de átomos não ligados, fazem parte da energia de interação intermolecular e podem também fazer parte da energia de interação intramolecular, se a molécula tiver mais que 4 átomos. Abaixo, são exemplificadas formas funcionais para esses termos que descrevem a energia de interação para o campo de força OPLS [22]:

$$
\begin{aligned}
& E_{\text {bond }}=\sum_{\text {distâncias }} K_{r}\left(r-r_{e q}\right)^{2} \\
& E_{\text {angle }}=\sum_{\text {angulos }} K_{\theta}\left(\theta-\theta_{e q}\right)^{2} \\
& E_{\text {torsion }}=\sum_{\text {torsionais }} \sum_{i=1,6} \frac{V_{i}}{2}\left[1-(-1)^{i} \cos \left(i \varphi+\delta_{i}\right)\right] \\
& E_{\mathrm{vdW}}=\sum_{\mathrm{i}} \sum_{j} 4 \varepsilon_{i j}\left[\left(\frac{\sigma_{i j}}{r_{i j}}\right)^{12}-\left(\frac{\sigma_{i j}}{r_{i j}}\right)^{6}\right] f_{i j} \\
& E_{\text {elect }}=\sum_{\mathrm{i}} \sum_{j}\left[\frac{q_{i} q_{j} e^{2}}{r_{i j}}\right] f_{i j}
\end{aligned}
$$


onde $r_{i j}$ é a distância entre os pares de átomos $i$ e $j ; f_{i j}$ é uma constante que assume três valores: zero $\left(f_{i j}=0\right)$ se os pares de átomos $i$ e $j$ forem primeiros e segundos vizinhos (considerados nos termos $E_{\text {bond }}$ e $E_{\text {angle }}$ ), meio $\left(f_{i j}=0.5\right)$ se os pares de átomos $i$ e $j$ forem terceiros vizinhos (considerados no termo $\left.E_{\text {torsion }}\right)$, e um $\left(f_{i j}=1\right)$ para os demais pares; a lista dos primeiros, segundos, terceiros e demais vizinhos de cada átomo é definida na topologia de cada molécula e é com essa informação que serão definidos os somatórios das equações (1) até (6); e $\left\{K_{r}\right.$ e $\left.r_{e q}\right\},\left\{K_{\theta}\right.$ e $\left.\theta_{e q}\right\},\left\{V_{i}\right.$ e $\left.\delta_{i}\right\},\left\{\varepsilon_{i j}, \sigma_{i j}\right.$ e $\left.q_{i}\right\}$ são os conjuntos de parâmetros do campo de força que dependem dos tipos de átomos envolvidos na interação, suas vizinhanças e as condições termodinâmicas a que eles estão submetidos. Esses parâmetros são determinados de forma a melhor reproduzir propriedades experimentais dos sistemas estudados, como por exemplo: densidade, entalpia de vaporização e funções de distribuição de pares (obtidas com espalhamento de raio-X ou difração de nêutrons) para os solventes; estruturas tridimensionais de proteínas/enzimas e diagrama de Ramachandran para aminoácidos; estruturas tridimensionais de DNA/RNA para nucleotídeos, nucleosídeos e bases nitrogenadas, entre outros. Quando dados experimentais não estão disponíveis, é comum utilizar resultados de cálculos quânticos para realizar a parametrização. É importante ressaltar que todos os campos de força tentam utilizar o princípio da transferabilidade dos parâmetros de pequenos grupos funcionais como é o caso de anéis aromáticos, anéis heterogêneos de cinco e seis membros, grupos amina, amida, carbonila, carboxila, cadeias hidrocarbonetos, etc., ou até mesmo de moléculas inteiras como é o caso dos aminoácidos, bases nitrogenadas, açúcares, cadeias hidrocarbônicas, entre outras. Porém a grande quantidade de parâmetros empíricos necessários para uma simulação clássica é sempre um ponto de vulnerabilidade do modelo e requer experiência, cautela e inúmeros testes para garantir uma escolha adequada do campo de força e seus parâmetros. Adicionalmente a isso, existem outros aspectos que inviabilizam a utilização das simulações clássicas, como por exemplo: (i) a inadequação das formas funcionais da energia de interação; (ii) a falta de informações que permitem a parametrização do campo de força de uma determinada molécula; (iii) a rigidez na topologia das moléculas ao longo da simulação, implementada nos códigos computacionais. Existem vários grupos teóricos que trabalham em problemas relacionados aos exemplos (i) e (ii), testando e implementando outras formas funcionais e desenvolvendo novos procedimentos de parametrização. Entretanto, pouco vem se fazendo no exemplo (iii) que é fundamental para o estudo de reações químicas, por exemplo. No caso de uma reação química, existe um rearranjo dos átomos e as topologias das moléculas envolvidas antes e depois da reação são diferentes. Sendo assim, não é possível através dos métodos tradicionais de simulação computacional estudar os caminhos ou processos de reações químicas. Vale ressaltar que existem alguns métodos, que acoplados com as simulações clássicas, permitem calcular variações de energia livre sobre o caminho de reação pré-definido. Entretanto, esses métodos não são suficientes e apresentam grandes limitações quando o caminho de reação das moléculas em fase gasosa difere muito do caminho em solução. 
Apesar disto, as simulações clássicas são métodos amplamente utilizados para gerar configurações moleculares acessíveis a sistemas moleculares densos em condições termodinâmicas específicas, principalmente no estudo de macromoléculas biológicas como proteínas, enzimas, etc. e agregados supramoleculares como bicamadas lipídicas, micelas, vesículas, etc. Isto devido ao baixo custo computacional comparativamente as simulações quânticas. Para as simulações clássicas também são necessários computadores de alto desempenho, devido à necessidade de uma grande quantidade de processadores e grande capacidade de armazenamento, mas com pequena capacidade de memória, o que deixa o equipamento bem mais barato. É claro que, a necessidade de recursos computacionais e tempo de processamento dos cálculos aumentam com o número de átomos do sistema e com o número de passos da simulação.

É interessante ressaltar aqui, que essas simulações computacionais de sistemas moleculares com campos de força se baseiam em conceitos fundamentais da mecânica newtoniana e mecânica estatística e por isso são comumente chamadas de mecânica molecular (MM), abrangendo assim os métodos clássicos de dinâmica molecular e Monte Carlo Metropolis.

Devido às limitações naturais dos campos de força, sua utilização no estudo de alguns sistemas e propriedades é inadequada e existe a real necessidade de modelos quânticos de interação molecular. É considerando essa necessidade, juntamente com os custos computacionais envolvidos nas simulações quânticas e clássicas, que foi proposto o método híbrido que utiliza tanto a mecânica quântica como a mecânica molecular para o cálculo das interações moleculares de um sistema específico. Esse método híbrido é conhecido como QM/MM [24],[25]. Um trabalho bastante conhecido, desenvolvido por Warshell e Levitt [26], certamente está na origem do método híbrido que utilizam QM e MM. Nesse trabalho, para estudar reações enzimáticas, parte do sistema enzima-substrato é tratado com QM e parte com MM. O uso combinado de simulações computacionais e mecânica quântica é talvez a ferramenta teórica para estudo de moléculas que tem apresentado mais avanços recentes e foi assunto de vários trabalhos de revisão [24],[25],[27]-[29].

O método híbrido QM/MM comumente utilizado une a mecânica quântica e as simulações clássicas para estudar os efeitos de solventes sobre as propriedades eletrônicas de moléculas [24],[26],[30],[31]. Nesse método, uma parte do sistema simulado utiliza um hamiltoniano quântico, $\widehat{H}^{Q M}$, e o restante do sistema utiliza campos de forças clássicos para descrever as interações moleculares, $\widehat{H}^{M M}$. Ambas as partes interagem através de um termo de acoplamento, $\widehat{H}^{Q M / M M}$. Sendo assim, o hamiltoniano efetivo que descreve as interações das moléculas é expresso da seguinte forma:

$$
\widehat{H}_{e f}=\widehat{H}^{Q M}+\widehat{H}^{M M}+\widehat{H}^{Q M / M M}
$$

Existem vários procedimentos de acoplar a parte quântica e a parte clássica, mas usualmente, esse acoplamento é descrito por três termos: 


$$
\widehat{H}^{Q M / M M}=\widehat{H}_{\mathrm{elect}}^{Q M / M M}+\widehat{H}_{\mathrm{vdW}}^{Q M / M M}+\widehat{H}_{\mathrm{bonded}}^{Q M / M M},
$$

as interações eletrostáticas, $\widehat{H}_{\mathrm{elect}}^{Q M / M M}$, as interações de van der Waals, $\widehat{H}_{\mathrm{vdW}}^{Q M / M M}$, e as interações entre átomos ligados, $\widehat{H}_{\text {bonded }}^{Q M / M M}$, que pertencem aos diferentes termos $\widehat{H}^{Q M}$ e $\widehat{H}^{M M}$. Esse último termo só aparece quando uma molécula é fragmentada e parte dela é tratada com QM e outra com MM. A fragmentação molecular, no tratamento QM/MM, ocorre muito em macromoléculas biológicas como é o caso das proteínas e enzimas, mas não costuma ser usado quando a molécula de interesse é pequena, ou seja, tem menos que duas centenas de átomos. As interações eletrostáticas são calculadas incluindo um campo eletrostático da parte clássica no hamiltoniano quântico. Esse campo eletrostático é gerado em cada configuração pelas cargas atômicas pontuais das moléculas definidas pelo campo de força clássica. As interações de van der Waals são calculadas incluindo os átomos da parte quântica no termo de van der Waals do campo de força (ver equação 5). Para isso, é necessário atribuir para cada átomo $i$ da parte quântica um conjunto de parâmetros que descrevem esse termo do campo de força ( $\varepsilon_{i}$ e $\sigma_{i}$ na equação 5 ). As interações entre átomos ligados é o termo de acoplamento mais complexo e existem vários procedimentos propostos para tratá-lo [32]. Entretanto, independentemente do procedimento escolhido, no cálculo com QM cada orbital molecular envolvido na ligação química fragmentada deve ser corrigido e no cálculo com MM cada ligação química fragmentada deve ser saturada. Sendo assim, é fácil notar que o termo de acoplamento é inserido no cálculo QM e no cálculo MM. Portanto, em cada passo da simulação, são realizados dois cálculos para determinação das energias de interação: um com mecânica quântica, $\widehat{H}^{Q M}+\widehat{H}_{\text {elect }}^{Q M / M M}+\widehat{H}_{\text {bonded }}^{Q M / M M}$, e outro com mecânica molecular, $\widehat{H}^{M M}+\widehat{H}_{\mathrm{vdW}}^{Q M / M M}+\widehat{H}_{\text {bonded }}^{Q M / M M}$. Com relação ao custo computacional, as simulações com QM/MM são mais rápidas que as dinâmicas quânticas, devido ao cálculo quântico ser realizado num sistema menor. Mas ainda assim, são necessários milhões de cálculos com QM.

Outros trabalhos influentes que seguem outra linha de método híbrido que combina cálculos com QM e MM são os desenvolvidos em 1989 e 1990 por Blair e coautores [33]. Nesses trabalhos, foram realizados cálculos quânticos do espectro eletrônico de absorção e emissão do formaldeído em água em configurações soluto-solvente geradas em simulações clássicas. É interessante notar que nesse procedimento o cálculo do efeito do solvente é feito em duas etapas. Na primeira etapa, simulações computacionais são realizadas para gerar as configurações soluto-solvente e, na segunda, os cálculos quânticos são feitos nessas configurações. A vantagem desse método está na enorme redução do número de cálculos quânticos que implica numa grande redução do custo computacional, sem perda de qualidade/precisão numérica nos valores calculados das propriedades eletrônicas. Pouco tempo depois, em 1993 e 1994, são publicados os trabalhos de Zeng e coautores [34] e os nossos [35] utilizando esse procedimento em duas etapas. Eles estudaram os espectros de 
absorção e emissão da pirimidina em água e o íon $\mathrm{Fe}^{+2}$ em água e estudamos o espectro de absorção do benzeno sólido, líquido e em solução aquosa. Em seguida, em 1997, fizemos a proposta do nome, método híbrido sequencial QM/MM, S-QM/MM [2], e apresentamos algumas análises estatísticas para sistematizar o procedimento de seleção das configurações das simulações para os subsequentes cálculos quânticos. Sendo assim, hoje o método SQM/MM é uma variante da abordagem QM/MM convencional, que visa à obtenção de valores estatisticamente convergidos para todas as propriedades de interesse. Isto é particularmente interessante porque utiliza um procedimento de amostragem muito eficiente, reduzindo consideravelmente o número de cálculos quânticos. Nossa proposta foi de utilizar o conceito de tempo, ou intervalo, de correlação estatística para selecionar configurações estatisticamente descorrelacionadas para os cálculos quânticos e em seguida analisar a convergência dos valores médios com relação ao número de configurações utilizadas. Pois, apenas valores médios estatisticamente convergidos têm significado e as distribuições dos valores refletem o simples fato de que as condições termodinâmicas impõem flutuações estruturais. Essas análises serão descritas em detalhes no capítulo de metodologia (capítulo 2) como parte da descrição do método S-QM/MM, juntamente com a descrição da técnica de simulação implementado em nosso código computacional DICE, e também nossas propostas seguintes de aperfeiçoamento na metodologia de estudo de efeitos de solventes, como a função de distribuição de mínima distância (MDDF), a análise de delocalização dos orbitais moleculares, a configuração eletrostática média do solvente (ASEC) e procedimento de polarização iterativo. Também apresentamos métodos para cálculo de variações de energia livre e suas aplicações em nosso trabalho. No capítulo 3, apresentaremos os resultados e discussões dos seguintes trabalhos publicados (ver Apêndices de A até Q):

1) Método sequencial QM/MM (S-QM/MM)

- "Solvent Effects from a Sequential Monte Carlo - Quantum Mechanical Approach", S. Canuto and K. Coutinho; Adv. Quantum Chem., 28, 89 (1997) [2] (ver Apêndice A)

- "Sampling Configurations in Monte Carlo Simulations for Quantum Mechanical Studies of Solvent Effects", K. Coutinho, M. J. de Oliveira and S. Canuto; Int. J. Quantum Chem., 66, 249 (1998) [3] (ver Apêndice B).

- "A Monte Carlo-Quantum Mechanics Study of the Solvatochromic Shifts of the Lowest Transition of Benzene", K. Coutinho, S. Canuto and M. C. Zerner, J. Chem. Phys., 112, 9874 (2000) [36] (ver Apêndice C).

- "From Hydrogen Bond to Bulk: Solvation Analysis of the $n-\pi *$ Transition of Formaldehyde in Water", S. Canuto and K. Coutinho, Int. J. Quantum Chem., 77, 192 (2000) [37] (ver Apêndice D).

- "Solvent Effects in Emission Spectroscopy. A Monte Carlo-Quantum Mechanics Study of the $n-\pi^{*}$ Shift of Formaldehyde in Water", K. Coutinho and S. Canuto, J. Chem. Phys., 113, 9132 (2000) [38] (ver Apêndice E). 
2) Função de distribuição de mínima distância (MDDF)

- "New Developments in Monte Carlo/Quantum Mechanics Methodology. The Solvatochromism of $\beta$-Carotene in Different Solvents", S. Canuto, K. Coutinho and D. Trzesniak, Adv. Quantum Chem. 41, 161 (2002) [39] (ver Apêndice F).

- "Solvent Effects on the UV-visible Absorption Spectrum of Benzophenone in Water: A Combined Monte Carlo Quantum Mechanics Study Including Solute Polarization”, H. C. Georg, K. Coutinho and S. Canuto, J. Chem. Phys. 126, 34507-1 (2007) [40] (ver Apêndice G).

3) Análise de delocalização dos orbitais moleculares

- "Solvent Effects on Global Reactivity Properties for Neutral and Charged Systems Using the Sequential Monte Carlo - Quantum Mechanics Model”, P. Jaramillo, P. Pérez, P. Fuentealba, S. Canuto and K. Coutinho, J. Phys. Chem. B 113, 4314 (2009) [41] (ver Apêndice H).

- "Delocalized Water and Fluoride Contributions to Dyson Orbitals for Electron Detachment from the Hydrated Fluoride Anion", S. Canuto, K. Coutinho, B. J. C. Cabral, V. G. Zakrzewski and J. V. Ortiz, J. Chem. Phys. 132, 214507 (2010) [42] (ver Apêndice I).

4) Configuração eletrostática média do solvente (ASEC)

- "An Efficient Statistically Converged Average Configuration for Solvent Effects", K. Coutinho, H. C. Georg, T. L. Fonseca, V. Ludwig and S. Canuto, Chem. Phys. Lett. 437, 148 (2007) [43] (ver Apêndice J).

5) Procedimento de polarização iterativo

- "Converged Electronic Polarization of Acetone in Liquid Water and the Role in the n$\pi^{*}$ Transition", H. C. Georg, K. Coutinho and S. Canuto, Chem. Phys. Lett. 429, 119 (2006) [44] (ver Apêndice K).

- "Molecular Dynamics Investigations of Prodan in a DLPC Bilayer", W. Nitschke, C. Vequi-Suplicy, K. Coutinho and H. Stassen, J. Phys. Chem. B, 116, 2713 (2012) [45] (ver Apêndice L).

6) Cálculo de variações de energia livre

- "Solute Relaxation on the Solvatochromism of Ortho-Betaine Dye. A Sequential Monte Carlo - Quantum Mechanics Study", M. Z. Hernandes, R. Longo, K. Coutinho and S. Canuto, Phys. Chem. Chem. Phys. 6, 2088 (2004) [46] (ver Apêndice M).

- "A sequential MC/TD-DFT Study of the Solvatochromic Shift of the Pyridinium-Nphenoxide Betaine Dye in Water Using Standard and Long-range Corrected Functionals", L. B. A. Oliveira, T. L. Fonseca, K. Coutinho and S. Canuto, Chem. Phys. Lett. 514, 251 (2011) [47] (ver Apêndice N). 
- "Reaction Mechanism and Tautomeric Equilibrium of 2-Mercaptopyridine in Gas Phase and in Aqueous Solution: A Combined Monte Carlo and Quantum Mechanics Study”, M. C. P. Lima, K. Coutinho, W. R. Rocha and S. Canuto, J. Phys. Chem. A 110, 7253 (2006) [48] (ver Apêndice O).

- "Structure and Electronic Properties of Pydrated Mesityl Oxide: A Sequential Quantum Mechanics/Molecular Mechanics Approach”, M. V. A. Damasceno, B. J. C. Cabral and K. Coutinho, Theor. Chem. Acc. 131, 1214 (2012) [49] (ver Apêndice P).

\section{Metodologia}

\subsection{Simulação Computacional}

As simulações computacionais de sistemas moleculares geram informações sobre um sistema em nível microscópico, como as posições e velocidades atômicas, $\{\boldsymbol{r}\}_{i}=$ $\left(\vec{r}_{1}, \vec{r}_{2}, \cdots, \vec{r}_{N}\right)$ e $\{\boldsymbol{v}\}_{i}=\left(\vec{v}_{1}, \vec{v}_{2}, \cdots, \vec{v}_{N}\right)$. A conversão dessas informações detalhadas em termos macroscópicos, como energia interna, pressão, calor específico, etc., são determinadas pela mecânica estatística. Nessas simulações, o sistema é representado por $N$ átomos, ou moléculas, que têm energia cinética, $K_{i}=K\left(\{\boldsymbol{v}\}_{i}\right)$, interagem através da energia potencial, $U_{i}=U\left(\{\boldsymbol{r}\}_{i}\right)$, e, portanto têm uma energia interna, $E_{i}=K_{i}+U_{i}$. Os átomos são confinados numa caixa e o conjunto de posições atômicas $\{\boldsymbol{r}\}_{i}$ definem uma configuração $i$, denotada por $\Gamma_{i}=\Gamma\left(\{\boldsymbol{r}\}_{i}\right)$. De acordo com o método de simulação, regras que definem os movimentos atômicos são estabelecidas. A cada novo conjunto de posições atômicas, $\{\boldsymbol{r}\}_{i}$, uma nova configuração $\Gamma_{i}$ é gerada e a evolução da simulação se dá através do movimento sucessivo dos átomos, ou seja, da geração sucessiva de configurações. Todas as configurações geradas através da simulação pertencem ao espaço de configurações $\left\{\Gamma_{i}\right\}$. No equilíbrio térmico deseja-se gerar configurações de acordo com a distribuição de probabilidades de Gibbs no ensemble específico. Nos ensemble NVT e NPT, essa distribuição de probabilidades é escrita como

$$
\rho_{N V T}=\frac{\exp \left(-E_{i} / k T\right)}{Z}
$$

$\mathrm{e}$

$$
\rho_{N P T}=\frac{\exp \left(-\left(E_{i}+P V_{i}\right) / k T\right)}{Z}
$$


respectivamente, onde $k(=0.001985 \mathrm{kcal} / \mathrm{mol})$ é a constante de Boltzmann, $T$ é a temperatura e $Z$ é a função de normalização, ou também conhecida por função de partição.

Existem dois processos para gerar as configurações $\Gamma_{i}$, o determinístico e o estocástico. O processo determinístico é implementado no método de simulação conhecido como Dinâmica Molecular (MD). Nesse método, a partir do conjunto das coordenadas e velocidades atômicas de uma configuração $i,\{\boldsymbol{r}\}_{i}$ e $\{\boldsymbol{v}\}_{i}$, são calculadas: a energia potencial de interação, $U_{i}$, e as forças que atuam sobre cada átomo $a, \vec{F}_{a}=-\vec{\nabla}_{a} U_{i}$, e são resolvidas as equações de movimento para um intervalo de tempo, $\delta$, para gerar uma nova configuração $\Gamma_{i+1}$. Sendo assim, os átomos se movem em trajetórias geradas a partir da integração das equações de movimento, e as propriedades observáveis são obtidas através de médias temporais sobre a trajetória do sistema.

O processo estocástico para gerar configurações, é implementado no método de simulação conhecido como método de Monte Carlo (MC). Nesse método, a partir do conjunto das coordenadas atômicas de uma configuração $i,\{\boldsymbol{r}\}_{i}$, são realizados movimentos aleatórios para gerar uma nova configuração $j$, é calculada a variação da energia potencial de interação, $\Delta U_{i j}$, e são realizados testes de aceitação dessa nova configuração, de tal forma a gerar um conjunto de configurações $\left\{\Gamma_{i}\right\}$ que satisfaça a distribuição de probabilidades de Gibbs. As propriedades observáveis são obtidas através de médias sobre o espaço configuracional do sistema.

Todo desenvolvimento teórico feito sobre simulações computacionais é baseado na hipótese de que tanto o processo determinístico quanto o estocástico para gerar configurações são ergódicos [50]. Isto significa que em simulações infinitamente longas, todo o espaço de configurações é visitado, ou seja, todas as configurações acessíveis pertencentes ao espaço de configurações são geradas pela simulação. Portanto, existe equivalência entre os dois processos, ou os dois métodos de simulação, MD e MC. Entretanto, em simulações finitas não existe garantia de equivalência entre eles. Porém é esperado que em simulações suficientemente longas, exista certa semelhança na distribuição de configurações geradas pelos dois métodos, pois regiões do espaço de configurações mais densas com trajetórias geradas com MD são regiões mais prováveis e, portanto mais acessíveis na simulação com MC.

É senso comum afirmar que MC e MD são métodos equivalentes para estudar propriedades termodinâmicas e estruturais de sistemas moleculares. Entretanto só simulações com MD podem ser usada para estudar dependências temporais das propriedades. Portanto, embora MD seja um método mais abrangente, MC é um método vantajosamente mais rápido e mais simples para implementação computacional e generalizações. Por isto, considerando que não estamos interessados em estudar propriedades com dependência temporal, escolhemos simular sistemas moleculares utilizando o método Monte Carlo. 


\subsection{Método Monte Carlo Implementado no Código DICE}

Devido à variedade e complexidade de simulações de sistemas moleculares optamos por desenvolver nosso próprio código computacional, DICE, utilizando procedimentos bem estabelecidos [13]. Desta forma, temos mais controle das simulações e do campo de força implementado. A seguir faremos uma descrição geral do método Monte Carlo (MC) com amostragem de Metropolis, tal qual implementado no DICE.

Os sistemas moleculares que podem ser simulados no DICE são gases, líquidos, soluções e misturas em qualquer proporção e concentração, interfaces líquido-superfície e gás-superfície. As moléculas têm geometria rígida, sendo assim os termos do potencial de interação intramolecular não são calculados (equações 2 a 4). O número total de moléculas $N$ e a temperatura $T$ são fixos, mas o volume $V$ ou a pressão $P$ pode flutuar durante a simulação. Portanto, o ensemble NVT ou NPT pode ser escolhido. O potencial de interação intermolecular utilizado é a soma do potencial de Lennard-Jones e o potencial de Coulomb (equações 5 e 6 com $f_{i j}=1$ ), ou seja, entre as moléculas $A$ e $B$ temos:

$$
U_{\mathrm{AB}}=\sum_{i}^{\mathrm{em} A} \sum_{j}^{\mathrm{em} B} 4 \varepsilon_{i j}\left[\left(\frac{\sigma_{i j}}{r_{i j}}\right)^{12}-\left(\frac{\sigma_{i j}}{r_{i j}}\right)^{6}\right]+\frac{q_{i} q_{j} e^{2}}{r_{i j}}
$$

onde $e\left(=18.22(\AA \mathrm{kcal} / \mathrm{mol})^{1 / 2}\right)$ é a carga elementar do elétron, $\varepsilon_{i j}=\sqrt{\varepsilon_{i} \varepsilon_{j}}, \sigma_{i j}=\sqrt{\sigma_{i} \sigma_{j}}$ ou $\sigma_{i j}=\left(\sigma_{i}+\sigma_{j}\right) / 2$ e $\varepsilon_{i}, \sigma_{i}$ e $q_{i}$ são os parâmetros dos sítios de interação. Usualmente, os átomos são sítios de interação, mas não necessariamente todos os sítios são átomos e viceversa.

Os átomos ou moléculas do sistema são colocados num caixa de simulação cúbica ou em forma de paralelepípedo e aplica-se a condição de contorno periódica, para conservar o número de partículas do sistema. Para eliminar, ou minorar, os efeitos de tamanho finito do sistema, aplica-se o método das imagens, ou réplicas. Para reduzir o tempo de processamento e eliminar a periodicidade incluída com o método das imagens, utiliza-se o raio de corte nas interações intermoleculares. E para minorar os erros introduzidos com a inclusão do raio de corte, calculam-se as correções de longo alcance do potencial desprezado. Utilizamos a correção de longo alcance do potencial Lennard-Jones integrando uma densidade uniforme do raio de corte até infinito e do potencial de Coulomb através da interação dipolar do sistema interno ao raio de corte com um meio dielétrico contínuo. Todos esses procedimentos são bem estabelecidos e estão explicados em livros texto sobre as simulações moleculares [13].

Inúmeras propriedades estruturais e termodinâmicas podem ser calculadas diretamente na simulação e/ou utilizando outros códigos computacionais auxiliares. Desenvolvemos os códigos ORDER [51] e CORRELATION [52], que utilizam os arquivos de saída do DICE. O primeiro código calcula funções de distribuição de pares de átomos, realiza análises de 
ligação de hidrogênio entre soluto-solvente e solvente-solvente, gera uma configuração eletrostática média do solvente, gera configurações soluto-solvente reduzidas e envolvidas por um campo eletrostático do solvente, e separa configurações estatisticamente descorrelacionadas. O segundo código gera as funções normalizadas de autocorrelação e a ineficiência estatística para análise do intervalo, ou tempo, de correlação estatística, que serão discutidos posteriormente nesta seção.

Esses códigos foram escritos em FORTRAN/77 com vários comentários ao longo do código computacional e desenvolvidos de forma a serem facilmente manuseado por outros usuários. Outra ferramenta que desenvolvemos foi a interface gráfica DiceWin [53], em JAVA, que integra esses programas, gera arquivos de entrada e visualiza os arquivos de saída na forma gráfica. Temos também uma documentação ampla que envolve um manual de utilização e arquivos de exemplos disponíveis na internet [54].

Iniciamos uma simulação MC com uma configuração qualquer de um sistema com $N$ moléculas confinadas em uma caixa de volume $V$ a uma temperatura $T$. A evolução da simulação se dá através de sucessão de passos, conhecidos como passos MC. Um passo MC no ensemble $N V T$ é realizado quando uma molécula é selecionada para uma tentativa de translação e rotação. Essas seleções são aleatórias e 6 números aleatórios são gerados em cada passo: um para o rótulo da molécula sorteada entre 1 e $N$, outros três para o movimento de translação $\delta x, \delta y$ e $\delta z$ num intervalo de $\pm \delta r_{\max }$, e outros dois para o movimento de rotação, dos quais um eixo é sorteado $(1=x, 2=y$ e $3=z)$ e um ângulo $\delta \theta$ num intervalo de $\pm 15^{\circ}$. Esses números definem um movimento molecular aleatório composto por uma translação de $\delta \vec{r}=(\delta x, \delta y, \delta z)$ e uma rotação de um ângulo $\delta \theta$ num eixo sorteado. No ensemble NPT, adicionalmente ao movimento das moléculas também são realizadas tentativas de modificar o volume. Nesse caso, é sorteado mais um número aleatório, $\delta L$, para um reescalonamento da caixa de simulação e da posição de centro de massa de todas as moléculas. $\mathrm{O} \delta L$ é sorteado num intervalo de $\pm \delta L_{\max }$ e o reescalonamento é feito com o fator $\zeta=(L+\delta L) / L$. Nem todos os movimentos moleculares e/ou mudanças no volume são aceitos. É a técnica de amostragem que estabelece as regras de aceitação, ou rejeição, dos movimentos. Os valores do máximo deslocamento possível para cada molécula num eixo cartesiano, $\delta r_{\max }$, e do máximo reescalonamento da caixa de simulação, $\delta L_{\max }$, são autoajustados ao longo da simulação para manter o percentual de aceitação em torno de 50\%. Existem várias técnicas de amostragem para sistemas moleculares e todas elas têm como objetivo gerar configurações de acordo com a distribuição de equilíbrio de Gibbs num ensemble específico. Usamos a técnica de amostragem de Metropolis que usa a variação de energia e de volume, quando existir, entre as configurações como termo decisivo na regra de aceitação de uma nova configuração.

Antes de discutir a técnica de amostragem de Metropolis é importante lembrar que o valor médio de qualquer propriedade $f$, que depende das posições e velocidades atômicas, $f(\{\boldsymbol{v}\},\{\boldsymbol{r}\})$, no equilíbrio termodinâmico é calculado sobre um ensemble da seguinte forma: 


$$
\langle f\rangle_{\text {ens }}=\iint f(\{\boldsymbol{v}\},\{\boldsymbol{r}\}) \rho_{\text {ens }} d\{\boldsymbol{v}\} d\{\boldsymbol{r}\}=\iint f(\{\boldsymbol{v}\},\{\boldsymbol{r}\}) \rho_{\text {ens }}^{\text {cin }} d\{\boldsymbol{v}\} \rho_{\text {ens }}^{\text {conf }} d\{\boldsymbol{r}\}
$$

onde

$$
\rho_{\text {ens }}^{\text {cin }}=\frac{\exp (-K(\{\boldsymbol{v}\}) / k T)}{\int \exp (-K(\{\boldsymbol{v}\}) / k T) d\{\boldsymbol{v}\}}
$$

e $\rho_{\text {ens }}^{\text {conf }}$ depende do ensemble escolhido. Para o ensemble NVT escreve-se

$$
\rho_{N V T}^{\text {conf }}=\frac{\exp (-U(\{\boldsymbol{r}\}) / k T)}{\int \exp (-U(\{\boldsymbol{r}\}) / k T) d\{\boldsymbol{r}\}},
$$

e para o ensemble NPT escreve-se

$$
\rho_{N P T}^{\text {conf }}=\frac{\exp (-(U(\{\boldsymbol{r}\})+\mathrm{PV}) / k T)}{\int \exp (-(U(\{\boldsymbol{r}\})+\mathrm{PV}) / k T) d\{\boldsymbol{r}\}}=\frac{\exp (-(H(\{\boldsymbol{r}\})) / k T)}{\int \exp (-(H(\{\boldsymbol{r}\})) / k T) d\{\boldsymbol{r}\}}
$$

onde $H=U+P V$ é a entalpia conformacional do sistema.

É fácil mostrar que a integração cinética pode ser separada da parte configuracional desde que a propriedade seja aditiva com relação às posições e velocidades atômicas, $f=f(\{\boldsymbol{v}\})+f(\{\boldsymbol{r}\})$. Então,

$$
\langle f\rangle_{\text {ens }}=\int f(\{\boldsymbol{v}\}) \rho_{\text {ens }}^{\text {cin }} d\{\boldsymbol{v}\}+\int f(\{\boldsymbol{r}\}) \rho_{\text {ens }}^{\text {conf }} d\{\boldsymbol{r}\}=\langle f\rangle_{\text {ens }}^{\text {cin }}+\langle f\rangle_{\text {ens }}^{\text {conf }}
$$

Conhecendo a forma funcional simples da energia cinética, $K=(1 / 2) m v^{2}$, é possível realizar a integração da parte cinética de forma analítica ou numérica. Sendo assim, nas simulações de sistemas moleculares com o método Monte Carlo realiza-se apenas o cálculo do termo conformacional deixando-se o termo cinético para ser adicionado a posteriori.

A amostragem de Metropolis se baseia na ideia de gerar (amostrar) configurações que satisfazem a distribuição de probabilidades conformacional de Gibbs (ver equações 14 e 15), $\{\Gamma\}_{\text {ens. }}$. Desta forma, ao invés de multiplicar $\rho_{\text {ens }}^{\text {conf }}$ à propriedade e realizar uma integração sobre todas as coordenadas para obter o valor médio, é possível realizar uma média simples sobre os valores da propriedade calculados nas várias configurações devidamente amostradas $\{\Gamma\}_{\text {ens }}$,

$$
\langle f\rangle_{\text {ens }}^{\text {conf }}=\int f(\{\boldsymbol{r}\}) \rho_{\text {ens }}^{\text {conf }} d\{\boldsymbol{r}\}=\sum_{\xi_{i}}^{\{\Gamma\}_{\text {ens }}} f\left(\Gamma\left(\xi_{i}\right)\right) .
$$


A questão agora é como gerar esse conjunto de configuração que satisfaça $\rho_{\text {ens }}^{\text {conf }}$. A solução matemática dessa questão é gerar uma cadeia de Markov de configurações, $\left\{\Gamma_{i}\right\}$, com a distribuição limite $\rho_{\text {ens }}^{\text {conf }}$, ou seja, a probabilidade de cada configuração $\Gamma_{i}$ existir é $\rho_{i}=$ $\rho_{\text {ens }}^{\text {conf }}\left(\Gamma_{i}\right)$. A cadeia markoviana pode ser gerada através de uma matriz de transição $\pi$ que satisfaz a condições especiais. A matriz de probabilidade de transição $\boldsymbol{\pi}$ é definida de forma que o elemento $\pi_{i j}$ representa a probabilidade de mudar da configuração $\Gamma_{i}$ para $\Gamma_{j}$, e as condições especiais são:

- Existe uma densidade de probabilidade limite;

$$
\rho_{\text {ens }}^{\text {conf }}=\lim _{n \rightarrow \infty} \rho \pi^{n}
$$

- Após atingir esse limite todas as configurações geradas satisfazem a distribuição limite; $\mathrm{e}$

$$
\rho_{\text {ens }}^{\text {conf }} \pi=\rho_{\text {ens }}^{\text {conf }} \quad \text { ou } \quad \sum_{i} \rho_{i} \pi_{i j}=\rho_{j}
$$

- Todo estado é acessível a partir de qualquer outro (condição de ergodicidade)

$$
\pi_{i j}>0 \text { e } \sum_{i} \pi_{j i}=1 \text { para todo } j
$$

Um recurso muito utilizado para encontrar $\boldsymbol{\pi}$ é substituir a condição mostrada na equação 19 por uma condição muito mais rígida, porém mais fácil de ser aplicada, que é a condição do balanceamento detalhado ou também conhecido como reversibilidade microscópica,

$$
\rho_{i} \pi_{i j}=\rho_{j} \pi_{j i}
$$

Assim, a probabilidade de estar em $\Gamma_{i}$ e mudar para $\Gamma_{j}$ é a mesma que estar em $\Gamma_{j}$ e mudar para em $\Gamma_{i}$. Note que somando sobre o índice $i$ em ambos os lados da equação 21 e usando a condição da equação 20, volta-se a satisfazer a equação 19.

Existem várias formas de propor a matriz de transição $\pi$, a mais utilizada é a proposta por Metropolis [55] 


$$
\begin{aligned}
& \pi_{i j}=\alpha_{i j} \quad \text { se } \rho_{j} \geq \rho_{i} \quad \text { para } j \neq i \\
& \pi_{i j}=\alpha_{i j}\left(\rho_{j} / \rho_{i}\right) \text { se } \rho_{j}<\rho_{i} \quad \text { para } j \neq i \\
& \pi_{i j}=1-\sum_{j \neq i} \pi_{i j} \quad \operatorname{para} j=i
\end{aligned}
$$

onde $\boldsymbol{\alpha}$ é uma matriz estocástica simétrica, $\alpha_{i j}=\alpha_{j i}$, usada para garantir que as condições de ergodicidade (equação 20) e reversibilidade microscópica (equação 21) sejam satisfeitas. Para simplificar, em geral o procedimento de gerar novas configurações aleatórias é definido de maneira a ter $\alpha_{i j}$ constante. Esse é o caso do procedimento que implementamos,

$$
\alpha_{i j}=\frac{1}{N} \frac{\delta V}{V} \frac{1}{36}
$$

onde a primeira fração é devido a escolha aleatória de uma molécula dentre as $N$ possíveis, a segunda é devido ao deslocamento da molécula ser permitido apenas numa fração do volume total, $\delta V=\left(\delta r_{\text {max }}\right)^{3}$, e a terceira é devido à rotação da molécula ser permitida apenas num dos 3 eixos e numa fração de $1 / 12$ do ângulo total. Portanto, considerando que a matriz $\boldsymbol{\alpha}$ está definida dentro do procedimento de gerar novas configurações aleatórias, o teste de aceitação da amostragem de Metropolis, no ensemble NVT, fica simplificado a

$$
\begin{aligned}
& \text { Aceitar sempe se } U_{j} \leq U_{i} \\
& \text { Aceitar com probabilidade }=\left(\rho_{j} / \rho_{i}\right)=\exp (-\Delta U / k T) \text { se } U_{j}>U_{i} \text {. }
\end{aligned}
$$

Observa-se que essa matriz de transição é estocástica, pois a probabilidade de mudar de uma configuração para outra só depende de ambas, independentemente do caminho, ou sequencia anterior.

Na prática, a amostragem de Metropolis é implementada no ensemble NVT da seguinte forma: uma molécula é sorteada e movida para uma nova posição aleatoriamente dentro de um subespaço uniforme em coordenadas cartesianas, se a energia do sistema diminui ou fica igual, então essa nova posição é aceita; porém se essa nova posição provoca um aumento da energia, então um número aleatório $\xi_{i}$ entre 0 e 1 é gerado e se esse número for menor ou igual à probabilidade de transição, $\xi_{i} \leq \exp (-\Delta U / k T)$, a nova posição é aceita, apesar da energia ter aumentado; caso contrário, $\xi_{i}>\exp (-\Delta U / k T)$, a nova posição é rejeitada e a posição antes do movimento é mantida.

No ensemble NPT, o mesmo procedimento é adotado e adicionalmente o volume é modificado juntamente com o reescalonamento de todas as posições de centro de massa das moléculas. Desta forma, o teste de aceitação é equivalente 


$$
\begin{array}{ll}
\text { Aceitar sempe } & \text { se } \mathcal{H}_{j} \leq \mathcal{H}_{i} \\
\text { Aceitar com probabilidade }=\left(\rho_{j} / \rho_{i}\right)=\exp (-\Delta \mathcal{H} / k T) & \text { se } \mathcal{H}_{j}<\mathcal{H}_{i}
\end{array}
$$

onde $\mathcal{H}_{i}=U_{i}+P V_{i}-N k T \ln \left(V_{i}\right)$ é a entalpia conformacional da configuração $i$ somada a um termo que decorre do reescalonamento de todas as posições moleculares devido a mudança de volume. Esse reescalonamento é implementado na simulação para evitar que as moléculas fiquem fora da caixa quando o volume diminui, ou que existam espaços vazios quando o volume aumenta.

Em resumo, no ensemble $N V T$, iniciando a simulação com uma configuração qualquer, selecionamos uma molécula $i$; fazemos um movimento aleatório nessa molécula; aplicamos o teste de aceitação de Metropolis (mostrado na equação 24); caso o movimento seja aprovado, a nova posição é aceita; caso contrário, ela é rejeitada e mantemos a configuração anterior; selecionamos outra molécula e repetimos o mesmo procedimento anterior até completarmos o ciclo com as $N$ moléculas; daí, completamos um ciclo $\mathrm{MC}$; salvamos a configuração e começamos um novo ciclo. Ao final da simulação, temos uma cadeia de configurações que descrevem a evolução da simulação. No ensemble NPT, após poucos ciclos MC o volume é reescalado; aplicamos o teste de aceitação de Metropolis (mostrado na equação 25); caso a mudança do volume seja aprovada, a nova configuração é aceita; caso contrário, ela é rejeitada e mantemos a configuração anterior.

Em geral, a evolução de uma simulação pode ser dividida em duas etapas. A primeira é uma etapa não estacionária, conhecida como termalização, e a segunda é uma etapa estacionária, que é conhecida como etapa de equilíbrio, de médias, ou de produção. Essas duas etapas da simulação podem ser facilmente observadas no comportamento da energia do sistema durante a simulação, pois o sistema sai da energia inicial e gradualmente atinge um patamar, em torno do qual fica flutuando. A etapa de equilíbrio é, então, descrita por esse patamar. Só as configurações geradas na etapa de equilíbrio são consideradas nos cálculos das propriedades estruturais e termodinâmicas. Portanto a forma como o sistema chega ao equilíbrio não é relevante. Em nossas simulações, a configuração inicial, em geral, é gerada aleatoriamente e possui energia muito maior que a energia média do equilíbrio. Levando em conta que o sistema leva muitos passos MC para chegar ao equilíbrio (cerca de 5000 ciclos MC), optamos por usar um procedimento inicial diferente, onde só são aceitas configurações que diminuem a energia do sistema. Dessa forma, o sistema sai rapidamente da energia inicial para energias mais próximas da energia média de equilíbrio. Em geral, 150 ciclos MC são suficientes para trazer os sistemas com energia total muito positiva (devido à configuração inicial aleatória) para energia total negativa.

Após a simulação realizamos os cálculos das propriedades médias sobre as configurações geradas durante a etapa de equilíbrio através das médias e flutuações da energia potencial, $\langle U\rangle$ e $\left\langle\delta U^{2}\right\rangle$, do primeiro virial $W=-(1 / 3) r(\delta U / \delta r),\langle W\rangle$ e $\left\langle\delta W^{2}\right\rangle$, do segundo virial $\Theta=(1 / 9) r(\delta(r \delta U / \delta r) / \delta r),\langle\Theta\rangle$ e $\left\langle\delta \Theta^{2}\right\rangle$, e do volume, $\langle V\rangle$ e $\left\langle\delta V^{2}\right\rangle$. Como 
temos uma expressão para $U(r)$, calculamos analiticamente as expressões para o $W(r)$ e $\Theta(r)$. Para cada configuração $\Gamma_{i}$, calculamos $\mathrm{U}_{i}, U_{i}^{2}, \mathrm{~V}_{i}, V_{i}^{2}, \mathrm{~W}_{i}, W_{i}^{2}, \Theta_{i}$ e $\Theta_{i}^{2}$, e em seguida calculamos as médias dessas grandezas. Essas médias são utilizadas para os cálculos das propriedades termodinâmicas da seguinte forma, no ensemble NVT:

- Energia interna:

$$
\langle E\rangle=\frac{3+v}{2} N k T+\langle U\rangle
$$

onde $v=$ graus de liberdade além da translação.

- Calor específico a volume constante:

$$
\left\langle c_{V}\right\rangle=\frac{3+v}{2} N k+\frac{\left\langle\delta U^{2}\right\rangle}{k T^{2}}
$$

onde $\left\langle\delta U^{2}\right\rangle=\left\langle U^{2}\right\rangle+\langle U\rangle^{2}$.

- Pressão:

$$
\langle P\rangle=\frac{N k T+\langle W\rangle}{V}
$$

- Compressibilidade isotérmica:

$$
\left\langle\kappa_{T}\right\rangle=\left[\langle P\rangle-\frac{\left\langle\delta W^{2}\right\rangle}{V k T}+\frac{\langle\Theta\rangle}{V}\right]^{-1}
$$

onde $\langle\delta W \delta U\rangle=\langle W U\rangle-\langle W\rangle\langle U\rangle$.

Note que em todas essas propriedades, (equações 26 a 29) apenas o segundo termo é calculado ao longo das simulações e o primeiro termo é o cinético, adicionado após a simulação.

No ensemble NPT, as propriedades termodinâmicas calculadas são:

- Entalpia:

$$
\langle H\rangle=\frac{3+v}{2} N k T+\langle U\rangle+P\langle V\rangle
$$


onde $v=$ graus de liberdade além da translação.

- Calor específico à pressão constante:

$$
\left\langle c_{P}\right\rangle=\frac{3+v}{2} N k+\frac{\left\langle\delta H_{\text {conf }}^{2}\right\rangle}{k T^{2}}
$$

onde $H_{\text {conf }}=U+P V$ e $\left\langle\delta H_{\text {conf }}^{2}\right\rangle=\left\langle H_{\text {conf }}^{2}\right\rangle+\left\langle H_{\text {conf }}\right\rangle^{2}$.

- Compressibilidade isotérmica:

$$
\left\langle\kappa_{T}\right\rangle=\frac{\left\langle\delta V^{2}\right\rangle}{\langle V\rangle k T}
$$

onde $\left\langle\delta V^{2}\right\rangle=\left\langle V^{2}\right\rangle+\langle V\rangle^{2}$. As definições e deduções dessas expressões estão apresentadas no apêndice $\mathrm{B}$ da ref. [1].

Para estudar as propriedades estruturais, comumente é usada a função de distribuição radial de pares (RDF) ou $G(r)$. Essa função pode ser obtida em experiências com difração de raio-X e nêutrons [56] e espalhamento de raio-X [57],[58]. Ela dá a probabilidade de encontrar um par de átomos a uma distância $r$ relativa à probabilidade esperada para um sistema de mesma densidade e uma distribuição uniforme. Nas simulações, a RDF entre átomos do tipo $i$ e $j, G_{i j}(r)$, é calculada através do histograma de distâncias dos pares dos átomos:

$$
G_{i j}(r)=\frac{\text { Histograma }_{i j}\left(r_{-}, r_{+}\right)}{N^{u n i f}\left(r_{-}, r_{+}\right)}
$$

onde $r_{-}=r-(d r / 2), r_{+}=r+(d r / 2)$, Histograma $i j\left(r_{-}, r_{+}\right)$é o número de pares $i j$ que estão separados por uma distância entre $r_{-}$e $r_{+}$, ou seja, numa casca esférica de espessura $d r$

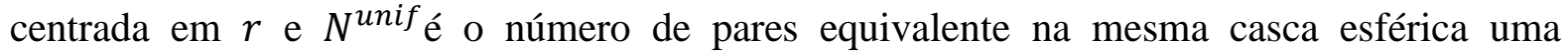
distribuição uniforme de mesma densidade:

$$
N^{\text {unif }}(r)=\frac{4 \pi}{3} \frac{N}{V} \quad\left[r_{+}^{3}-r_{-}^{3}\right]=\frac{N \delta V_{e s f}(r)}{V}
$$

onde $\delta V_{e s f}(r)$ é o volume da casca esférica de espessura $d r$ centrada em $r$. Sendo assim, a função $G_{i j}(r)$ fornece a densidade relativa do sistema comparativamente a uma distribuição uniforme. Tipicamente, essa função apresenta a curtas distâncias alguns picos que definem as camadas de solvatação e a longas distâncias tende ao valor unitário, ou seja, tende a 
distribuição uniforme. Somando-se o histograma ij de zero até uma distância $r$, obtém-se o número de pares $i j$ até essa distância, $N_{i j}(r)$.

Na Figura 1 mostramos $G(r)$ entre o centro de massa do soluto e os centros de massa das moléculas de solvente, típica para a fase líquida. Em ambos gráficos, é possível identificar pelo menos 2 camadas de solvatação bem definidas pelos picos mostrados na $G_{C M-C M}(r)$, entre pirimidina, $\mathrm{C}_{4} \mathrm{H}_{4} \mathrm{O}_{2}$, e tetracloreto de carbono, $\mathrm{CCl}_{4}$, (a esquerda) e água, $\mathrm{H}_{2} \mathrm{O}$, (a direita) [59]. No gráfico da esquerda, a primeira camada contem $13 \mathrm{CCl}_{4}$ e vai até $7.9 \AA$, ou seja, $N_{1}=N_{C M-C M}(7.9)=13$; e a segunda camada contem $48 C C l_{4}$, indo de $7.9 \AA$ até $13.2 \AA$, ou seja, $N_{C M-C M}(13.2)=61$ e $N_{2}=N_{C M-C M}(13.2)-N_{C M-C M}(7.9)=48$. O sistema soluto-solvente contendo até a segunda camada de solvatação tem 1 pirimidina $+61 \mathrm{CCl}_{4}$. No gráfico da direita, a primeira camada contem $21 \mathrm{H}_{2} \mathrm{O}$ e vai até $5.4 \AA$, a segunda camada contem $50 \mathrm{H}_{2} \mathrm{O}$, indo de $5.4 \AA$ até $8.0 \AA$ A e a terceira camada contem $142 \mathrm{H}_{2} \mathrm{O}$, indo de $8.0 \AA$ até $11.5 \AA$.
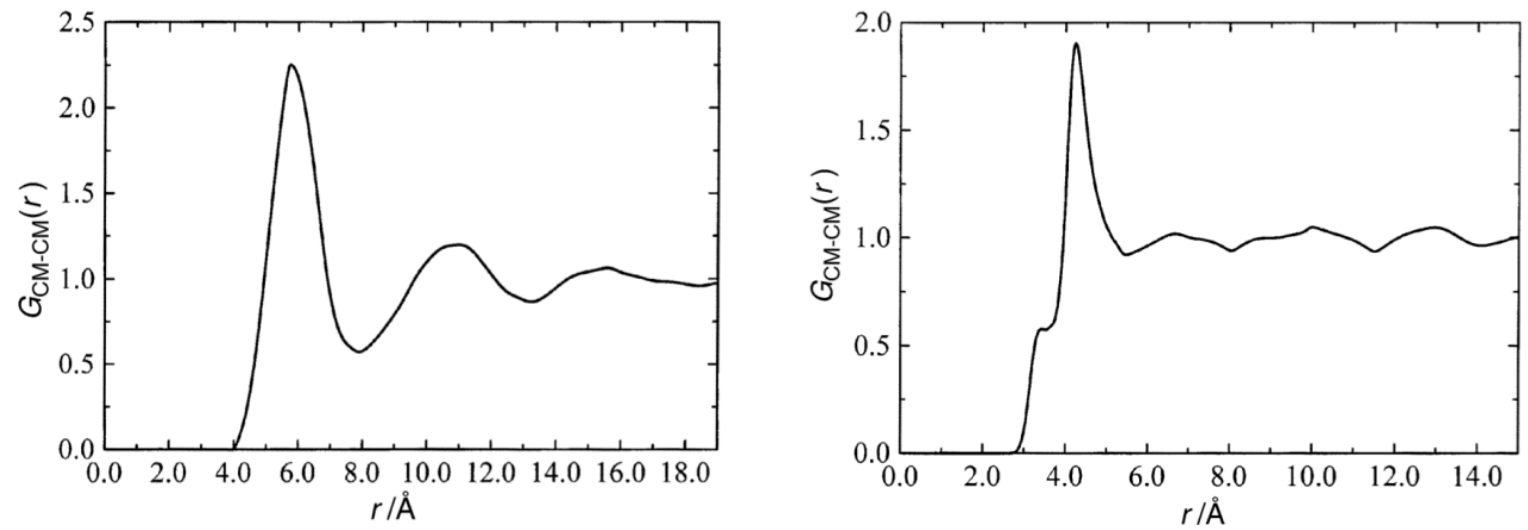

Figura 1: Exemplos de funções de distribuição radial de pares entre centros de massa para sistemas em fase líquida: pirimidina em tetracloreto de carbono (esquerda) e em água (direita). Gráficos retirados da ref. [59].

É interessante notar que na solução aquosa de pirimidina, no primeiro pico existe um ombro a curtas distâncias. Isso representa uma estruturação de moléculas de água a curtas distâncias e é típico em sistemas onde existe a formação de ligações de hidrogênio entre a molécula de soluto e algumas moléculas de água. Quando as ligações de hidrogênio são muito estruturadas o ombro se torna num pico bem definido a curtas distâncias e é possíveis determinar a quantidade de moléculas de água que formam essa microcamada de solvatação. Porém esse procedimento não é muito preciso para caracterizar as ligações de hidrogênio entre um soluto e as moléculas de água e muitas vezes é necessário analisar também o caráter orientacional dessa ligação. Nesse sistema, a formação de ligações de hidrogênio é mais bem caracterizada analisando as funções de distribuição radial entre os nitrogênios da pirimidina e os oxigênios e hidrogênios das moléculas de água, $G_{N-O}(r)$ e $G_{N-H}(r)$. Na Figura 2, mostramos uma configuração molecular, obtida na simulação computacional, da pirimidina rodeada por: 2 moléculas de água que formam ligações de hidrogênio com os nitrogênios da pirimidina (esquerda), 21 moléculas de água que formam a primeira camada de solvatação 
(centro) e 71 moléculas de água que formam a primeira e segunda camada de solvatação (direita).
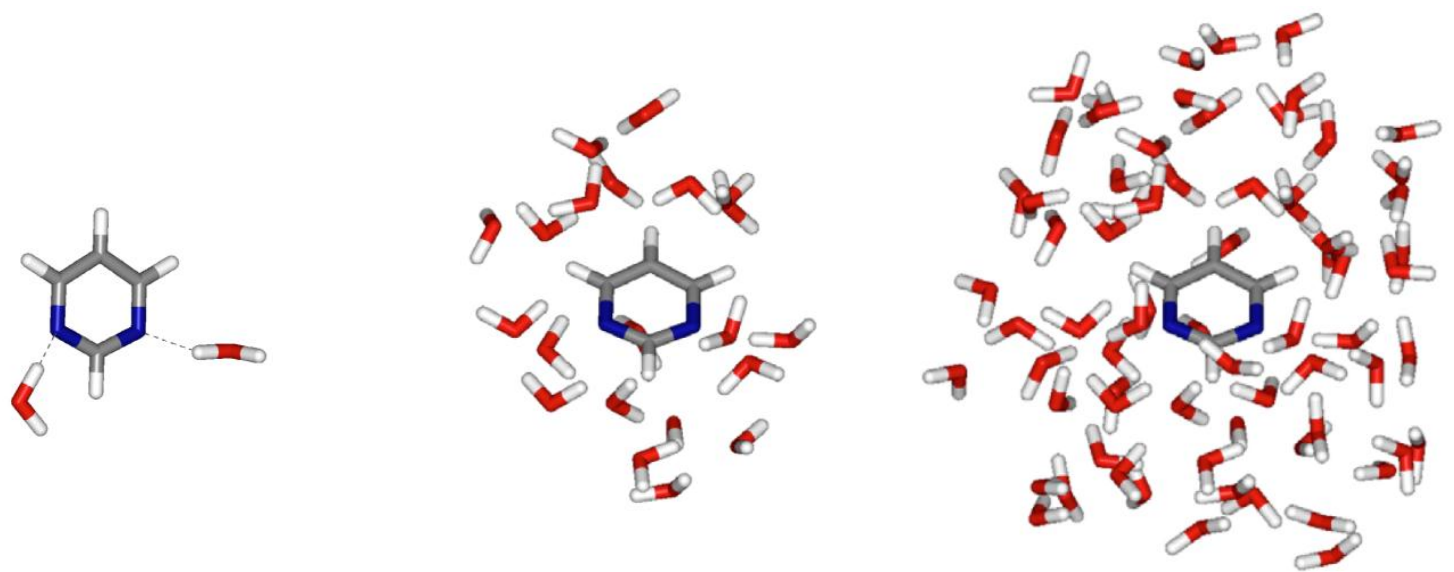

Figura 2: Ilustração de uma configuração molecular da pirimidina rodeada pelas moléculas de água que formam: ligações de hidrogênio (esquerda), a primeira camada de solvatação (centro) e até a segunda camada de solvatação (direita).

Na equação 34, o termo $N / V$ é a densidade total do sistema, que é constante no ensemble NVT, mas varia no ensemble NPT. Para o cálculo da RDF no ensemble NPT, a densidade total é substituída pela densidade média $\langle N / V\rangle$. Aparentemente a simulação feita nesse ensemble parece ser computacionalmente muito mais custosa que no NVT, pois cada vez que o tamanho da caixa de simulação é modificado, de $L \rightarrow L+\delta L$, a interação entre todos os pares de moléculas deve ser recalculada. Entretanto, como o potencial de interação intermolecular (equação 11) tem 3 termos em lei de potencial $r^{-n}$, onde $n=12$, 6 e 1 , é possível simplesmente reescalar os termos da energia potencial total para obter seu valor após a mudança do volume, com o fator $((L+\delta L) / L)^{-n}$. Sendo assim, a simulação no ensemble NPT é pouco mais lenta, mas muito mais vantajosa, considerando que nesse ensemble podemos utilizar a densidade de equilíbrio como um teste importante da parametrização do campo de força. Desta forma, vamos dar preferência às simulações no ensemble NPT.

\subsection{Método Híbrido Sequencial com Mecânica Quântica e Mecânica Molecular}

O método híbrido sequencial QM/MM é um método de duas etapas. Na primeira etapa, são realizadas simulações computacionais com mecânica molecular para gerar configurações dos sistemas de interesse numa condição termodinâmica específica. Em geral, são geradas da ordem de $10^{5}-10^{7}$ configurações compostas por cerca de $10^{3}-10^{5}$ átomos, dependendo do sistema de interesse e do método de simulação. Na segunda etapa, são realizados cálculos com mecânica quântica para determinação de propriedades eletrônicas, magnéticas, óticas, entre outras, sobre as configurações moleculares geradas na primeira etapa. Nesse método duas questões são importantes: 
1) De todas as configurações geradas nas simulações quantas devem ser utilizadas nos cálculos quânticos? Quais ?

2) Qual o tamanho do sistema (átomos/moléculas) que devem ser considerados nos cálculos quânticos?

Respondendo a primeira questão, nossa proposta foi de levar para os cálculos quânticos apenas configurações estatisticamente descorrelacionadas e analisar a convergência da média das propriedades calculadas com relação ao número de configurações utilizadas. Desta forma, conseguimos mostrar que cerca de 100 configurações estatisticamente descorrelacionadas são suficientes para descrever a diversidade de configurações amostradas numa simulação [2],[3],[36],[60].

As configurações sucessivas, geradas nas simulações computacionais, são muito parecidas umas com as outras e geram valores muito próximos, ou estatisticamente correlacionados, das propriedades. Sendo assim, é um desperdício de tempo, ou informação estatística, realizar cálculos quânticos em configurações sucessivas. Para estabelecer um intervalo entre as configurações que produzem informação estatística nova, propomos utilizar a correlação estatística e/ou a ineficiência estatística da energia potencial de interação por molécula. Essa energia foi escolhida por ser uma grandeza calculada em todos os passos da simulação e por caracterizar macroscopicamente a configuração.

A correlação estatística entre duas quantidades diferentes pode ser medida de maneira usual pelo coeficiente de correlação [61] e esse conceito é normalmente estendido, considerando essas duas quantidades como a mesma propriedade avaliada em tempos diferentes. Para um tempo $t$ específico, o coeficiente de correlação é conhecido como um coeficiente de autocorrelação, mas para vários valores de tempo num certo intervalo é construída a função de autocorrelação temporal, $C(t)$. A integração dessa função fornece o tempo de correlação estatística, $\tau$,

$$
\tau=\int_{0}^{\infty} C(t) d t
$$

Tempo aqui significa passo MC e não tem nenhuma relação com tempo real. Esta nomenclatura "tempo" é usada devido à origem do cálculo de $C(t)$ que se deu em análises de série temporal onde cada valor da série representa uma propriedade avaliada num tempo real diferente.

A função de autocorrelação temporal da energia potencial $U$ é definida por

$$
C(t)=\frac{\left\langle\delta U_{0} \delta U_{t}\right\rangle}{\left\langle\delta U^{2}\right\rangle}
$$

porém na simulação, devido a ergodicidade do sistema a configuração inicial $\Gamma_{0}$ pode ser qualquer configuração acessível $\Gamma_{i}$, então reescreve-se a equação 36 como 


$$
C(t)=\frac{\left\langle\delta U_{i} \delta U_{i+t}\right\rangle}{\left\langle\delta U^{2}\right\rangle}=\frac{\left\langle U_{i} U_{i+t}\right\rangle_{l-t}-\left\langle U_{i}\right\rangle_{l-t}\left\langle U_{i+t}\right\rangle_{l-t}}{\left\langle U^{2}\right\rangle_{l}-\langle U\rangle_{l}^{2}}
$$

onde $l$ é a quantidade de configurações geradas na simulação. No cálculo de $\left\langle U_{i}\right\rangle_{l-t}$ as $t$ últimas configurações são desprezadas, enquanto que no cálculo de $\left\langle U_{i+t}\right\rangle_{l-t}$ as configurações desprezadas são as $t$ primeiras. Note que nesses cálculos as médias são tomadas sobre $l-t$ configurações e à medida que $t$ cresce o cálculo de $C(t)$ fica cada vez menos preciso. Tipicamente, o máximo valor de $t$ que utilizamos é cerca de $0.5 \%$ de $l$. Portanto, não é factível fazer o cálculo do tempo de correlação $\tau$ (equação 35) através de integração numérica da $C(t)$. A forma usual de calcular $\tau$ é fazer a integração analítica da função que melhor ajusta à $C(t)$. Quando os valores sucessivos de $U_{i}$ diferem por pequenas flutuações, que é o nosso caso, a função de autocorrelação segue um decaimento exponencial [61],[62],

$$
C(t)=\sum_{i} c_{i} \exp \left(-t / \tau_{i}\right)
$$

onde os $\tau_{i}$ representam tempos de correlação característicos do sistema. Para simulações realizadas com método Monte Carlo utilizando amostragem de Metropolis, verificou-se que a função de autocorrelação da energia potencial [36],[38] e de outras propriedades [62],[63] pode ser bem representada por uma ou duas funções exponenciais. Portanto, o tempo de correlação pode ser facilmente obtido ajustando a função de autocorrelação $C(t)$, calculada pela equação 37 , por uma função exponencial dupla, $C(t)=c_{1} \exp \left(-t / \tau_{1}\right)+c_{2} \exp (-t /$ $\tau_{2}$ ), e integrando analiticamente de zero a infinito. Isso dá $\tau=c_{1} \tau_{1}+c_{2} \tau_{2}$, onde normalmente $\tau_{2} \gg \tau_{1}$. Um exemplo deste comportamento é mostrado na Figura 3 .

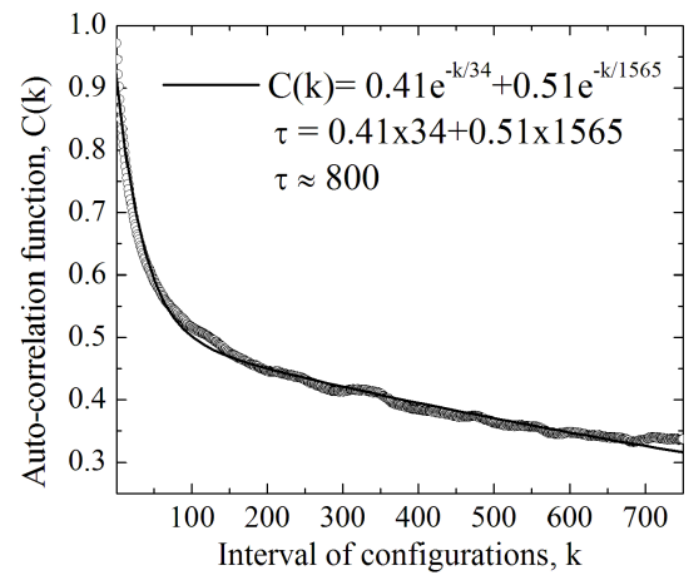

Figura 3: Exemplo de função de autocorrelação da energia potencial por molécula (círculos) e do ajuste da função exponencial de decaimento duplo (linha). Os valores ajustados e o tempo de correlação também estão apresentados. Gráfico retirado da ref. [64]. 
Em geral, para um intervalo de cerca de $2 \tau$, a correlação estatística é aproximadamente $13 \%$, isto é, $C(2 \tau) \sim 0.13$. Os valores de $U_{i}$ separados por esse intervalo podem ser considerados como estatisticamente descorrelacionados. Sendo assim, vamos escolher configurações separadas com intervalos de $2 \tau$ e considerá-las configurações estatisticamente descorrelacionadas.

Outro método utilizado para calcular o intervalo entre configurações estatisticamente descorrelacionadas é a ineficiência estatística [65], que se baseia no desvio quadrático médio de médias sobre blocos de configurações. A cadeia de $l$ configurações geradas durante a simulação é dividida em $n_{b}$ blocos com $l_{b}$ configurações sucessivas, de forma que $l=l_{b} n_{b}$ e a média da energia potencial por molécula calculada sobre o $b$-ésimo é

$$
\langle U\rangle_{b}=\frac{1}{l_{b}} \sum_{i=b_{i}}^{b_{f}} U_{i}
$$

onde $b_{i}=(b-1) l_{b}+1, b_{f}=b l_{b}$ e $b$ pode assumir valores entre 1 e $n_{b}$. O desvio quadrático médio das médias sobre os blocos é

$$
\left\langle\delta U^{2}\right\rangle_{n_{b}}=\frac{1}{n_{b}} \sum_{b=1}^{n_{b}}\left(\langle U\rangle_{b}-\langle U\rangle_{l}\right)^{2}
$$

e a ineficiência estatística $s$ é

$$
s=\lim _{l_{b \rightarrow \infty}}\left(\frac{l_{b}\left\langle\delta U^{2}\right\rangle_{n_{b}}}{\left\langle\delta U^{2}\right\rangle_{l}}\right)=\lim _{l_{b \rightarrow \infty}} S\left(l_{b}\right)
$$

Para cadeias de valores correlacionados, $S\left(l_{b}\right)$ cresce com $l_{b}$, pois $\left\langle\delta U^{2}\right\rangle_{n_{b}}$ tende uma constante. Quando os valores são descorrelacionados $\left\langle\delta U^{2}\right\rangle_{n_{b}}$ tende a zero, enquanto que $l_{b}$ tende a infinito. Isso gera uma indeterminação que faz $S\left(l_{b}\right)$ tender para um valor limite $s$. Esse limite só é atingido quando o tamanho do bloco $l_{b}$ se tornar tão grande a ponto de não existir correlação entre os blocos. Como o tamanho de cada bloco $l_{b}$ está relacionado com o número de blocos $n_{b}$ através da relação $l=l_{b} n_{b}$, para uma dada cadeia de tamanho $l$, à medida que $l_{b}$ cresce, $n_{b}$ diminui. Com isto, aumenta a imprecisão no cálculo de $S\left(l_{b}\right)$ e consequentemente aumenta a imprecisão na estimativa do valor de $s$, que representa o intervalo de passos MC necessários para descorrelacionar configurações. Portanto, uma análise de $s$ com respeito ao tamanho da cadeia é muito importante na estimativa do melhor valor para $s$. Ver um exemplo dessa análise na Figura 4. 


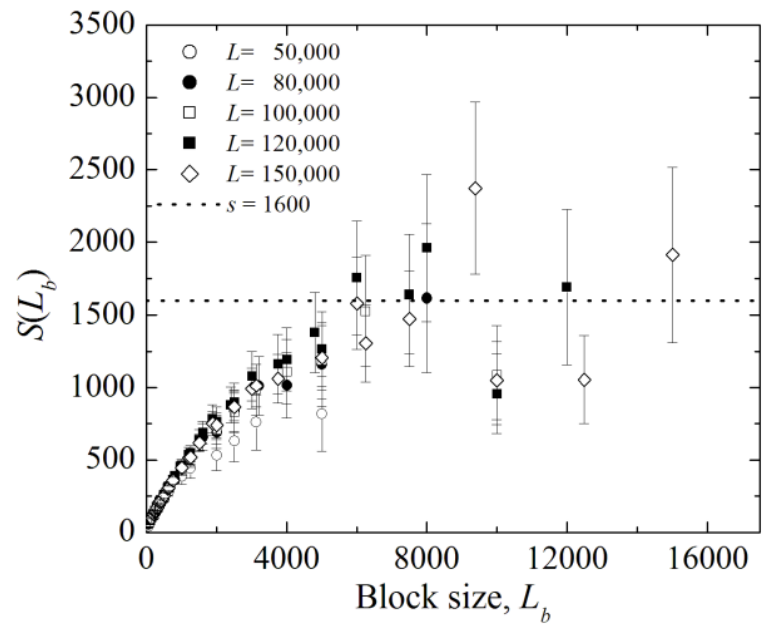

Figura 4: Exemplo de análise da ineficiência estatística, s, calculada para cadeia de valores $\left\{U_{i}\right\}$ com diferentes tamanhos $L$. A linha tracejada representa o valor estimado de s. Gráfico retirado da ref. [64].

O tempo de correlação $\tau$ e a ineficiência estatística $s$ são duas quantidades que são calculadas de formas independentes, mas pode-se mostrar que essas quantidades estão relacionadas [13] por

$$
s \approx 2 \tau .
$$

Como exemplo da relação 42 entre a ineficiência estatística e o tempo, ou intervalo, de correlação, mostramos que utilizando o mesmo conjunto de valores da energia potencial por molécula obtivemos $\tau=800$ (ver Figura 3) e $s=1600$ (ver Figura 4). Para esse sistema, é necessário selecionar configurações em intervalos de 1600 ciclos MC para se obter configurações estatisticamente descorrelacionadas. Então para simulações típicas de cerca de 160 mil ciclos MC, serão selecionadas cerca de 100 configurações estatisticamente descorrelacionadas.

Analisando a distribuição dos valores de propriedades calculadas com as configurações estatisticamente descorrelacionadas verificamos, em geral, uma distribuição gaussiana (ver Figura 5). Essa distribuição garante que o valor médio equivale ao valor mais provável. Sendo assim, analisando como esse valor médio varia com a quantidade de configurações consideradas no cálculo da média (ver Figura 6), é possível identificar quando a média converge e assume um valor confiável e estatisticamente representativo. 

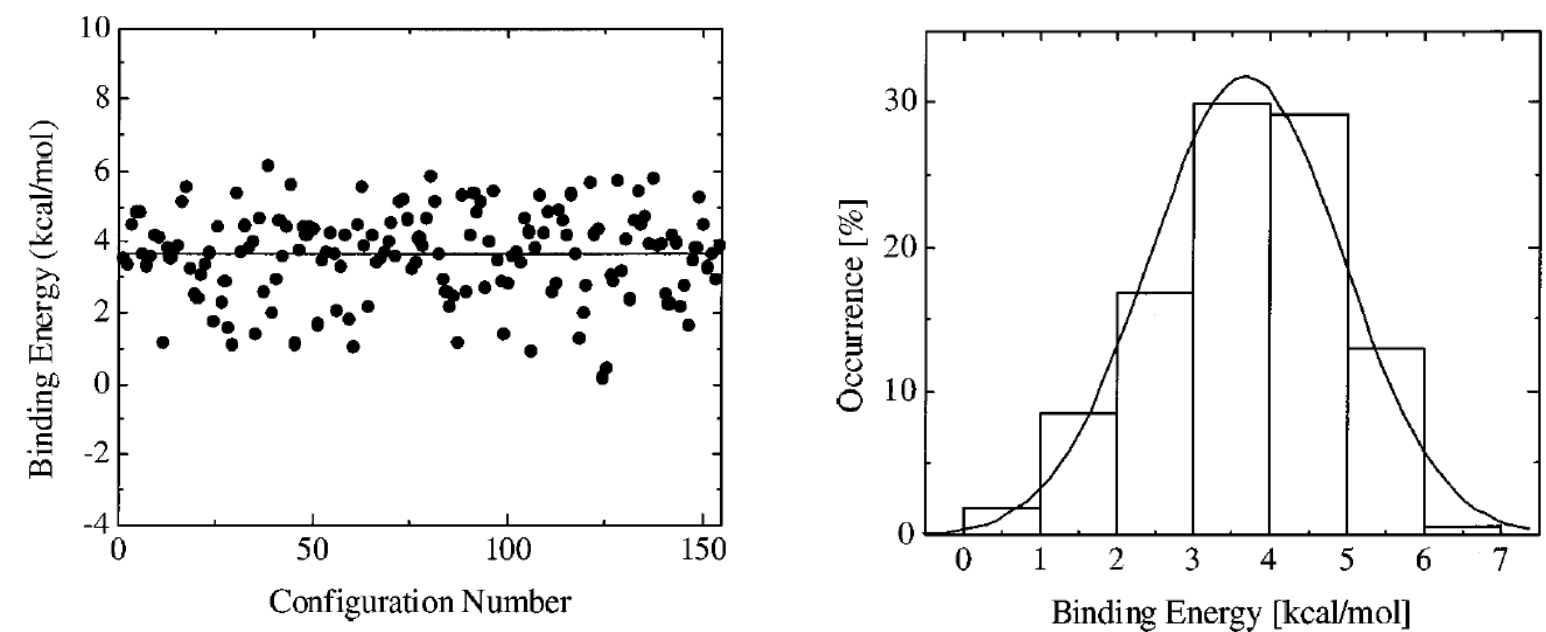

Figura 5: Exemplo de valores calculados para energia de ligação (esquerda) e a distribuição gaussiana (direita) obtida para 160 configurações estatisticamente descorrelacionadas. Gráfico retirado da ref. [60].

No exemplo mostrado na Figura 6, a partir de 80 configurações estatisticamente descorrelacionadas atinge-se uma média convergida para a energia da ligação de hidrogênio entre a molécula de piridina e a molécula de água numa solução aquosa [60].

Com relação à segunda questão sobre o tamanho do sistema que deve ser considerado nos cálculos quânticos, após estudo de várias propriedades e vários sistemas, concluímos que não há uma única resposta. A quantidade de moléculas de solvente necessária para saturar os efeitos de solventes numa dada propriedade depende inerentemente das interações moleculares e se a propriedade estudada tem natureza de curto ou longo alcance. Entretanto, mostramos que estudos da dependência da propriedade com relação à quantidade de moléculas de solvente incluídas nos cálculos quânticos podem elucidar essa questão caso a caso.

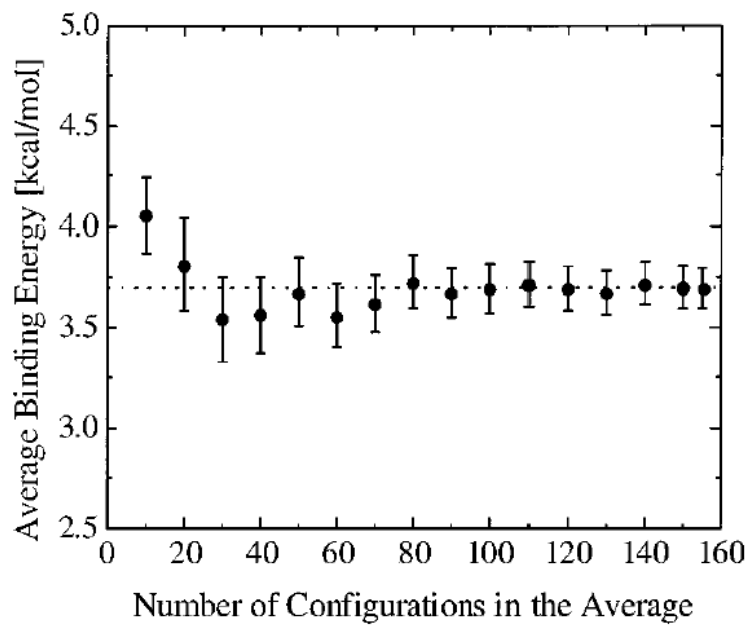

Figura 6: Exemplo da convergência da média em relação à quantidade de configurações utilizadas na média. Os valores utilizados na média estão mostrados na Figura 5. Gráfico retirado da ref. [60]. 
Na Figura 7 mostramos dois exemplos desse tipo de estudo para o deslocamento da energia de emissão e absorção eletrônica devido ao solvente, solvatocrômico, calculada para formaldeído em solução aquosa (esquerda) [38] e pirimidina em solução aquosa (direita) [66], respectivamente. Cada ponto dos gráficos mostrados nessa figura representa a média de cerca de 100 configurações estatisticamente descorrelacionadas. Nesses gráficos estão mostrados os valores calculados quando são incluídas só as moléculas de água que formam ligações de hidrogênio (HB) e as moléculas de água até a primeira, segunda e terceira camada de solvatação (ver exemplo dessas configurações reduzidas na Figura 2). Note que essa propriedade apresenta natureza de longo alcance e mesmo com a inclusão de moléculas de água até a terceira camada de solvatação, o solvatocromismo ainda não está saturado. No caso de consideramos as moléculas do solvente apenas como campo eletrostático, ou seja, como cargas atômicas pontuais (ver Figura 7, esquerda), notamos uma supervalorização das interações de curto alcance (valor mostrado no primeiro círculo aberto). Quando combinamos moléculas explícitas e o campo eletrostático, verificamos que aumentando o número de moléculas explícitas o efeito do campo eletrostático remanescente vai diminuindo, como esperado. Nesse caso, o valor do solvatocromismo calculado para a terceira camada de solvatação está próximo da saturação, pois o valor calculado para essa camada de solvatação e o campo eletrostático remanescente está pouco acima.
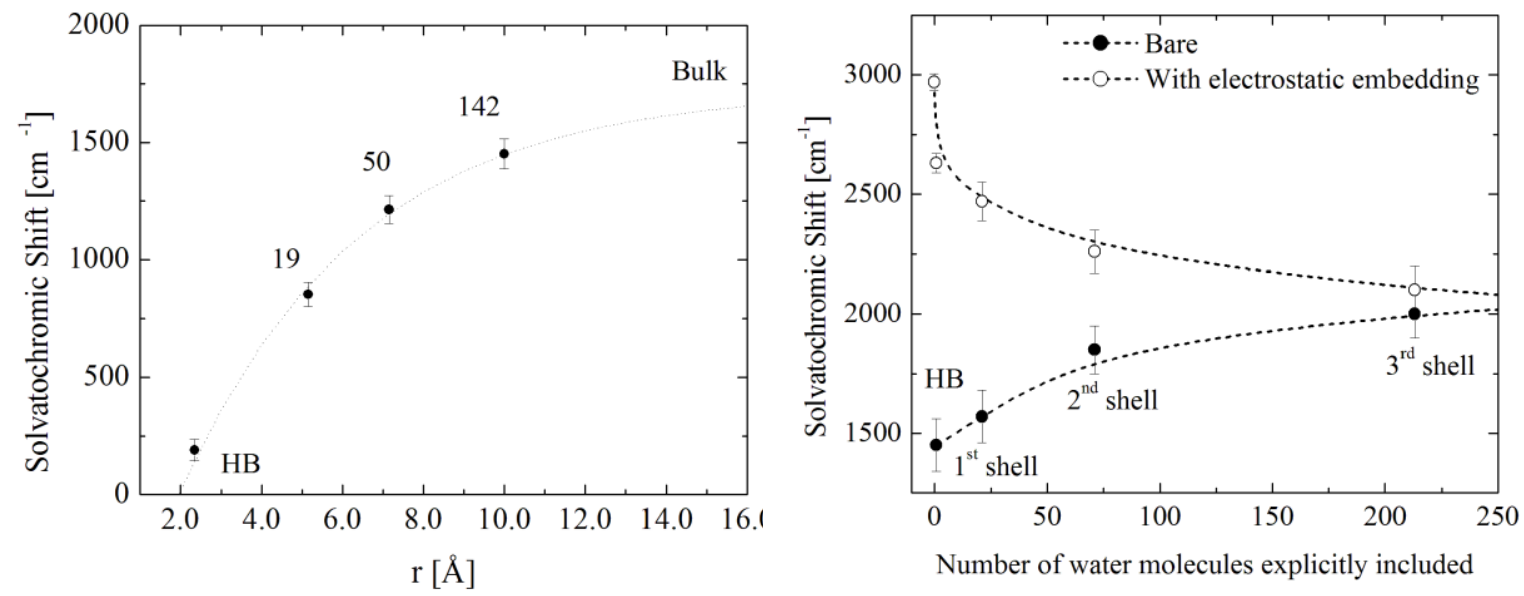

Figura 7: Exemplo da dependência do deslocamento da banda de transição eletrônica com relação à quantidade de moléculas de solvente incluídas explicitamente nos cálculos quânticos. Gráfico da esquerda retirado da ref. [38]. Gráfico da direita mostra diferenças em considerar o campo eletrostático remanescente do solvente além das moléculas explícitas (dados da ref. [66]).

No capítulo 3, discutiremos os resultados que obtivemos na aplicação deste método híbrido sequencial, S-QM/MM, para vários sistemas [2],[3],[36]-[49]. A vantagem clara da utilização desse método é o baixo custo computacional sem a perda da qualidade numérica dos valores calculados. Adicionalmente, os efeitos de temperatura e pressão são incluídos indiretamente 
nas propriedades eletrônica devido à distribuição de configurações selecionadas das simulações computacionais. Outro aspecto importante é a análise estatística da convergência das propriedades com relação ao número de configurações utilizadas e número de moléculas de solvente incluídas nos cálculos quânticos. Desta forma, garantimos que os valores que obtemos estão convergidos e têm representação estatística.

\subsection{Função de Distribuição de Mínima Distância}

Do ponto de vista das propriedades estruturais de sistemas densos, uma análise importante é a distribuição das moléculas de solvente ao redor do soluto, isto é, as camadas de solvatação e as ligações de hidrogênio. Essa distribuição é normalmente analisada através das funções de distribuição radial de pares, RDF ou $G_{i j}(r)$, (ver equações 33 e 34 para definição). As RDFs podem ser calculadas entre qualquer átomo do soluto e qualquer átomo do solvente [13]. Elas também podem ser calculadas entre os centros de massa das moléculas de soluto e solvente, $G_{C M-C M}(r)$. Entre todas as possibilidades, a $G_{C M-C M}(r)$ é a mais usada para definir as camadas de solvatação (ver exemplo na Figura 1). No entanto, ela não é apropriada para definir as camadas de solvatação de solutos alongados, ou que não se aproximem da forma esférica [39]. Nesses casos, fizemos a proposta da função de distribuição de mínima distância, MDDF, onde o histograma usado para calcular a função de distribuição não é a distância entre centros de massa ou átomos do soluto e do solvente, mas a distância mínima entre as moléculas de soluto e solvente [39],[40]. A MDDF é definida da mesma forma que uma $G_{i j}(r)$ (equação 33) só que o histograma acumula a menor distância entre todos os átomos do soluto com todos os átomos do solvente. Nesse caso, a normalização utilizando cascas esféricas (equação 34) passa a ser inadequada, pois a MDDF não é radial em relação a um ponto da molécula de soluto. Essa função segue a forma do soluto e não há escolha óbvia para o volume de normalização. Uma escolha possível, que propusemos [40], é o volume de normalização de uma casca de paralelepípedo. Desta forma, o soluto é representado por um paralelepípedo de dimensões $a, b$ e $c$, que caracterizam o seu tamanho e o $\delta V_{p r l}(r)$, que é o volume de uma casca de paralelepípedo de espessura $d r$ e lados $a+2 r, b+2 r$ e $c+2 r$, é escrito como

$$
\delta V_{p r l}(r)=\left(a+2 r_{+}\right)\left(b+2 r_{+}\right)\left(c+2 r_{+}\right)-\left(a+2 r_{-}\right)\left(b+2 r_{-}\right)\left(c+2 r_{-}\right)
$$

onde $r_{-}$e $r_{+}$são definidos da mesma forma anterior, $r_{-}=r-(d r / 2)$ e $r_{+}=r+(d r / 2)$. Na Figura 8, comparamos os dois volumes de normalização, a casca esférica da RDF (esquerda) e a casca de paralelepípedo da MDDF (direita). 

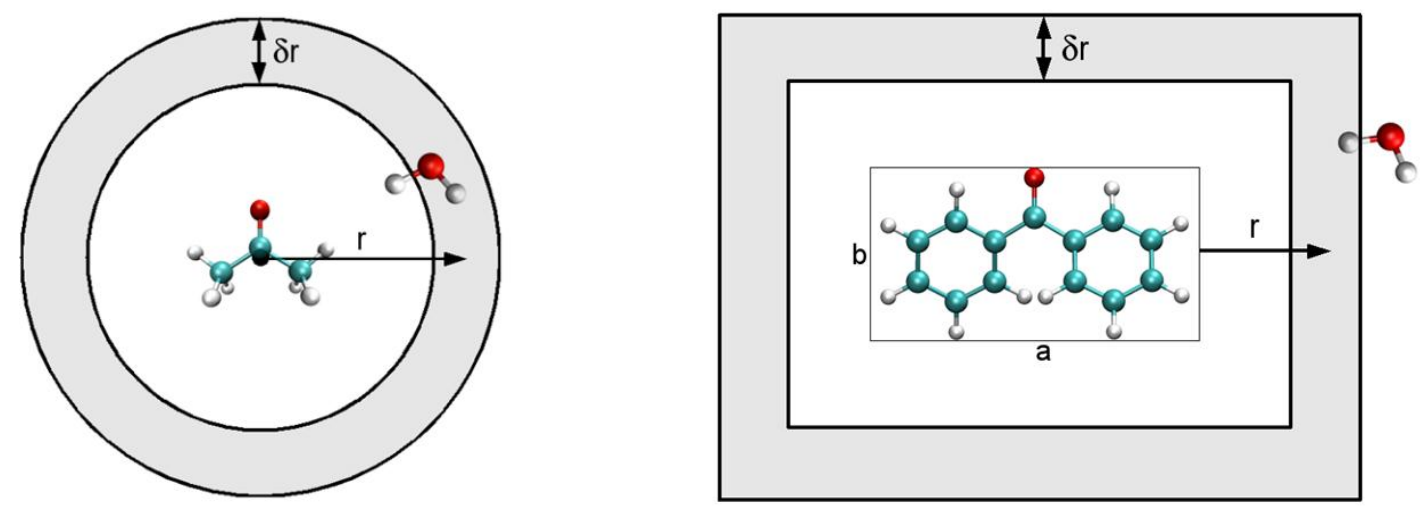

Figura 8: Ilustração do volume normalização da RDF no formato de casca esférica (esquerda) e da MDDF no formato de casca de paralelepípedo (direita). Figura retirada da ref. [40].

Note que para moléculas não esféricas, como é o caso da benzofenona com as dimensões $a=11.5, b=7.0$ e $c=4.0 \AA$ (direita), a MDDF leva em consideração seu formato alongado na direção de $a$. Sendo assim, ilustramos na Figura 9 uma configuração dessa molécula rodeada pelas 45 moléculas de água mais próximas considerando o critério de distância de centro de massa (esquerda) e de mínima distância (direita). É notório que a configuração, que usa o critério de mínima distância (direita), apresenta uma distribuição de moléculas do solvente mais uniforme ao redor do soluto. Porém para solutos pequenos, como é o caso do formaldeído, acetona, piridina, pirimidina, etc., essas duas distribuições, RDF e MDDF, não são muito diferentes e, portanto a utilização da RDF é adequada. Entretanto para solutos grandes, a utilização da MDDF faz toda a diferença e pode ser de grande importância para definição correta da solvatação do soluto. Por isso, daremos prioridade à utilização da MDDF para análises estruturais das soluções.
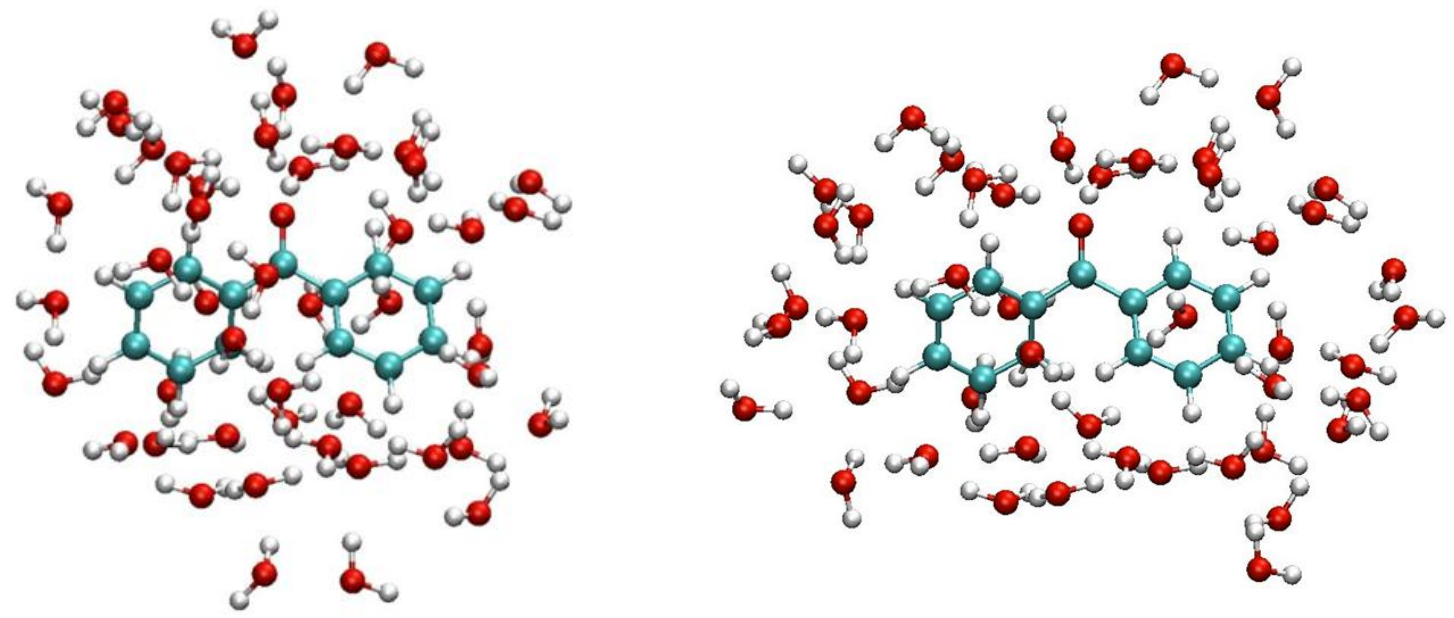

Figura 9: Ilustração da molécula de benzofenona rodeada por 45 moléculas de água em uma configuração gerada na simulação utilizando o critério de proximidade: do centro de massa (esquerda) e da mínima distância (direita). Figura retirada da ref. [40]. 
É importante ressaltar que nem todo soluto será bem representado por um paralelogramo e desta forma, essa normalização com casca de paralelepípedo não será adequada. Quando isso ocorrer a MDDF ficará com a normalização inadequada e não tenderá para o valor unitário para longas distâncias. Porém, se mesmo assim, os picos ficarem bem definidos ainda é possível caracterizar as camadas de solvatação e a quantidade de moléculas de solventes essas camadas sem nenhum erro.

No capítulo 3 discutiremos resultados das camadas de solvatação obtidas para as moléculas de $\beta$-caroteno em vários solventes [39], e benzofenona [40], orto-betaína [46] e óxido mesitil [49] em solução aquosa.

\subsection{Cálculos Quânticos e Análise da Delocalização dos Orbitais Moleculares}

Após as simulações computacionais e seleção de configurações moleculares estatisticamente descorrelacionadas são realizados cálculos quânticos. Todos os cálculos quânticos em nível $a b$ initio reportados neste texto foram realizados com o programa GAUSSIAN [67] e em nível semiempírico com o programa ZINDO [68]. Utilizamos diferentes métodos teóricos e conjuntos de funções de base para realizar os cálculos QM. Neste texto vamos apenas lista-los. Descrições detalhadas desses métodos podem ser encontradas em livros texto [69]-[71]. Para as otimizações de geometria e cálculo de propriedades do estado fundamental, em geral, utilizamos Teoria do Funcional da Densidade, DFT [72] com o funcional de troca-correlação B3LYP [73] e teoria de perturbação MøllerPlesset de segunda ordem, MP2 [74]. Esses métodos foram usados em combinação com a família de funções de base de Pople, 6-31+G(d), 6-311+G(d, p) e 6-311++G(d, p) [75], e a família de funções de base hierárquica de Dunning consistentes para métodos com correlação eletrônica, cc-pVxZ e aug-cc-pVxZ (x = D e T) [76]. As energias de excitação eletrônica foram calculadas com método semiempirico INDO [77] e interação de configuração com excitações simples, CIS [77],[78] com parametrização espectroscópica [79], com métodos $a b$ initio utilizamos CIS e métodos dependentes do tempo: TD-HF, TD-DFT [80] com várias aproximações para o funcional de troca-correlação B3LYP, CAM-B3LYP, BHandHLYP, entre outros, e EOM-CCSD (equation-of-motion coupled cluster with single and doubles excitations) [81]. O conjunto de cargas atômicas de uma molécula pode ser gerado de várias formas num cálculo QM. Nosso interesse nesse conjunto de cargas é o de descrever corretamente o potencial eletrostático da molécula com o objetivo de posteriormente descrever as interações dessa molécula com o meio solvente que a envolve. Sendo assim, escolhemos um procedimento, conhecido como CHELPG [82], para gerar as cargas atômicas através do ajuste do potencial eletrostático da molécula, gerado numa grade reticulada próxima a uma superfície acessível ao solvente. 
Quando cálculos quânticos são realizados em configurações moleculares, a função de onda é construída para um sistema composto por várias moléculas. Os orbitais moleculares, $\psi^{(j)}$, que são combinação linear dos orbitais atômicos, $\varphi_{i}$,

$$
\psi^{(j)}=\sum_{i} c_{i}^{(j)} \varphi_{i}
$$

passam a ser orbitais que podem, ou não, se delocalizar por mais de uma molécula. Quando ocorre essa delocalização dos orbitais de fronteira, o orbital molecular mais alto ocupado, HOMO (Highest Occupied Molecular Orbital), e o orbital molecular mais baixo desocupado, LUMO (Lowest Unoccupied Molecular Orbital), alguns aspectos conceituais podem mudar e questões interessantes aparecem. Um exemplo dessas questões é quanto à localização do elétron excedente no fluoreto, $F^{-}$, em solução aquosa (ver ilustração do HOMO desse sistema na Figura 10 à direita), ou a questão da reatividade de solutos que está associada a propriedades dos orbitais de fronteira (ver ilustração do HOMO de metil amina, $\mathrm{CH}_{3} \mathrm{NH}_{2}$, em solução aquosa na Figura 10 à esquerda).
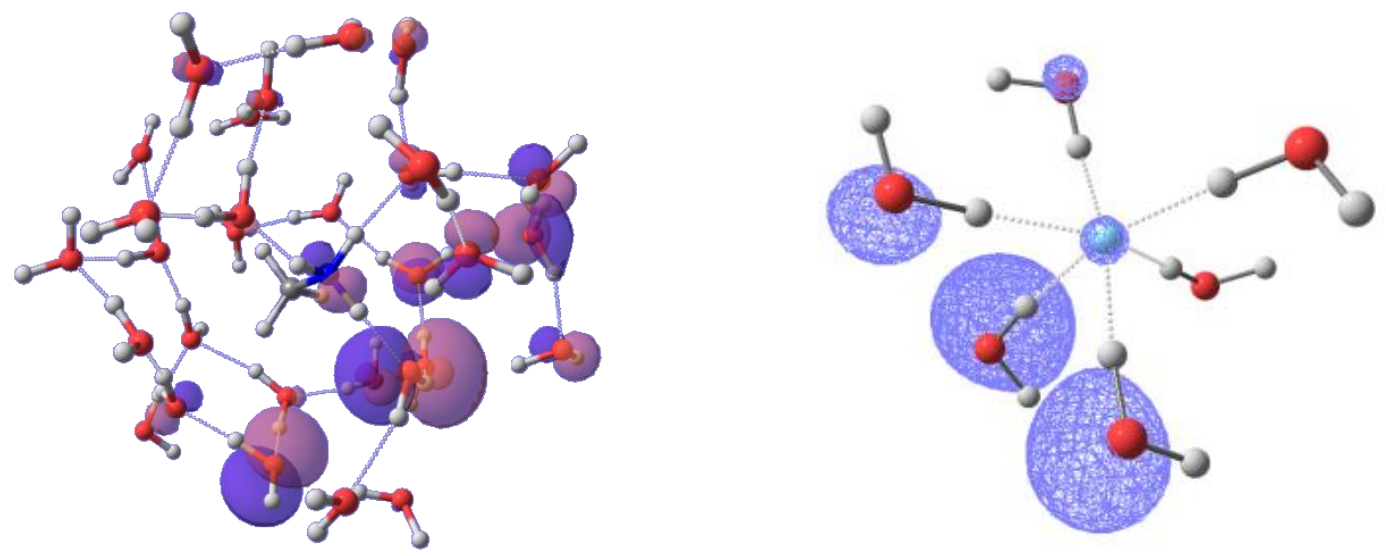

Figura 10: Ilustração da delocalização do orbital mais alto ocupado, HOMO, na solução aquosa de metilamina (esquerda) e de fluoreto (direita), ambos soluto rodeados pela primeira camada de solvatação.

Esses tópicos foram abordados em alguns dos nossos trabalhos [41],[42] que serão discutidos em detalhes no capítulo 3. Para realizar esses trabalhos desenvolvemos um código computacional de análise que utiliza o arquivo de saída dos cálculos quânticos. Com esse código, identificamos os coeficientes dos orbitais atômicos, $c_{i}^{(j)}$, que compõem cada orbital molecular $j$ e através do quadrado desses coeficientes calculamos a contribuição de cada átomo na composição de um orbital molecular específico. Sendo assim, o percentual de contribuição do átomo $A$ para o orbital molecular $j$ é escrito por $P_{A}^{(j)}$ : 


$$
P_{A}^{(j)}=\sum_{i \in A}\left(c_{i}^{(j)}\right)^{2} / \sum_{i}\left(c_{i}^{(j)}\right)^{2}
$$

Desta forma, é possível analisar a localização, ou delocalização, de cada orbital molecular e responder as questões pertinentes a este assunto. Adicionalmente, analisamos se essas contribuições dependem da quantidade de moléculas que são incluídas nos cálculos quânticos e também da presença do campo eletrostático remanescente do solvente envolvendo o soluto.

\subsection{Configuração Eletrostática Média do Solvente}

Como vimos na seção 2.3, no método S-QM/MM apenas poucos cálculos quânticos, cerca de centenas, são suficientes para gerar propriedades médias convergidas. Isso nos permite tentar ampliar a quantidade de moléculas incluídas explicitamente nesses cálculos ou o tamanho da molécula de interesse. Entretanto, o alto custo computacional dos cálculos quânticos e seu rápido escalonamento com relação ao número de elétrons do sistema ainda é um grande gargalo. Uma aproximação alternativa que tem sido muito utilizada é, ao invés de incluir explicitamente as moléculas de solvente nos cálculos quânticos, incluir apenas o campo eletrostático dessas moléculas descrito via cargas atômicas pontuais, usualmente oriundas do termo coulombiano dos campos de força clássico. Esse campo eletrostático do solvente é conhecido como envolvimento eletrostático (electrostatic embedding). Nos cálculos quânticos do soluto com envolvimento eletrostático (ver ilustração na Figura 11 à esquerda) apenas as interações eletrostáticas entre o soluto e o solvente são consideradas e isso pode não ser necessário para descrever corretamente os efeitos de solventes em várias propriedades. Porém para algumas propriedades essa aproximação tem se mostrado eficiente [44],[83],[84] e o tempo de processamento para cada cálculo do soluto com envolvimento eletrostático é quase igual ao do soluto isolado, independentemente da quantidade cargas pontuais utilizadas no envolvimento eletrostático. Sendo assim, para calcular o efeito de solvente utilizando 100 configurações estatisticamente descorrelacionadas, o tempo total de processamento fica cerca de centenas de vezes maior que o de um soluto isolado. Então, seria desejável reduzir ainda mais o número necessário de cálculos quânticos para obter qualquer propriedade média. Seria desejável executar apenas um cálculo quântico. Para isso, uma possibilidade seria ter um potencial soluto-solvente médio que pudesse reproduzir as informações contidas nas centenas de configurações amostradas. 

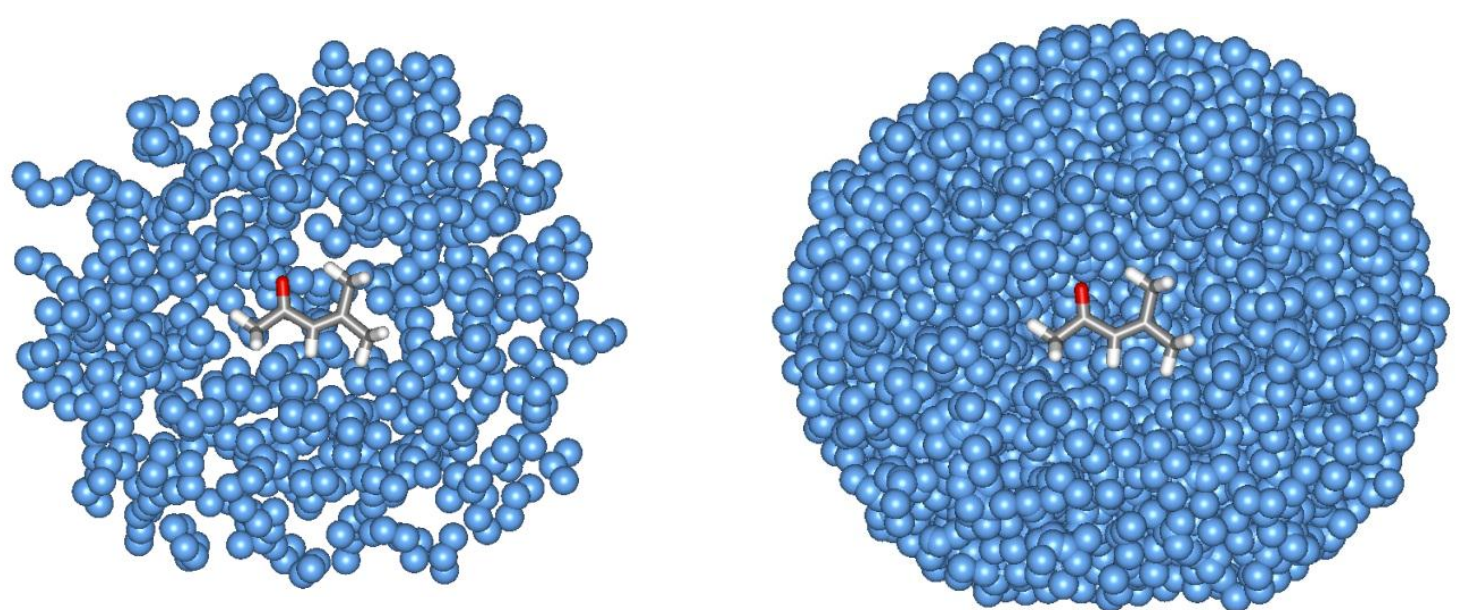

Figura 11: Ilustração de uma molécula: com envolvimento eletrostático gerado a partir de uma configuração selecionada da simulação, com 250 moléculas de água descritas como cargas pontuais (esquerda), e com ASEC gerada a partir de 60 configurações estatisticamente descorrelacionadas selecionada da simulação, e cada configuração com 250 moléculas de água descritas como cargas pontuais (direita).

Na prática, essa possibilidade foi desenvolvida por Aguilar e coautores utilizando um potencial eletrostático médio do solvente, ASEP (Average Solvent Electrostatic Potential) [85]. O procedimento para gerar o ASEP é:

(i) Inúmeras configurações vindas da simulação são selecionadas e são aplicadas translações e rotações para deixar o soluto na mesma origem e orientação;

(ii) É definido um volume para o soluto e gera-se uma grade reticulada nesse volume;

(iii) Cada configuração selecionada produz uma distribuição de cargas atômicas pontuais devido as diferentes posições das moléculas de solvente ao redor do soluto; essa distribuição de cargas é usada para o cálculo do potencial eletrostático sobre os vários pontos da grade do soluto;

(iv) Esse cálculo é repetido para várias configurações, é feita uma média em cada ponto da grade e o ASEP é gerado como uma média do potencial eletrostático produzido pelas várias configurações do solvente no volume reticulado do soluto;

(v) Na região do solvente é escolhido um conjunto mínimo de posições e cargas para descrevem o melhor possível o ASEP;

(vi) Ao final esse conjunto fictício de cargas, que descreve o ASEP, é levado ao cálculo quântico como sendo o envolvimento eletrostático do soluto.

Baseando-se nessa ideia, fizemos a proposta de uma configuração eletrostática média do solvente, ASEC (Average Solvent Electrostatic Configuration), quando o soluto for rígido durante a simulação [43]. O procedimento para gerar a ASEC é:

(i) Inúmeras configurações estatisticamente descorrelacionadas, $m$, vindas da simulação são selecionadas e são aplicadas translações e rotações para deixar o soluto na mesma origem e orientação; 
(ii) É gerada uma superposição de todas as $m$ configurações do solvente ao redor do soluto e gerando uma distribuição de $m \times n \times n_{a}$ cargas pontuais atômicas, onde $n$ é a quantidade de molécula de solvente em cada configuração e $n_{a}$ é a quantidade de átomos de cada molécula do solvente;

(iii) Como cada carga atômica aparece $m$ vezes na configuração superposta, é feita um normalização de cada carga atômica por um fator de $(1 / m)$ e assim é gerada a ASEC, como resultado de uma superposição e normalização das cargas atômicas das moléculas de solvente.

$\mathrm{Na}$ Figura 11 (direita) ilustramos a ASEC. Note que comparativamente ao envolvimento eletrostático de uma única configuração (esquerda), a ASEC é muito mais densa e uniforme, pois é a superposição de várias configurações.

Em nosso trabalho [43], mostramos que os valores de várias propriedades calculadas para o soluto com envolvimento eletrostático da ASEC é o mesmo valor da média dos valores obtidos nos cálculos do soluto com envolvimento eletrostático de cada configuração. A única desvantagem desse envolvimento eletrostático com ASEC é a perda da informação da distribuição de valores acessível para uma dada condição termodinâmica. Porém algumas vezes essa informação é interessante, mas não relevante para a compreensão/solução do problema estudado. Aplicamos esse procedimento com ASEC em vários trabalhos [40],[43],[45],[47],[49] que serão discutidos no capítulo 3.

\subsection{Procedimento de Polarização Iterativo}

O potencial de interação intermolecular desempenha um papel fundamental nas simulações MM e também é muito importante para o tratamento adequado dos efeitos de solventes em métodos híbridos QM/MM. A grande preocupação na parametrização dos campos de força é a polarização do soluto que promove diferentes valores para momento de dipolo induzido do soluto na presença de diferentes solventes. Em geral, as cargas atômicas utilizadas no termo coulombiano do potencial de interação (ver equação 11) incluem uma polarização padrão implícita nos parâmetros eletrostáticos. Essa polarização padrão é obtida a partir de cálculos quânticos que geram as distribuições de cargas com o método/base, HF/6$31 \mathrm{G}(\mathrm{d})$. É sabido, que esse conjunto de método/base, tipicamente, resulta num momento de dipolo aumentado em 20-30\% comparativamente ao valor da molécula isolada [86]. Em alguns casos, esse aumento do dipolo é provavelmente suficiente para explicar a polarização eletrônica do soluto em solventes polares, mas em outros casos, a polarização pode atingir percentual mais elevado e uma análise mais profunda desse processo de polarização do soluto devido à presença do solvente é necessária. De fato, uma descrição mais precisa da polarização molecular em fase densa é sempre desejável, considerando que esse é um termo importante do potencial de interação molecular. 
Alguns estudos teóricos importantes têm sido feitos sobre a polarização eletrônica de moléculas em solução [87],[88],[89]. O momento de dipolo de uma única molécula em solução não é fácil de ser medido experimentalmente. Resultados indiretos podem ser inferidos, como por exemplo, através da integração de intensidades de infravermelhos [90], mas poucos valores estão disponíveis. Portanto, um procedimento teórico confiável para prever momentos de dipolo em fase densa ou em solução é de grande interesse.

Dentro deste tema, fizemos uma proposta para calcular a polarização eletrônica de solutos em solução [44], através de um procedimento iterativo utilizando o método SQM/MM. O procedimento de polarização iterativa S-QM/MM é:

(i) Inicia-se uma simulação computacional de uma molécula em solução utilizando o conjunto de cargas atômicas pontuais do soluto gerado por cálculo quântico, para descrever o potencial eletrostático da molécula isolada.

(ii) Em seguida, configurações estatisticamente descorrelacionadas são selecionadas da simulação. A partir delas são geradas configurações do soluto com envolvimento eletrostático do solvente que são submetidas a cálculos quânticos. Desses cálculos, é gerado um novo conjunto médio de cargas atômicas pontuais do soluto na presença do campo eletrostático do solvente.

(iii) Esse novo conjunto médio de cargas é utilizado para iniciar uma nova simulação. Nessa simulação, as moléculas de solvente vão interagir com o soluto de forma diferente devido ao novo conjunto de cargas que leva em consideração o campo eletrostático do solvente.

(iv) As etapas (ii) e (iii) são repetidas algumas vezes até se obter a convergência do momento de dipolo do soluto ou das cargas atômicas pontuais. Assim, ao final desse processo iterativo será gerado um conjunto médio de cargas atômicas pontuais considerando implicitamente a polarização do soluto devido à presença do solvente. Esse conjunto de cargas do soluto está em equilíbrio eletrostático com o solvente que também está estruturado de acordo com esse equilíbrio.

Na Figura 12 mostramos dois exemplos de comportamento típico do valor do momento de dipolo obtido durante o procedimento de polarização iterativo S-QM/MM. Na esquerda, cada valor do momento de dipolo representa a média sobre 100 cálculos quânticos do soluto com envolvimento eletrostático de configurações estatisticamente descorrelacionadas e as barras de erro representam o desvio padrão dos valores. Na direita, cada valor do momento de dipolo representa um único cálculo quântico do soluto com envolvimento eletrostático da ASEC, portanto não há barras de erro. Nesse gráfico, também é interessante ressaltar que os círculos brancos representam a polarização de uma molécula específica, neste caso benzofenona, em solução aquosa nas condições normais e os círculos pretos em condições supercríticas [91]. 

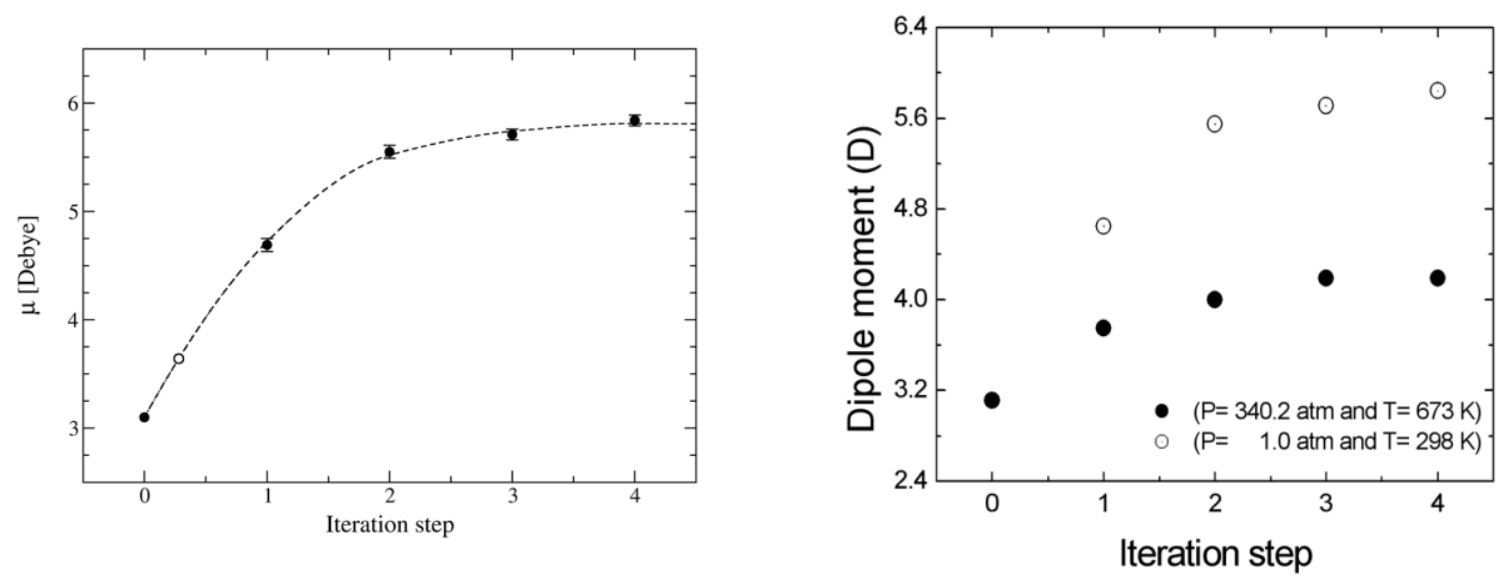

Figura 12: Exemplo da dependência do momento de dipolo durante o procedimento de polarização iterativo SQM/MM para benzofenona em solução aquosa. Na esquerda, cálculos com 100 configurações para solução aquosa em condições normal, o círculo branco representa o momento de dipolo obtido com o procedimento padrão dos campos de força. Na esquerda, cálculos com ASEC, os círculos brancos são obtidos para solução aquosa em condições normal e os círculos pretos em condições supercríticas. Gráficos retirados da ref. [40]

(esquerda) e da ref. [91] (direita).

Esse procedimento foi testado e comparado com outros procedimentos de polarização utilizando mecânica quântica para vários sistemas. No capítulo 3 vamos discutir os resultados que obtivemos para as moléculas: benzofenona [40], acetona [44], orto-betaína [47] e óxido mesitil [49] em solução aquosa e prodan em bicamadas lipídicas [45].

\subsection{Cálculo de Variações de Energia Livre}

O comportamento das moléculas é governado pela energia livre, desde agregação a preferências conformacionais. Sendo assim, métodos precisos, para calcular e prever perfil de energia livre, são essenciais para a compreensão e predição de qualquer propriedade molecular. Existem vários métodos estabelecidos para calcular variações de energia livre em simulações computacionais [13],[92]. O método que implementamos do programa DICE para cálculo de variações de energia livre foi a Teoria de Perturbação Termodinâmica, TPT, ou também conhecida como FEP (Free Energy Perturbation) [93]. Nesse método utiliza-se a relação termodinâmica entre energia livre e função de partição

$$
A=-k T \ln Z,
$$

onde $A=F$ é a energia livre de Helmholtz no ensemble $N V T$ e $A=G$ é a energia livre de Gibbs no ensemble NPT. Sendo assim, a variação de energia livre entre dois estados A e B é escrita de forma exata como 


$$
\Delta A_{\mathrm{AB}}=-k T \ln \left(\frac{Z_{\mathrm{B}}}{Z_{\mathrm{A}}}\right)=-k T \ln \left(\frac{\int \rho_{\text {ens }}^{\operatorname{cin}}(\mathrm{B}) d\{\boldsymbol{v}\} \int \rho_{\text {ens }}^{\text {conf }}(\mathrm{B}) d\{\boldsymbol{r}\}}{\int \rho_{\text {ens }}^{\text {cin }}(\mathrm{A}) d\{\boldsymbol{v}\} \int \rho_{\text {ens }}^{\text {conf }}(\mathrm{A}) d\{\boldsymbol{r}\}}\right),
$$

onde $\boldsymbol{\rho}_{\boldsymbol{e n s}}^{\boldsymbol{c i n}}$ é o termo cinético da distribuição de probabilidade de Gibbs (ver equação 13) e $\boldsymbol{\rho}_{\text {ens }}^{\text {conf }}$ é o termo configuracional (ver equações 14 e 15). Assumindo que o termo cinético se cancela, pois na mudança do estado A para o B não utilizaremos mudança nas massas dos átomos nem da quantidade total de átomos do sistema, temos

$$
\Delta A_{\mathrm{AB}}=-k T \ln \left(\frac{\int \rho_{\text {ens }}^{\text {conf }}(\mathrm{B}) d\{\boldsymbol{r}\}}{\int \rho_{\text {ens }}^{\text {conf }}(\mathrm{A}) d\{\boldsymbol{r}\}}\right)=-k T \ln \left(\frac{\int \rho_{\text {ens }}^{\text {conf }}(\mathrm{B})\left(\frac{\rho_{\text {ens }}^{\text {conf }}(\mathrm{A})}{\rho_{\text {ens }}^{\text {conf }}(\mathrm{A})}\right) d\{\boldsymbol{r}\}}{\int \rho_{\text {ens }}^{\text {conf }}(\mathrm{A}) d\{\boldsymbol{r}\}}\right)
$$

Sendo assim, reorganizando os termos obtemos

$$
\Delta F_{\mathrm{AB}}=-k T \ln \left\langle\exp \left(-\Delta U_{\mathrm{BA}} / k T\right)\right\rangle_{\mathrm{A}}
$$

no ensemble NVT e

$$
\Delta G_{\mathrm{AB}}=-k T \ln \left\langle\exp \left(-\Delta H_{\mathrm{BA}} / k T\right)\right\rangle_{A}=-k T \ln \left\langle\exp \left(-\left(\Delta U_{\mathrm{BA}}+P \Delta V_{\mathrm{BA}}\right) / k T\right)\right\rangle_{\mathrm{A}}
$$

no ensemble $N P T$. A expressão $\langle\cdots\rangle_{\mathbf{A}}$ denota que a média do termo $\exp (\cdots)$ é amostrada no estado A. Portanto para calcula variações de energia livre entre dois estados é necessário calcular a média da função exponencial da diferença de energia potencial, ou entalpia conformacional, divido pela energia térmica, $\boldsymbol{k T}$, numa simulação feita sobre um dos estados apenas. $\mathrm{Na}$ teoria esse cálculo é simples, mas na prática temos um cálculo bastante complicado devido à dificuldade da amostragem do termo exponencial. Pois se as diferenças de energia, ou entalpia, forem muito grandes (diferenças positivas), esse termo tende a zero e se forem muito pequenas (diferenças negativas), esse termo tende a infinito. É devido a essa dificuldade de amostragem que foi implementada uma forma perturbativa de variar o sistema do estado A para o estado B e assim realizar o cálculo da variação de energia livre como a soma de várias diferenças de energia livre entre estados intermediários. Por simplificação vamos apresentar as expressões apenas para o ensemble NPT, que podem ser facilmente modificadas para expressar o ensemble $N V T$. Nesse caso escreve-se a entalpia do sistema da forma perturbativa

$$
H_{\mathrm{AB}}(\lambda)=H_{\mathrm{A}}-\lambda\left(H_{\mathrm{A}}-H_{\mathrm{B}}\right)
$$


onde $\lambda$ é o termo de perturbação que varia de 0 , quando o sistema está no estado $\mathrm{A}$, a 1 , quando o sistema está no estado B. Naturalmente, existem várias formas de escrever a expressão de perturbação. Em geral, escolhe-se essa forma linear, pois é muito simples de ser implementada. Agora variando lentamente o $\lambda$ dentre um conjunto de valores discretos $\left\{\lambda_{i}\right\}$ é possível calcular a diferença de energia livre como

$$
\Delta G_{\lambda_{i} \lambda_{i+1}}=-k T \ln \left\langle\exp \left(-\left(H_{\lambda_{i+1}}-H_{\lambda_{i}}\right) / k T\right)\right\rangle_{\lambda_{i}}
$$

Escrevendo o $\Delta G$ desta forma fica fácil notar que é possível implementar a técnica de dupla amostragem [94]. Nessa técnica é realizada uma simulação num valor $\lambda_{i}$ e dois cálculos de variação de energia livre são realizados, um para $\lambda_{i+1}$ e outro para $\lambda_{i-1}, \Delta G_{\lambda_{i} \lambda_{i+1}}$ e $\Delta G_{\lambda_{i} \lambda_{i-1}}$. Portanto, utilizando essa técnica de dupla amostragem reduz-se a metade a quantidade de simulações necessárias.

Outro procedimento, que é comumente utilizado para simplificar os cálculos de $\Delta G$, é o uso dos ciclos termodinâmicos. Neste caso, muitas vezes são utilizadas rotas indiretas para o cálculo do $\Delta G$ devido ao fato da energia livre ser uma função de estado $\mathrm{e}$ independentemente do caminho escolhido o $\Delta G$ é o mesmo. Na Figura 13 apresentamos o esquema de um dos ciclos termodinâmicos mais usados para o cálculo de $\Delta G$ em soluções.

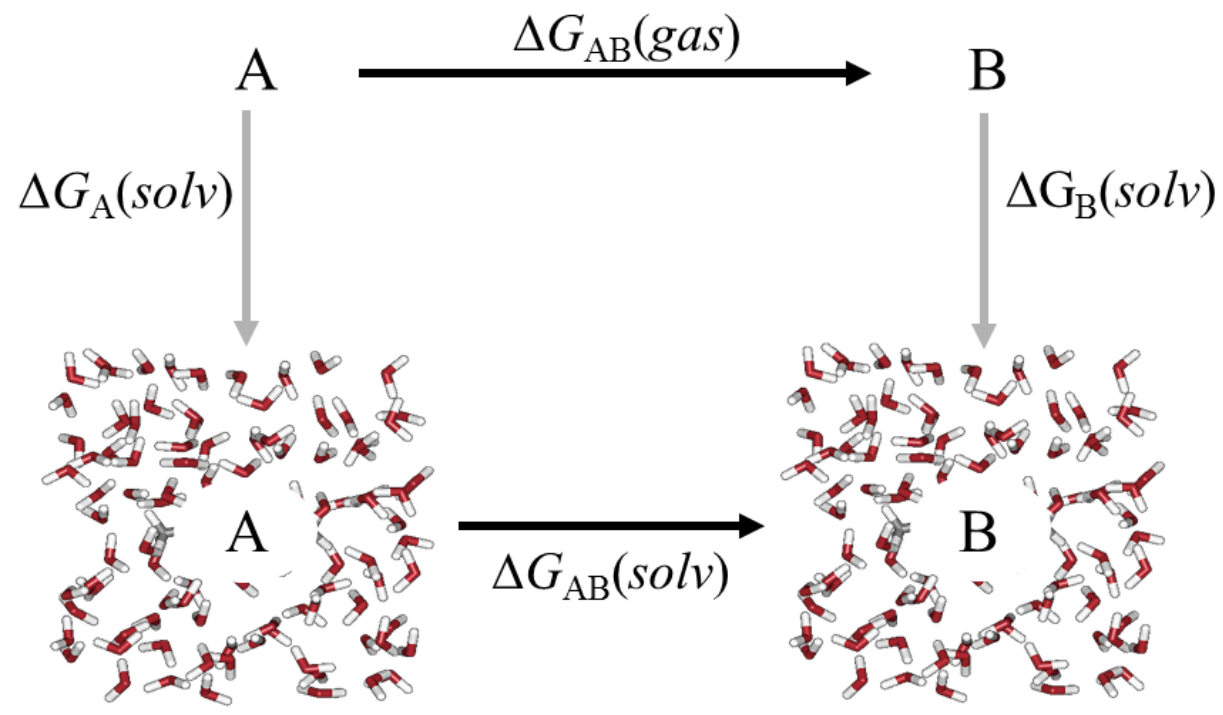

Figura 13: Esquema do ciclo termodinâmico.

Nesse ciclo, é mostrado que a variação da energia livre para o sistema mudar do estado A para $\mathrm{B}$ em solução, $\Delta G_{\mathrm{AB}}(s o l v)$, pode sem escrita em função da variação da energia livre para o sistema mudar do estado A para B em vácuo, ou em fase gasosa, $\Delta G_{\mathrm{AB}}$ (gas), e das energias livre de solvatação dos estados separadamente, $\Delta G_{\mathrm{A}}(\operatorname{solv})$ e $\Delta G_{\mathrm{B}}(\operatorname{solv})$, da seguinte forma 
$\Delta G_{\mathrm{AB}}($ solv $)=\Delta G_{\mathrm{AB}}($ gas $)+\left[\Delta G_{\mathrm{B}}(\right.$ solv $)-\Delta G_{\mathrm{A}}($ solv $\left.)\right]=\Delta G_{\mathrm{AB}}($ gas $)+\Delta \Delta G($ solv $)$

onde $\boldsymbol{\Delta} \boldsymbol{\Delta} \boldsymbol{G}(\boldsymbol{s o l v})$ é a energia livre de solvatação diferencial dos estados A e B. O termo $\boldsymbol{\Delta} \boldsymbol{G}_{\mathrm{AB}}$ (gas) pode ser diretamente obtido dos cálculos quânticos. O cálculo da energia livre de solvatação poder ser obtido dos cálculos quânticos utilizando modelo contínuo do solvente ou através das simulações MM utilizando o processo hipotético de aniquilação do soluto [95], como mostrado na Figura 14.

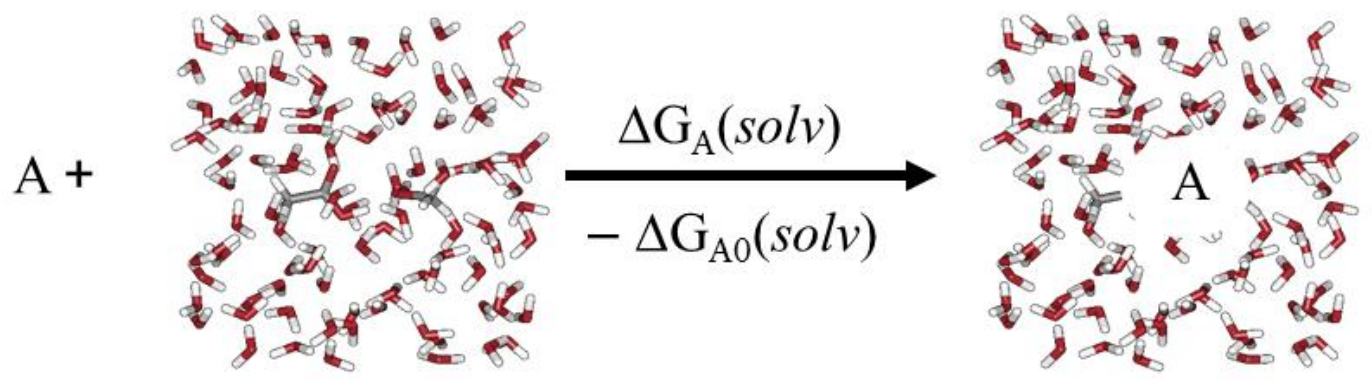

Figura 14: Esquema do processo de solvatação ou aniquilação.

A energia livre de solvatação do soluto em solução no estado $\mathrm{A}, \boldsymbol{\Delta} \boldsymbol{G}_{\mathbf{A}}(\boldsymbol{s o l v})$, tem valor igual e sinal oposto à energia livre de aniquilação, $\boldsymbol{\Delta}_{\mathbf{A 0}}(\boldsymbol{s o l v})$, $\boldsymbol{\Delta} \boldsymbol{G}_{\mathbf{A}}(\boldsymbol{s o l v})=-\boldsymbol{\Delta} \boldsymbol{G}_{\mathbf{A 0}}(\boldsymbol{s o l v})$. É interessante notar que embora os processos sejam equivalentes, na simulação as variações de entalpia envolvidas são bem menores no processo de aniquilação que no de solvatação. Pois no primeiro processo, o soluto já existe dentro do solvente e vai lentamente desaparecendo, enquanto que no segundo é necessário criar um soluto num ambiente denso que está inteiramente ocupado pelo solvente. Na prática, mesmo o processo de aniquilação é realizado utilizando vários valores de $\boldsymbol{\lambda}$. Para solutos polares, um procedimento bastante utilizado [46]-[49],[95],[96] é o de sumir, ou zerar, primeiramente o conjunto de cargas atômicas $\left\{\boldsymbol{q}_{\boldsymbol{i}}\right\}$ do soluto que descreve o potencial coulombiano de interação e em seguida zerar o conjunto de parâmetros $\left\{\boldsymbol{\varepsilon}_{\boldsymbol{i}} \mathbf{e} \boldsymbol{\sigma}_{\boldsymbol{i}}\right\}$ do potencial Lennard-Jones. Usualmente, realizamos o procedimento de aniquilação do soluto em três etapas:

(a) inicialmente as cargas atômicas são reduzidas gradativamente até zerar, utilizando 9 fatores de escala $\lambda=1.00,0.95,0.90,0.80,0.70,0.60,0.40,0.20$ e 0.00 ;

(b) em seguida os parâmetros $\varepsilon$ são reduzidos gradativamente até $1 \%$, usando 5 fatores de escala $\lambda=1.00,0.75,0.50,0.25$ e 0.01 ; e

(c) por fim os parâmetros $\sigma$ serão reduzidos gradativamente até zerar, usando 6 fatores de escala $\lambda=1.0,0.80,0.60,0.40,0.20$ e 0.00 . 
Nas duas primeiras etapas é utilizada a técnica de dupla amostragem, ou seja, é realizada uma simulação com as cargas atômicas multiplicadas pelo fator $\lambda=0.95$ e durante essa simulação serão calculadas duas variações de energia livre, uma para o fator $\lambda=1.00 \mathrm{e}$ outra para o fator $\lambda=0.90$. Sendo assim, para realizar a primeira etapa são realizadas apenas 4 simulações com os fatores $\lambda=0.95,0.80,0.60$ e 0.20 e são perturbados para 1.00 e 0.90 , 0.90 e $0.70,0.70$ e 0.40 e por fim 0.40 e 0.00 . Na segunda etapa são realizadas apenas 2 simulações $\lambda=0.75$ e 0.25 e são perturbados para 1.00 e 0.50 , e 0.5 e 0.01 . Nessa etapa, basicamente eliminamos o potencial atrativo do potencial Lennard-Jones (ver Figura $15 \mathrm{com}$ exemplo). Já na terceira etapa devido ao potencial repulsivo ser muito íngreme, não é adequado usar a técnica de dupla amostragem e são realizadas 5 simulações apenas reduzindo o valor do $\sigma$, uma para cada fator de escala mostrado acima. Desta forma, em geral, é necessário realizar $11(=4+2+5)$ simulações para o cálculo da energia livre de aniquilação ou energia livre de solvatação de um soluto qualquer.

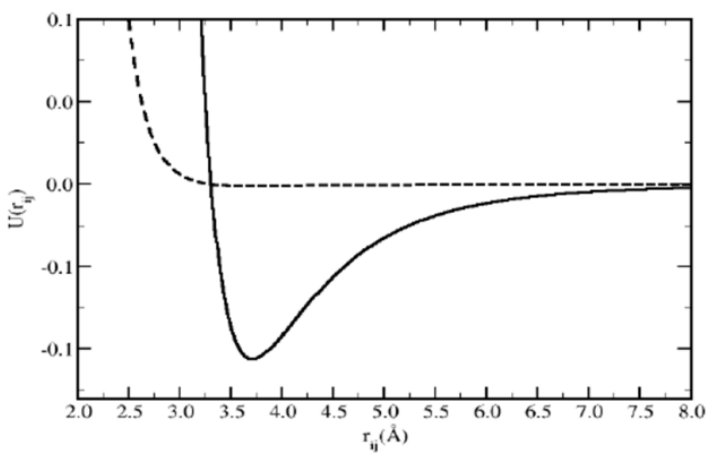

Figura 15: Exemplo da mudança do potencial Lennard-Jones no início (linha sólida) e fim (linha tracejada) da segunda etapa do processo de aniquilação. Gráfico retirado da ref. [97].

Utilizamos FEP para calcular variações de energia livre em vários processos, dentre eles ressaltamos: a mudança conformacional associada à transferência intramolecular de cargas da orto-betaína em solução aquosa [46],[47], ao processo de tautomerismo (transferência de hidrogênio) da mercaptopirimidina em solução aquosa [48] e a mudança conformacional syn-anti, ou também conhecida como cis-trans, do óxido mesitil em solução aquosa[49], a inserção de água na cavidade hidrofóbica da $\alpha$-ciclodextrina em solução aquosa, estabilização de dímeros, reações de homolítica, entre outros [96]. No capítulo 3 vamos discutir os resultados que obtivemos em 4 desses trabalhos. 


\section{Principais Resultados e Discussões}

Neste capítulo apresentarei e discutirei criticamente uma parte de minha obra científica. Selecionei 16 artigos publicados em revistas científicas indexadas que compõem minha linha de pesquisa teórica dentro do tema "Efeitos de Solventes em Propriedades Estruturais e Eletrônicas de Moléculas de Interesse Físico-Químico". Todos esses artigos estão anexados na íntegra nos apêndice de A a Q. Para não ampliar muito o tamanho deste texto não repetiremos os detalhes de cálculos, tabelas, figuras e referências dos artigos original, a menos que sejam estritamente necessários para a compreensão das discussões. Os trabalhos serão apresentados seguindo um ordenamento cronológico, do mais antigo para o mais recente, dentro dos tópicos já descritos no capítulo 2, que sintetizam minha contribuição individual e dos alunos por mim orientados.

\subsection{Método Híbrido Sequencial com Mecânica Quântica e Mecânica Molecular}

Nesta seção serão discutidos 5 trabalhos publicados.

Nos 3 primeiros trabalhos foram publicados parte dos resultados da minha tese de doutorado. Eles foram selecionados por comporem o início do método S-QM/MM que deu origem a quase todos os outros trabalhos que sou autora.

Os 2 trabalhos seguintes foram aplicações do método S-QM/MM subsequentes, que eu e o Prof. Canuto realizamos. Adicionalmente, comparamos os resultados que obtivemos com outros vários métodos propostos na literatura para estudos do solvatocromismo, ou seja, efeitos de solventes em deslocamentos de bandas de transição eletrônica na região do UVvisível.

\subsubsection{Advances in Quantum Chemistry, 28, 89, (1997)}

Neste trabalho de autoria minha e Prof. Canuto [2], anexado no Apêndice A, apresentamos pela primeira vez a ideia do método S-QM/MM utilizando um procedimento estatístico para selecionar as configurações estatisticamente descorrelacionadas. A descrição detalhada desse procedimento está apresentada na seção 2.3. Como aplicação desse método, estudamos os efeitos de solventes na estrutura eletrônica das moléculas de benzeno (soluto apolar) para determinar a capacidade do método S-QM/MM em calcular o deslocamento de banda do espectro de absorção eletrônica utilizando uma pequena quantidade de cálculos quânticos. Como resultados experimentais, estavam disponíveis as informações que a primeira banda de absorção eletrônica do benzeno é do tipo $\pi-\pi^{*}$ e apresenta um 
deslocamento devido à presença do solvente de $-310 \mathrm{~cm}^{-1}$ em ciclohexano e $-140 \mathrm{~cm}^{-1} \mathrm{em}$ água. Escolhemos o benzeno por ser um sistema pequeno, servir de modelo para outras moléculas aromáticas, ter resultados experimentais disponíveis e ser apolar, o que dificulta a aplicação de outros modelos teóricos mais simples, como é o caso dos modelos contínuo de solventes.

Realizamos as simulações MC desses sistemas nas condições normais de temperatura e pressão. Após as simulações realizamos os cálculos da ineficiência estatística $s$ e do intervalo de correlação $\tau$ e selecionamos 40 configurações estatisticamente descorrelacionadas para os subsequentes cálculos quânticos. Através da análise das RDFs entre os carbonos do benzeno e dos ciclohexanos, $G_{C C}(r)$, e oxigênios das águas, $G_{C O}(r)$, analisamos a estrutura das soluções e identificamos a quantidade de moléculas de solvente ao redor do soluto: 11 moléculas de ciclohexano e 18 moléculas de água na primeira camada de solvatação. Realizando cálculos quânticos com método semiempírico INDO/CIS com parametrização espectroscópica, calculamos o deslocamento da primeira energia de absorção eletrônica do benzeno isolado e em ciclohexano e em água. Analisamos como esse deslocamento varia com o número de moléculas de água incluídas nos cálculos quânticos, variando de 1 até 70 moléculas de água. Concluímos que apenas a primeira camada de solvatação é suficiente para saturar o efeito do solvente. Ao final obtivemos os valores de $-200 \mathrm{~cm}^{-1} \mathrm{e}-120 \mathrm{~cm}^{-1}$ para os deslocamentos da primeira energia de absorção eletrônica do benzeno em ciclohexano e água, respectivamente. Esses resultados estão em muito bom acordo com o resultado experimental, mostrando o pequeno valor negativo para o deslocamento e também a tendência correta de maior deslocamento para o ciclohexano e menor para a água. É interessante ressaltar aqui que o solvatocromismo do benzeno em ciclohexano, soluto apolar em solvente apolar, acredita-se ser principalmente de natureza dispersiva. Essa interação de dispersão não é comumente incluída nos modelos contínuo de solventes, o que nos levou a um valor de deslocamento de $+12 \mathrm{~cm}^{-1}$ [36], mostrando um desacordo quantitativo e qualitativo com a informação experimental. Utilizando um modelo contínuo com dispersão [98] o valor calculado para esse deslocamento foi de $-540 \mathrm{~cm}^{-1}$, mostrando uma concordância qualitativa com o resultado experimental, mas não quantitativa. Desta forma, o procedimento que propusemos com o método S-QM/MM, se mostrou de fato com grande potencialidade, pois conseguiu descrever o deslocamento desse tipo de sistema. No caso de benzeno em água, adicionalmente a informação experimental do deslocamento da banda de absorção eletrônica, existe o conhecimento comum sobre a hidrofobicidade do benzeno e sua imiscibilidade em água. Analisando esse tópico através do cálculo do potencial efetivo de interação entre benzeno em água a partir das RDFs geradas nessas simulações e com esses resultados publicamos outro trabalho com o estudante de doutorado S. Urahata [99].

Neste trabalho também reportamos resultados preliminares da acetona (soluto polar) em solução aquosa. A informação experimental disponível é que a primeira banda de absorção eletrônica da acetona é do tipo $n-\pi^{*}$ e apresenta um deslocamento de $1560 \mathrm{~cm}^{-1}$ em presença da solução aquosa. Para esse soluto também realizamos simulações MC nas 
condições normais de temperatura e pressão. Após as simulações através da RDF entre o oxigênio da acetona e hidrogênios das águas, $G_{O H}(r)$, analisamos as ligações de hidrogênio entre essas moléculas. Comparamos as configurações das ligações de hidrogênio obtidas da simulação com as obtidas em otimizações de geometria com vários métodos quânticos e funções base. Para configurações de acetona-água otimizadas calculamos um deslocamento da banda de absorção de $1739 \mathrm{~cm}^{-1}$, o que apresenta uma concordância razoável com o valor experimental. Para as configurações acetona-água geradas na simulação, analisamos como esse deslocamento varia com o número de moléculas de água incluídas nos cálculos quânticos, variando de 1 até 7 moléculas de água. Concluímos que apenas a primeira molécula de água, que está ligada a acetona através do hidrogênio, é suficiente para saturar o efeito do solvente e descrever um deslocamento de cerca de $1250 \mathrm{~cm}^{-1}$, que também apresenta uma concordância razoável com o valor experimental. Comparando o resultado da configuração otimizada com as obtidas da simulação, concluímos que a otimização superestima a contribuição da ligação de hidrogênio e isso se reflete no deslocamento solvatocrômico e que uma correta descrição das ligações de hidrogênio é fundamental para uma descrição adequada do deslocamento solvatocrômico da acetona.

\subsubsection{International Journal of Quantum Chemistry, 66, 249 (1998)}

Neste trabalho de autoria minha, Prof. Oliveira e Prof. Canuto [3], anexado no Apêndice $\mathrm{B}$, estudamos o procedimento de seleção das configurações estatisticamente descorrelacionadas a partir das simulações de benzeno em água realizadas no trabalho anterior [2]. Nele calculamos a média do descolamento solvatocrômico do benzeno, devido à presença da água, com sendo $-122 \pm 15 \mathrm{~cm}^{-1}$ obtida para 20 mil configurações sucessivas geradas na simulação MC. Fazendo a análise do intervalo de correlação, utilizando a ineficiência estatística $s$, identificamos que o conjunto das 20 mil configurações sucessivas também poderia ser descrito com a mesma informação estatística por apenas 25 configurações estatisticamente descorrelacionadas selecionadas em intervalos de $800 \mathrm{em} 800$. Com base nessa informação selecionamos 4 conjuntos diferentes de 25 configurações estatisticamente descorrelacionadas, mudando a configuração inicial e mantendo o mesmo intervalo entre elas, e realizamos o cálculo dos deslocamentos solvatocrômicos. Na Tabela 1, os resultados desses cálculos são apresentados. Note que os 4 valores médios obtidos com apenas 25 configurações estatisticamente descorrelacionadas estão em concordância com a média de $-122 \mathrm{~cm}^{-1}$ calculada para as 20 mil configurações sucessivas, considerando o erro estatística de $\pm 15 \mathrm{~cm}^{-1}$. Sendo assim, comprovamos que utilizar o intervalo de correlação estatística para selecionar configurações é um procedimento eficiente, pois implica numa redução dramática da quantidade de cálculos quânticos sem a perda da informação estatística relevante. 
Tabela 1: Imagem da tabela 1 retirada da ref. [3] com os valores médios do deslocamento solvatocrômico da primeira banda de absorção do benzeno em água calculado em 4 conjuntos diferentes de 25 configurações estatisticamente descorrelacionadas.

\begin{tabular}{lr}
$\left.\begin{array}{l}\text { TABLE I } \\
\text { Calculated shift of the } \boldsymbol{B}_{\mathbf{2 u}}(\boldsymbol{\pi}\end{array} \boldsymbol{\pi}^{*}\right)$ transition of \\
benzene in water. \\
\hline Set & $\langle\Delta E\rangle\left(\mathrm{cm}{ }^{1}\right)$ \\
\hline 1 & 124 \\
2 & 120 \\
3 & 114 \\
4 & 131 \\
\hline
\end{tabular}

The displayed shifts are the average over 25 uncorrelated configurations $\left(1 \mathrm{C}_{6} \mathrm{H}_{6}+18 \mathrm{H}_{2} \mathrm{O}\right)$. In all sets, the selected configurations are separated by $800 \mathrm{MC}$ steps and the difference between them is the first selected configuration, e.g., set 1 is composed of the following configurations: 1 , $801,1601,2401, \ldots$; set 2: $201,1001,1801, \ldots$; set 3: 401, $1201,2001, \ldots ;$ and set $4: 601,1401,2201, \ldots$.

\subsubsection{Journal of Chemical Physics, 112, 9874 (2000)}

Neste trabalho de autoria minha, Prof. Canuto e Prof. Zerner [36], anexado no Apêndice $\mathrm{C}$, apresentamos o método S-QM/MM utilizando todo procedimento estatístico pertinente para mostrar a eficiência dele no estudo de propriedades eletrônicas de moléculas em solução. Como aplicação desse método, estudamos o deslocamento da primeira banda de absorção eletrônica do benzeno em 4 solventes diferentes: benzeno $\left(C_{6} H_{6}\right)$, ciclohexano $\left(\mathrm{C}_{6} \mathrm{H}_{12}\right)$, tetracloreto de carbono $\left(\mathrm{CCl}_{4}\right)$ e água. Como resultados experimentais, estavam disponíveis as informações que a primeira banda de absorção eletrônica do benzeno apresenta um deslocamento devido a presença do solvente de $-308 \pm 20 \mathrm{~cm}^{-1} \mathrm{em}$ ciclohexano, $-458 \pm 20 \mathrm{~cm}^{-1}$ em tetracloreto de carbono, $-143 \pm 20 \mathrm{~cm}^{-1}$ em água e $-332 \pm$ $30 \mathrm{~cm}^{-1}$ para benzeno líquido, ou seja, solvente benzeno.

Realizamos as simulações MC desses sistemas nas condições normais de temperatura e pressão. Após as simulações realizamos os cálculos da ineficiência estatística $s$ e do intervalo de correlação $\tau$ e selecionamos $l$ configurações estatisticamente descorrelacionadas para os subsequentes cálculos quânticos. Através da análise das RDFs entre os carbonos do benzeno e carbonos dos solventes $\mathrm{C}_{6} \mathrm{H}_{6}, \mathrm{C}_{6} \mathrm{H}_{12}$ e $\mathrm{CCl}_{4}$, e oxigênios das águas (ver esquerda da Figura 16) identificamos a quantidade de moléculas de solventes na primeira camada de solvatação do benzeno, $N_{s}$. Realizando cálculos quânticos com método semiempírico INDO/CIS com parametrização espectroscópica, calculamos o deslocamento da primeira energia de absorção 
eletrônica do benzeno isolado e nos diferentes solventes. Analisamos como esse deslocamento varia com o número de moléculas de solvente incluídas nos cálculos quânticos, variando de 1 até cerca de 30 moléculas de solventes (ver direita da Figura 16). Concluímos que apenas a primeira camada de solvatação é suficiente para saturar o efeito do solvente no solvatocromismo do benzeno.
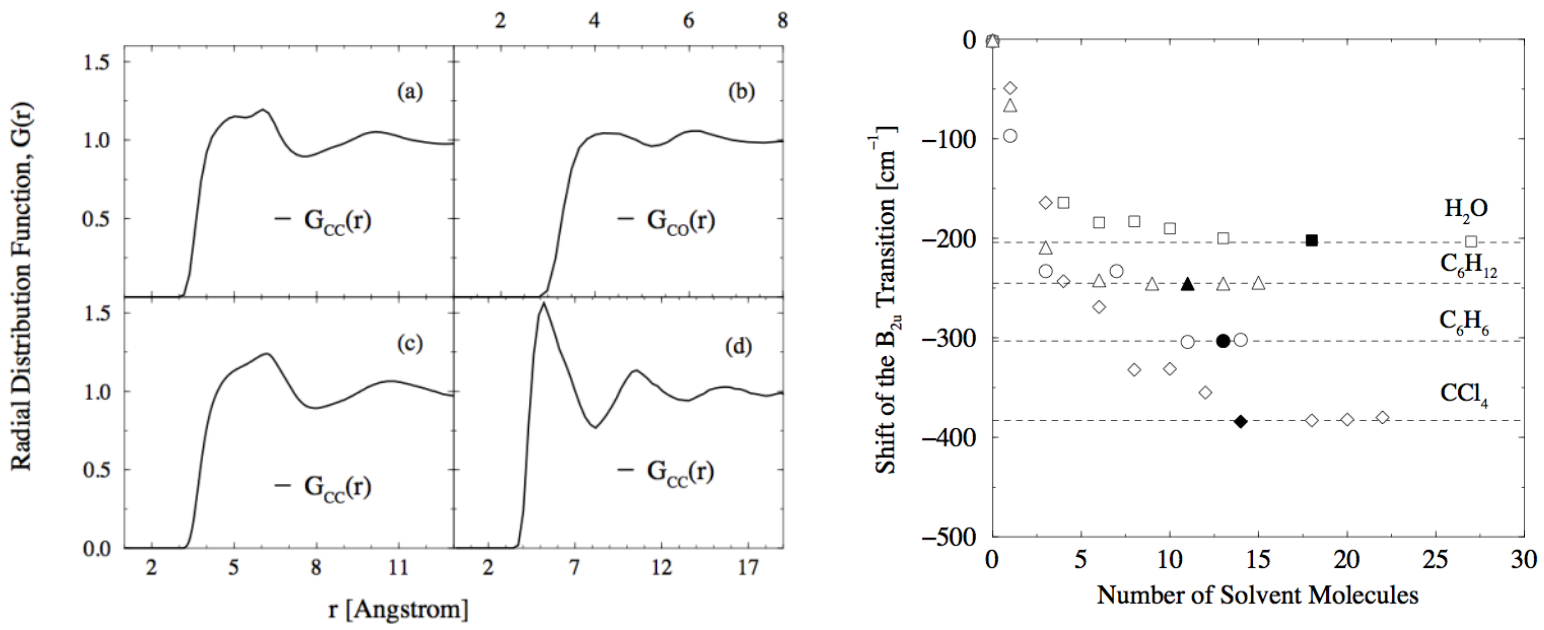

Figura 16: Funções de distribuição radial de pares dos carbonos do benzeno com carbonos e oxigênios de 4 solventes: (a) $\mathrm{C}_{6} \mathrm{H}_{6}$, (b) $\mathrm{H}_{2} \mathrm{O}$, (c) $\mathrm{C}_{6} \mathrm{H}_{12}$ e (d) $\mathrm{CCl}_{4}$ (esquerda) e dependência do solvatocromismo da primeira banda de absorção eletrônica do benzeno com relação ao número de moléculas do solvente explicitamente incluídos no cálculos quânticos (direita). Nesse gráfico os pontos sólidos mostram a primeira camada de solvatação. Gráficos retirados da ref. [36].

Na Tabela 2 mostramos o sumário dos resultados obtidos. Portanto, no caso de benzeno em $\mathrm{CCl}_{4}$ foram selecionadas 50 configurações estatisticamente descorrelacionadas em intervalos de 500 em 500. Essas 50 configurações selecionadas foram reduzidas para 1 benzeno rodeado pela primeira camada de solvatação composta por 14 moléculas de $C C l_{4} \mathrm{e}$ submetidas aos cálculos quânticos das energias de excitação eletrônica. Ao final obtivemos o valor médio de $-456 \pm 38 \mathrm{~cm}^{-1}$ em excelente concordância com o resultado experimental de $-458 \pm 20 \mathrm{~cm}^{-1}$. Os resultados obtidos para todos os solventes estudados estão em excelente acordo com os resultados experimentais. Mostrando que de fato, o método S-QM/MM é robusto e pode ser aplicado em sistemas, onde outros modelos geralmente falham, como é o caso de solutos apolares. Aqui chamamos a atenção para dois aspectos. Um é que embora os valores do solvatocromismo do benzeno tenham apresentado saturação com a inclusão da primeira camada de solvatação, isso não nos parece um resultado universal. Pois esperamos que para solutos polares, o efeito do solvente se estenda até camadas mais externas devido ao efeito eletrostático ser de mais longo alcance que a interação de dispersão, que parece ser dominante nesses sistemas de soluto apolar. Outro aspecto que é bastante notável é o fato desses cálculos supermoleculares conseguirem reproduzir os deslocamentos espectroscópicos 
de benzeno, utilizando o método CIS (com apenas excitações simples), pois a dispersão do estado fundamental e dos estados excitados é dominada pelas excitações duplas. Essa observação de que um modelo de CIS é bem sucedido levou-nos a provar um teorema bastante notável: dispersão está incluída em excitações calculadas com modelo de CIS aplicado em sistemas supermoleculares, mesmo que não esteja incluída nas energias dos estados individuais. Essa prova do teorema foi publicada separadamente [100] e se baseia na ideia de que os orbitais moleculares têm contribuições da molécula do soluto e das moléculas do solvente. Sendo assim, quando se realiza uma excitação simples nesses orbitais supermoleculares, isso corresponde a pequenas contribuições de excitações simples solutosoluto e solvente-solvente que são as que contribuem para dispersão. Desta forma, mostramos que parte da dispersão está incluída nesses cálculos e analisando nossos resultados para o benzeno, podemos dizer que essa parte é suficiente para a boa descrição das excitações eletrônicas.

Tabela 2: Imagem da tabela 4 retirada da ref. [36] com o valor calculado para o solvatocromismo da primeira banda de absorção eletrônica de benzeno na presença dos 4 solventes estudados, $\langle\Delta E\rangle_{l}$, o valor experimental, $\Delta E_{\text {exp }}$, a quantidade de moléculas, $N$, e quantidade de configurações estatisticamente descorrelacionadas $l$, incluídas no cálculo quântico e a ineficiência estatística, $s$.

TABLE IV. Calculated solvatochromic shift of the ${ }^{1} A_{1 g}-{ }^{1} B_{2 u}\left(\pi-\pi^{*}\right)$ transition of benzene in different solvents. $N$ (one solute $+N_{s}$ solvent) is the number of molecules used in the QM calculations, $l$ is the number of selected configurations to perform QM calculations, $s$ is the number of MC steps between the selected configurations, and $\langle\Delta E\rangle_{l}$ is the calculated average solvatochromic shift (in $\mathrm{cm}^{-1}$ ). Uncertainty in $\langle\Delta E\rangle_{l}$ is obtained from Eq. (11). Experimental results are from Ref. 35.

\begin{tabular}{lcrccc}
\hline \hline \multicolumn{1}{c}{ System } & $N$ & \multicolumn{1}{c}{$l$} & \multicolumn{1}{c}{$s$} & \multicolumn{1}{c}{$\langle\Delta E\rangle_{l}$} & $\Delta E_{\text {exp }}$ \\
\hline Liquid $\mathrm{C}_{6} \mathrm{H}_{6}$ & $1+13$ & 60 & 800 & $-306 \pm 15$ & $-332 \pm 30$ \\
$\mathrm{C}_{6} \mathrm{H}_{6}$ in $\mathrm{C}_{6} \mathrm{H}_{12}$ & $1+11$ & 100 & 500 & $-268 \pm 20$ & $-308 \pm 20$ \\
$\mathrm{C}_{6} \mathrm{H}_{6}$ in $\mathrm{CCl}_{4}$ & $1+14$ & 50 & 500 & $-456 \pm 38$ & $-458 \pm 20$ \\
$\mathrm{C}_{6} \mathrm{H}_{6}$ in $\mathrm{H}_{2} \mathrm{O}$ & $1+18$ & 100 & 800 & $-122 \pm 7$ & $-143 \pm 20$ \\
\hline \hline
\end{tabular}

\subsubsection{International Journal of Quantum Chemistry, 77, 192 (2000)}

Neste trabalho de autoria minha e Prof. Canuto [37], anexado no Apêndice D, aplicamos o método S-QM/MM para estudar o deslocamento da primeira banda de absorção eletrônica do formaldeído $\left(\mathrm{CH}_{2} \mathrm{O}\right.$, soluto polar) em solução aquosa. Aqui além de testar a aplicabilidade do método, queríamos comprovar nossa hipótese de que para solutos polares o efeito do solvente se estende até longas distâncias do soluto. Como resultados experimentais, estavam disponíveis as informações que a primeira banda de absorção eletrônica do formaldeído é do tipo $n-\pi^{*}$ e em fase gasosa está na região de $34000 \mathrm{~cm}^{-1}$. Em solução aquosa essa transição não está bem determinada, porém estima-se um deslocamento de cerca 
de $2000 \mathrm{~cm}^{-1}$ devido à presença da solução aquosa e uma largura da banda de cerca de 4000 $\mathrm{cm}^{-1}$. Escolhemos o formaldeído por ser um sistema polar e pequeno, servir de modelo para as transições $n-\pi^{*}$ de cetonas e aldeídos e ter bastante resultados de outros modelos teóricos de solvente. Os resultados teóricos para o solvatocromismo da transição $n$ - $\pi^{*}$ do formaldeído em água ficam entre $1100 \mathrm{~cm}^{-1}$ e $3500 \mathrm{~cm}^{-1}$. Enquanto que os resultados experimentais para o solvatocromismo da transição $n-\pi^{*}$ da acetona $\left(\left(\mathrm{CH}_{3}\right)_{2} \mathrm{CO}\right)$ em água ficam entre $1500 \mathrm{~cm}^{-1} \mathrm{e}$ $2000 \mathrm{~cm}^{-1}$.

Realizamos as simulações MC desses sistemas nas condições normais de temperatura e pressão. Só que para levar em consideração o estiramento da ligação $C=O$ devido às ligações de hidrogênio com as águas, realizamos as simulações com a geometria do formaldeído previamente otimizada na presença de uma molécula de água formando ligação de hidrogênio. Após as simulações realizamos os cálculos do intervalo de correlação $\tau$ e selecionamos 60 configurações estatisticamente descorrelacionadas para os subsequentes cálculos quânticos. Através da análise das RDFs entre o carbono do formaldeído e os oxigênios águas, $G_{C O}(r)$, analisamos a estrutura da solução e identificamos 15 moléculas de água até a primeira camada de solvatação, 35 até a segunda e 80 até a terceira camada. Para analisar as ligações de hidrogênio utilizamos a integração do primeiro pico da $G_{O O}(r)$ e também utilizamos critérios geométricos (distância $O \cdots O$ e ângulo $O \cdots O H$ ) e critérios geométricos combinados com critério energético (energia de ligação). Com essas análises obtivemos 2.6, 2.1 e 1.9 ligações de hidrogênio entre o formaldeído e água, respectivamente. Na Tabela 3 mostramos um sumário das estatísticas das ligações de hidrogênio obtidas com as últimas duas análises e suas respectivas contribuições para o solvatocromismo.

Tabela 3: Imagem da tabela 1 retirada da ref. [37] com os valores do percentual de configurações obtidas da simulação MC que formaram $N_{H B}(=1,2,3$ e 4) ligações de hidrogênio entre o formaldeído e as moléculas de água. O solvatocromismo dessas configurações de 1 formaldeído $+N_{H B}$ águas também é apresentado. Em parênteses estão mostrados o número total de ligações de hidrogênio encontradas nas 60 configurações estatisticamente descorrelacionadas.

TABLE I Statistics of the hydrogen bonds formed between formaldehyde and water and their contribution to the blue shift of the $n-\pi^{*}$ transition.

\begin{tabular}{|c|c|c|c|c|}
\hline \multirow[b]{2}{*}{ Number of $\mathrm{HB}$} & \multicolumn{2}{|c|}{ Geometric } & \multicolumn{2}{|c|}{ Geometric and energetic } \\
\hline & Occurrence (\%) & Shift $\left(\mathrm{cm}^{-1}\right)$ & Occurrence (\%) & Shift $\left(\mathrm{cm}^{-1}\right)$ \\
\hline 1 & 18.3 & 152 & 23.3 & 146 \\
\hline 2 & 60.0 & 335 & 63.3 & 313 \\
\hline 3 & 20.0 & 262 & 13.4 & 360 \\
\hline 4 & 1.7 & 988 & - & \\
\hline Total & 100 (123) & $305 \pm 65$ & $100(114)$ & $281 \pm 65$ \\
\hline
\end{tabular}

${ }^{a}$ First result uses the geometric criterion to obtain a hydrogen bond. The second uses in addition the energetic criterion [24].

Os cálculos quânticos para as energias de excitação foram obtidos com método semiempírico INDO/CIS com parametrização espectroscópica. Podemos ver na Tabela 3, que 
60\% das configurações apresentam 2 ligação de hidrogênio quando apenas o critério geométrico é utilizado e esse percentual muda para $63.3 \%$ quando o critério energético é adicionado. Como conclusão identificamos que existem cerca de 2 ligações de hidrogênio em média entre o formaldeído e as moléculas de água e que elas contribuem com cerca de 300 $\mathrm{cm}^{-1}$ para o deslocamento da transição $n-\pi^{*}$ do formaldeído em água. Seguindo esta linha de análise de ligações de hidrogênio publicamos outro trabalho com o aluno de doutorado N. Saavedra sobre acetona em solução aquosa [101].

Analisamos como esse deslocamento varia com o número de moléculas de água incluídas nos cálculos quânticos considerando as demais camadas de solvatação e apresentamos os resultados obtidos na Tabela 4. Nessa tabela também está incluído uma extrapolação para distâncias infinitas do soluto. Sendo assim, nosso melhor resultado para o solvatocromismo da transição $n-\pi^{*}$ do formaldeído em água é $+2200 \mathrm{~cm}^{-1}$ com uma largura de banda de cerca de $3000 \mathrm{~cm}^{-1}$. Concluímos que o efeito de solvente, de fato, se estende até longas distâncias do soluto. Porém diferente da opinião geral de que as ligações de hidrogênio apresentam grande contribuição para o solvatocromismo, observamos uma contribuição pequena de cerca de $14 \%$ para as ligações de hidrogênio, $56 \%$ quando incluímos até a primeira, $76 \%$ até a segunda e $88 \%$ até a terceira.

Os nossos resultados com S-QM/MM estão em concordância com outros resultados teóricos que consideramos de alto nível com o método QM/MM realizado por Blair e coautores [33] e Naka e coautores [87].

Tabela 4: Imagem da tabela 2 retirada da ref. [37] com os valores calculados para o solvatocromismo da transição $n-\pi^{*}$ do formaldeído em água, a largura da banda, a quantidade de moléculas de solvente, $N$, e quantidade de configurações estatisticamente descorrelacionadas, $L$, incluídas no cálculo quântico e algumas informações adicionais como o número de elétrons de valência, $M$, e a distância até a qual se estendem as moléculas de solvente. $\mathrm{O}$ valor limite corresponde a uma extrapolação dos valores calculados até uma distância infinita do soluto.

\begin{tabular}{|c|c|c|c|c|c|c|}
\hline Solvation shell & $N$ & $M$ & $L$ & Distance $(\AA)$ & Blue shift & Spread \\
\hline First & 15 & 132 & 60 & 4.75 & $1237 \pm 75$ & 2500 \\
\hline Second & 35 & 292 & 60 & 6.45 & $1667 \pm 90$ & 3100 \\
\hline Third & 80 & 652 & 60 & 8.35 & $1942 \pm 90$ & 3300 \\
\hline Limit & Bulk & & & & $\sim 2200$ & \\
\hline
\end{tabular}

${ }^{a} N$ is the number of water molecules included. $M$ is the total number of valence electrons. $L$ is the number of MC configurations used for ensemble average.

Logo em seguida, utilizamos os procedimentos e métodos aplicados aqui, em estudos de solvatocromismo de outros sistemas: piridina em solução aquosa [102], metilacetamide em solução aquosa [103] e pirimidina em solução aquosa e solução de tetracloreto de carbono [60]; e também o aumento do momento de dipolo da água devido à solução aquosa [104]. Esses últimos 3 trabalhos foram em coautoria com o aluno de doutorado W. R. Rocha, 
da UFMG orientado pelo Prof. W. B. de Almeida, que esteve visitando nosso grupo de pesquisa por um período de 6 meses.

\subsubsection{Journal of Chemical Physics, 113, 9132 (2000)}

Neste trabalho de autoria minha e Prof. Canuto [38], anexado no Apêndice E, aplicamos o método S-QM/MM para estudar o deslocamento da transição $n \leftarrow \pi^{*}$ de emissão eletrônica completamente relaxada do formaldeído em solução aquosa. Existem várias motivações para se estudar o processo de emissão de luz, dentre elas está à ampla utilização da fluorescência na biofísica, como ferramenta de análise de ambiente. Certamente o processo de emissão de luz é muito mais complexo que o de absorção, uma vez que existem vários tempos envolvidos no processo. Dentre eles estão principalmente o tempo de vida do estado excitado, o tempo de relaxação da geometria entre os estados verticalmente excitado e excitado relaxado e o tempo de completa relaxação que também envolve o meio que circunda a molécula excitada.

Na Figura 17 ilustramos o processo de transições eletrônicas da molécula isolada, onde $v_{0}$ e $v_{2}$ descrevem a absorção vertical e a emissão completamente relaxada, respectivamente, e a diferença entre eles é conhecida como deslocamento Stokes (Stokes shift), $\Delta E^{\text {Stokes }}=$ $h\left(v_{2}-v_{0}\right)$. Adicionalmente, também estão ilustrados os efeitos de solvente na absorção, $\Delta E_{\text {solv }}^{a b s}=h\left(v_{1}-v_{0}\right)$, na emissão completamente relaxada, $\Delta E_{\text {solv }}^{e m i}=h\left(v_{3}-v_{2}\right)$, e no deslocamento de Stokes, $\Delta E_{\text {solv }}^{\text {stokes }}=h\left[\left(v_{2}-v_{0}\right)-\left(v_{3}-v_{1}\right)\right]$. Esses processos são factíveis de serem modelados via o método S-QM/MM, pois dependem da geometria e distribuição de cargas descritas no estado fundamental (mínimo da curva $g$ na Figura 17) e no primeiro estado excitado (mínimo da curva $e$ na Figura 17).

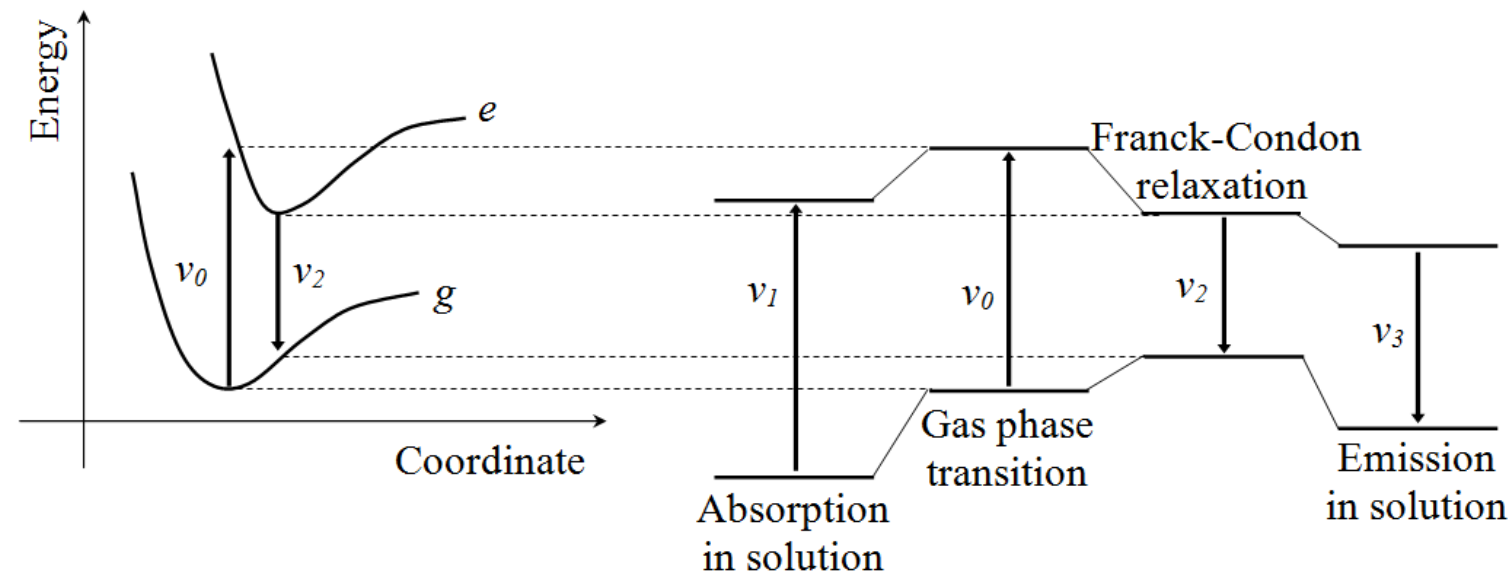

Figura 17: Ilustração das curvas de energia do estado fundamental, $g$, e primeiro estado excitado, $e$, dos processos de transição eletrônica através da absorção de luz, $v_{0}$, e emissão completamente relaxada de luz, $v_{2}$, e dos efeitos de solvente na absorção, $\Delta E_{\text {solv }}^{a b s}=h\left(v_{1}-v_{0}\right)$, na emissão, $\Delta E_{\text {solv }}^{e m i}=h\left(v_{3}-v_{2}\right)$, e no deslocamento de Stokes, $\Delta E_{\text {solv }}^{\text {Stokes }}=h\left[\left(v_{2}-v_{0}\right)-\left(v_{3}-v_{1}\right)\right]$. Figura retirada da ref. [38]. 
Os processos de emissão que ocorrem durante a relaxação de geometria e relaxação com o solvente são mais complexos e só podem ser estudados com método de dinâmica molecular de primeiros princípios ou métodos QM/MM convencionais. Sendo assim, estudamos os efeitos de solventes no processo de emissão completamente relaxado, pois até a época de publicação deste trabalho existiam pouquíssimos estudos teóricos dedicados ao processo de emissão. Mesmo sabendo que transições do tipo $n$ - $\pi^{*}$ normalmente não fluorescem, e em particular, o formaldeído não fluorescente, nosso interesse neste estudo estava relacionado com os efeitos de solvente na emissão, e a seleção do formaldeído se deu como exercício teórico e também motivado por outro trabalho teórico anterior sobre a dinâmica do primeiro estado excitado do formaldeído em água [33].

Realizamos o mesmo procedimento descrito no trabalho anterior sobre solvatocromismo na transição $n-\pi^{*}$ de formaldeído em água [37]. A única diferença se deu na geometria e distribuição de cargas do formaldeído que agora foram utilizadas as do primeiro estado excitado obtidas por Levy e coautores [33], como anteriormente. Os resultados obtidos para o solvatocromismo na emissão eletrônica estão mostrados na parte de cima da Tabela 5 .

Tabela 5: Imagem das tabelas 2 e 3 retiradas da ref. [38] (em cima) com os valores calculados para o solvatocromismo da transição $n \leftarrow \pi^{*}$ do formaldeído em água e outras informações equivalentes à Tabela 4, e (embaixo) com sumário das energias das transições eletrônicas mostradas na Figura 17.

TABLE II. The variation of the calculated (INDO/CIS) shift $\left(\right.$ in $\mathrm{cm}^{-1}$ ) of the $n-\pi^{*}$ emission transition of formaldehyde in water with the solvation shells. $N$ is the number of water molecules included. $M$ is the total number of valence electrons. $L$ is the number of MC structures used for an ensemble average.

\begin{tabular}{lrrrcr}
\hline \hline Solvation shell & \multicolumn{1}{c}{$N$} & \multicolumn{1}{c}{$M$} & \multicolumn{1}{c}{$L$} & Distance $(\AA)$ & Blue shift \\
\hline First & 19 & 164 & 60 & 5.15 & $822 \pm 70$ \\
& 19 & 164 & 100 & 5.15 & $854 \pm 51$ \\
Second & 50 & 412 & 60 & 7.15 & $1167 \pm 73$ \\
& 50 & 412 & 100 & 7.15 & $1213 \pm 59$ \\
Third & 142 & 1148 & 60 & 10.0 & $1427 \pm 72$ \\
& 142 & 1148 & 100 & 10.0 & $1451 \pm 63$ \\
Limit & Bulk & & & & $\sim 1650$ \\
\hline \hline
\end{tabular}

TABLE III. Summary of the calculated shifts of the $n-\pi^{*}$ transition of formaldehyde in water. Refer to Fig. 1 for definitions.

\begin{tabular}{lc}
\hline \hline & Calculated shift $\left(\mathrm{cm}^{-1}\right)$ \\
\hline$\nu_{1}-\nu_{0}$ & 2200 \\
$\nu_{3}-\nu_{2}$ & 1650 \\
$\nu_{2}-\nu_{0}$ & -1270 \\
$\nu_{3}-\nu_{0}$ & 380 \\
$\nu_{1}-\nu_{3}$ & 550 \\
\hline \hline
\end{tabular}


Nosso maior cálculo se refere ao formaldeído no estado excitado rodeado por 142 moléculas de água que se estendem até a terceira camada de solvatação em 100 configurações estatisticamente descorrelacionadas selecionadas para os subsequentes cálculos quânticos das energias de excitação eletrônica. Ao final obtivemos o valor médio de $+1451 \pm 63 \mathrm{~cm}^{-1}$. Na parte de cima dessa tabela também está incluído uma extrapolação para distâncias infinitas do soluto. Sendo assim, nosso melhor resultado para o solvatocromismo da transição $n \leftarrow \pi^{*}$ do formaldeído em água é $+1650 \mathrm{~cm}^{-1}$. Esse resultado está em muito boa concordância com o resultado obtido por Levy e coautores [33] de $\approx 1700 \mathrm{~cm}^{-1}$ após a relaxação de 1.0 ps de dinâmica. Na parte de baixo dessa tabela, apresentamos um sumário das energias das transições eletrônicas mostradas na Figura 17. Obtivemos um solvatocromismo na absorção de $+2200 \mathrm{~cm}^{-1}$, na emissão de $+1650 \mathrm{~cm}^{-1}$, um deslocamento Stokes em gás de $-1270 \mathrm{~cm}^{-1}$ (efeito apenas da relaxação da geometria do formaldeído no estado excitado), um deslocamento Stokes em solução aquosa de $-550 \mathrm{~cm}^{-1}$ (efeito da relaxação da geometria do formaldeído no estado excitado e do solvente) e um efeito de solvente no deslocamento Stokes de $720 \mathrm{~cm}^{-1}$ (efeito da relaxação do solvente). Sendo assim, a relaxação da geometria do formaldeído é maior que a relaxação do solvente.

Concluídos que é viável utilizar o método S-QM/MM para estudo de processos de emissão completamente relaxados e isso abre uma perspectiva para novas implementações para outros processos de emissão. Um ponto fraco desse estudo é a ausência de resultados experimentais que poderiam dar um melhor respaldo a nossos resultados.

\subsection{Função de Distribuição de Mínima Distância (MDDF)}

Nesta seção serão discutidos 2 trabalhos publicados.

No primeiro trabalho, em colaboração com o aluno de mestrado D. Trzesniak e seu orientador Prof. Canuto, fizemos a proposta da função de distribuição de mínima distância (MDDF) para estudar o solvatocromismo da molécula de $\beta$-caroteno em vários solventes.

No segundo trabalho, que faz parte da tese de doutorado do aluno H. C. Georg [105] sob minha orientação, fizemos a proposta da normalização da MDDF em forma de casca de paralelepípedo, para estudar o solvatocromismo da molécula de benzofenona em solução aquosa.

\subsubsection{Advances in Quantum Chemistry, 41, 161 (2002)}

Neste trabalho de autoria minha, D. Trzesniak e Prof. Canuto [39], anexado no Apêndice $\mathrm{F}$, apresentamos pela primeira vez a ideia de uma distribuição não esférica para identificar as camadas de solvatação de um soluto alongado. Essa distribuição, que denominados de MDDF, se baseia na distribuição de mínima distância entre o soluto e as 
moléculas de solvente. A descrição detalhada de como obter essa distribuição está apresentada na seção 2.4. Como aplicação dessa distribuição, estudamos o deslocamento da transição $\pi-\pi^{*}$ de absorção eletrônica da molécula de trans- $\beta$-caroteno em vários solventes: isopentano $\left(\left(\mathrm{CH}_{3}\right)_{2} \mathrm{CHCH}_{2} \mathrm{CH}_{3}\right)$, acetona $\left(\left(\mathrm{CH}_{3}\right)_{2} \mathrm{CO}\right)$, metanol $\left(\mathrm{CH}_{3} \mathrm{OH}\right)$ e acetonitrila $\left(\mathrm{CH}_{3} \mathrm{CN}\right)$, utilizando o método S-QM/MM. A escolha do $\beta$-caroteno (soluto apolar) se deu por ser uma molécula alongada, abundante em sistemas biológicos, ter muitos resultados experimentais disponíveis e apresentar dificuldade em ser tratado por outros métodos teóricos, principalmente modelos contínuos devido ao seu momento de dipolo nulo e seu formato alongado. Como resultados experimentais, estavam disponíveis as informações que a primeira banda de absorção eletrônica do $\beta$-caroteno é do tipo $\pi$ - $\pi^{*}$ e tem máximo em 22046 $\pm 20 \mathrm{~cm}^{-1}$ em acetona, $22070 \pm 20 \mathrm{~cm}^{-1}$ em acetonitrila, $22247 \pm 20 \mathrm{~cm}^{-1} \mathrm{em}$ metanol e 22364 $\pm 20 \mathrm{~cm}^{-1}$ em isopentano.

Realizamos as simulações MC desses sistemas nas condições normais de temperatura e pressão. Após as simulações realizamos os cálculos da ineficiência estatística e do intervalo de correlação e selecionamos configurações estatisticamente descorrelacionadas para os subsequentes cálculos quânticos. Para analisar a estrutura do solvente ao envolta do soluto calculamos a RDF entre centros de massa do $\beta$-caroteno e das moléculas de solvente e a MDDF dos mesmos sistemas. Na Figura 18 mostramos um exemplo dessas funções calculadas para a solução de acetona. Na RDF é possível identificar pelo menos 3 picos e na MDDF apenas 2. Integrando esses picos obtemos na RDF: 7 moléculas de acetona na primeira camada de solvatação (até $6.4 \AA$ ), 30 acetonas na segunda camada (de $6.4 \AA$ até $10.7 \AA$ ) e 46 acetonas na terceira camada (de $10.7 \AA$ até $13.9 \AA$ ); e na MDDF: 50 moléculas de acetona na primeira camada (até $4.4 \AA$ ) e 88 acetonas na segunda camada (de $4.4 \AA$ até $8.1 \AA$ ).

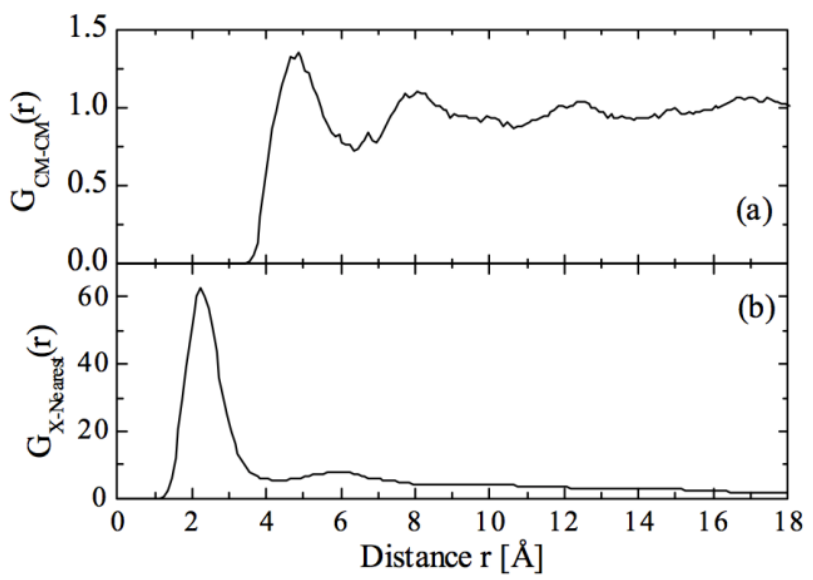

Figura 18: (a) Gráfico da RDF entre centros de massa do $\beta$-caroteno e das moléculas de acetona e (b) a MDDF para o mesmo sistema. Gráfico retirado da ref. [39]. 
Claramente, 7 moléculas de acetona é pouco para solvatar a molécula de $\beta$-caroteno, considerando que a molécula de benzeno (que tem apenas 1 anel aromático) tem 18 moléculas de água em sua primeira camada de solvatação [36]. Na

Figura 19 ilustramos a molécula de $\beta$-caroteno isolada (em cima à esquerda), rodeada pela primeira e segunda camadas de solvatação definidas pela $G_{C M-C M}(r)$ e utilizando o critério de distâncias entre centros de massa do soluto e do solvente (à direita), e rodeada pela primeira camada de solvatação definida pela MDDF e utilizando o critério de mínima distância entre o soluto e o solvente (embaixo à esquerda). É notório que a configuração, que usa a MDDF e o critério de mínima distância (embaixo à esquerda), apresenta uma distribuição de moléculas do solvente mais uniforme ao redor do $\beta$-caroteno que as outras. Sendo assim, utilizamos a MDDF para definir as camadas de solvatação do $\beta$-caroteno nos vários solventes e realizamos os subsequentes cálculos quânticos com método semiempírico INDO/CIS com parametrização espectroscópica. Obtivemos os resultados mostrados na Tabela 6.
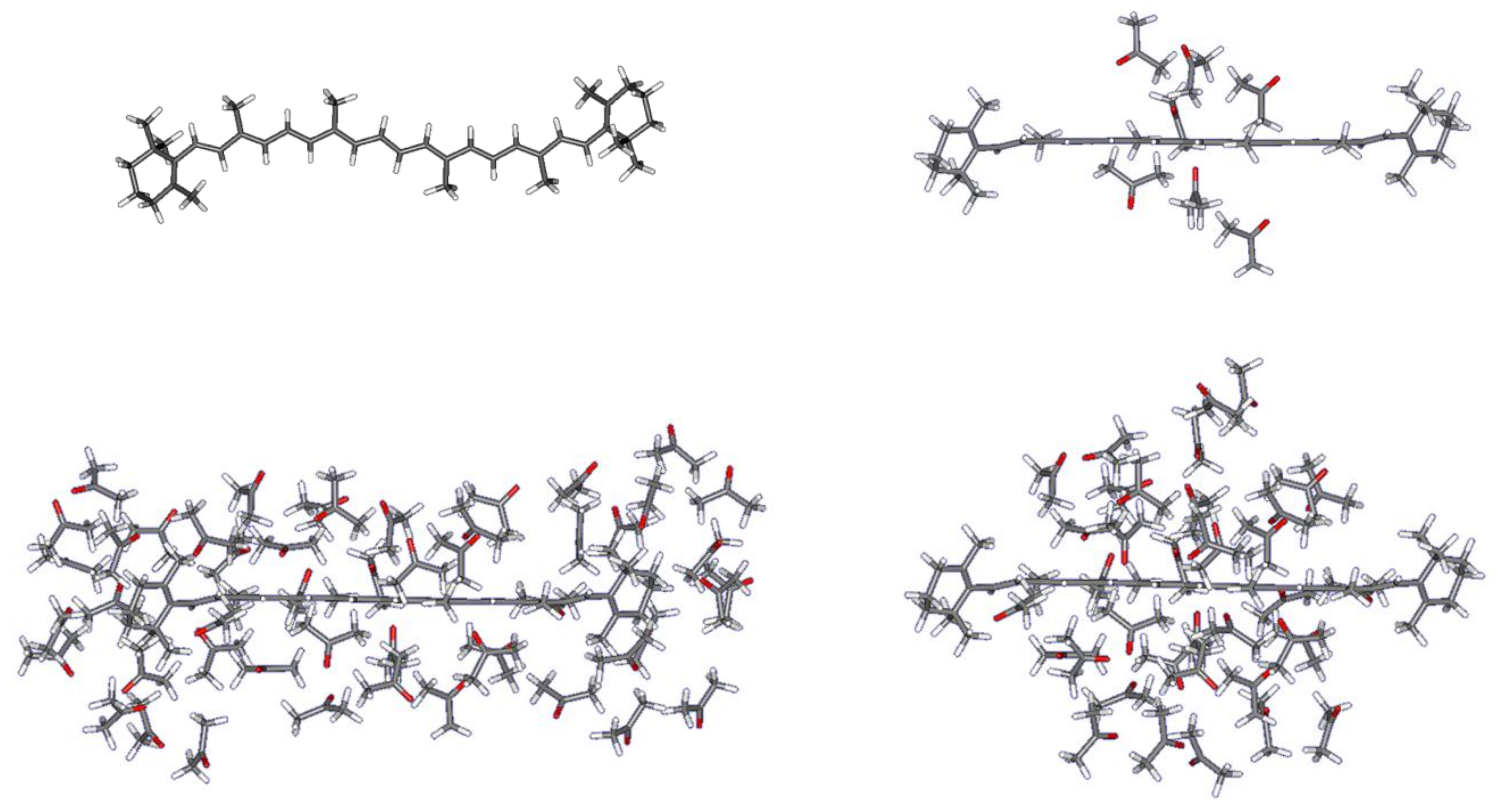

Figura 19: Ilustração do $\beta$-caroteno isolado (em cima à esquerda), rodeado pela primeira e segunda camada de acetona usando o critério de proximidade do centro de massa (direita) e pela primeira camada usando o critério mínima distância (embaixo à esquerda). 
Tabela 6: Imagem da tabela 4 retirada da ref. [39] com os valores calculados para o solvatocromismo da transição $\pi-\pi^{*}$ do $\beta$-caroteno em vários solvente, a quantidade de moléculas de solvente, $N$, e os valores experimentais.

\section{Table 4}

Summary of the calculated and experimental results for the first $\pi-\pi^{*}$ absorption transitions of the $\beta$-carotene in gas phase and in solution.

\begin{tabular}{lccccc}
\hline \hline \multicolumn{1}{c}{ Solvent } & \multicolumn{2}{c}{$1^{\text {st }}$ Shell } & \multicolumn{2}{c}{$1^{\text {st }}$ half Shell } & Experiment[42] \\
& $N$ & Transition & $N$ & Transition & \\
\hline Vacuum & 1 & 22230 & & & \\
Acetone & $1+50$ & $22071 \pm 17$ & $1+77$ & $22074 \pm 17$ & 22046 \\
Acetonitrile & $1+58$ & $22059 \pm 19$ & $1+92$ & $22095 \pm 11$ & 22070 \\
Methanol & $1+69$ & $22143 \pm 6$ & $1+90$ & $22143 \pm 7$ & 22247 \\
Isopentane & $1+40$ & $22181 \pm 4$ & $1+59$ & $22182 \pm 4$ & 22364 \\
\hline \hline
\end{tabular}

Nota-se que os valores para primeira camada de solvatação já estão saturados com relação à quantidade de moléculas de solvente incluídas no cálculo quântico e que os resultados teóricos estão em muito boa concordância com os resultados experimentais, tanto os valores absolutos como a tendência em relação aos solventes. Desta forma, mais uma vez identificamos o excelente desempenho do método S-QM/MM.

Um ponto fraco deste trabalho é a escala da MDDF (ver Figura 18). O primeiro pico é tão alto que não se consegue ver a distribuição uniforme $(\approx 1)$ a longas distâncias do soluto.

\subsubsection{Journal of Chemical Physics, 126, 34507 (2007)}

Neste trabalho de autoria minha, H. C. Georg e Prof. Canuto [40], anexado no Apêndice $\mathrm{G}$, apresentamos pela primeira vez uma proposta de normalização não esférica para a MDDF. Essa normalização se baseia em um volume de paralelepípedo de dimensões $(a, b, c)$ para o soluto e cascas de espessura $d r$ ao redor desse paralelepípedo central (ver equação 43). Como aplicação da MDDF, agora devidamente normalizada, estudamos o deslocamento de duas transições $n-\pi^{*}$ e $\pi-\pi^{*}$ de absorção eletrônica da molécula de benzofenona em solução aquosa, utilizando o método S-QM/MM. A escolha da benzofenona (soluto polar) se deu por ser uma molécula de forma não esférica, ter importância no contexto de sonda em ambiente supercrítico e ter resultados experimentais disponíveis. Como resultados experimentais, estavam disponíveis as informações que seu espectro eletrônico de absorção é composto por 2 bandas, uma $n-\pi^{*}$ de baixa intensidade na região de 320 a $370 \mathrm{~nm}$ e um $\pi-\pi^{*}$ de alta intensidade na região de 240 a $300 \mathrm{~nm}$. Os deslocamentos dessas bandas também são 
conhecidos quando o solvente muda de hexano para água. Eles são e tem máximo em $2200 \pm$ $35 \mathrm{~cm}^{-1} \mathrm{e}-1600 \pm 85 \mathrm{~cm}^{-1}$ respectivamente.

A benzofenona está mostrada na Figura 8 (direita) e tem dimensões $a=11.5, b=7.0$ e $c=4.0 \AA$ A . Após a simulação da benzofenona em solução aquosa, a RDF entre centros de massa e a MDDF foram calculadas e devidamente normalizadas, mostradas na Figura 20. Na MDDF, a distribuição das moléculas de água em torno do benzofenona é clara: i) um ombro do primeiro pico, terminando em cerca de $2.0 \AA$, que caracteriza as ligações de hidrogênio, ii) um primeiro pico, até $4.0 \AA$, que caracteriza 45 moléculas de água na primeira camada de solvatação, e iii) um segundo pico, entre 4.0 e 7.0 Å, que caracteriza 105 moléculas de água na segunda camada de solvatação. Na RDF, só é possível identificar um primeiro pico até 5.4 $\AA$ A que caracteriza 14 moléculas de água na primeira camada de solvatação. Claramente, 14 moléculas de água é pouco para solvatar a benzofenona, considerando que a molécula de benzeno (que tem apenas 1 anél aromático) tem 18 moléculas de água em sua primeira camada de solvatação [36].

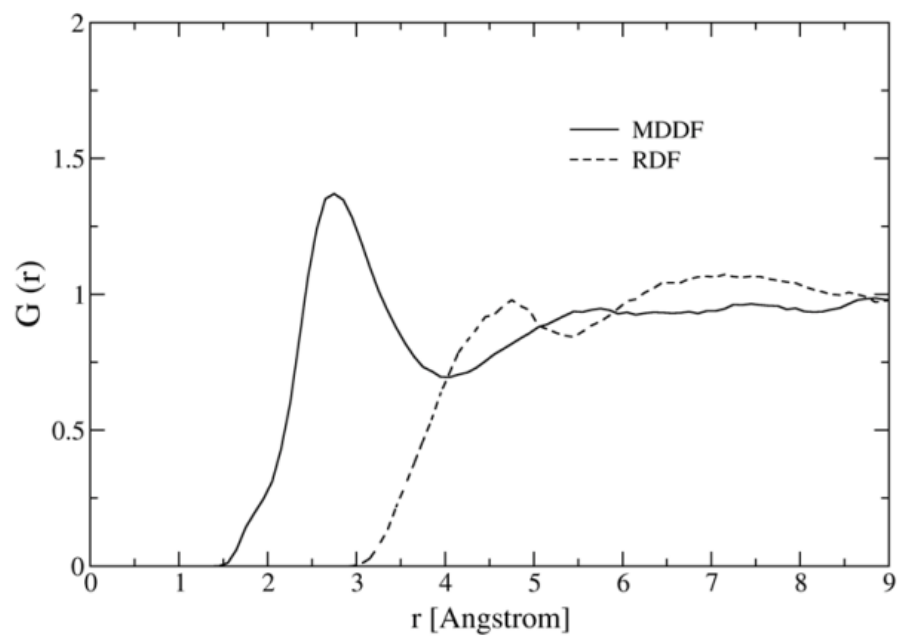

Figura 20: Funções de distribuição, RDF entre centros de massa e MDDF, calculado nas simulações de benzofenona em solução aquosa. Gráfico retirado da ref. [40].

Sendo assim, fica mais uma vez mostrado que a RDF de centros de massa não é capaz de caracterizar a solvatação de uma molécula alongada. Na Figura 9 foi mostrado que a seleção das moléculas mais próximas da benzofenona usando o critério de ordenamento das moléculas pela mínima distância é mais adequada que pela distância entre centros de massa.

Neste trabalho, diferentemente dos outros anteriormente discutidos neste texto, aparecem resultados sobre o procedimento de polarização iterativo (seções 2.7 e 3.5) com SQM/MM e seus efeitos na estrutura do solvente ao seu redor e no solvatocromismo. O procedimento de polarização iterativo, descrito na seção 2.7 , foi aplicado utilizando para 
cálculo do dipolo e cargas o método ab initio MP2/6-31++G(d,p)/CHELPG e os principais resultados desse procedimento estão mostrados na Figura 21. Na esquerda, o procedimento é iniciado com o dipolo da molécula isolada é de $3.11 \mathrm{D}$ e após a polarização em água se estabiliza em 5.84 D. Isso representa um aumento de $88 \%$, bem maior que o $17 \%$ que seria usado devido ao procedimento padrão de cálculos das cargas nos campos de força clássicos (3.64 D).
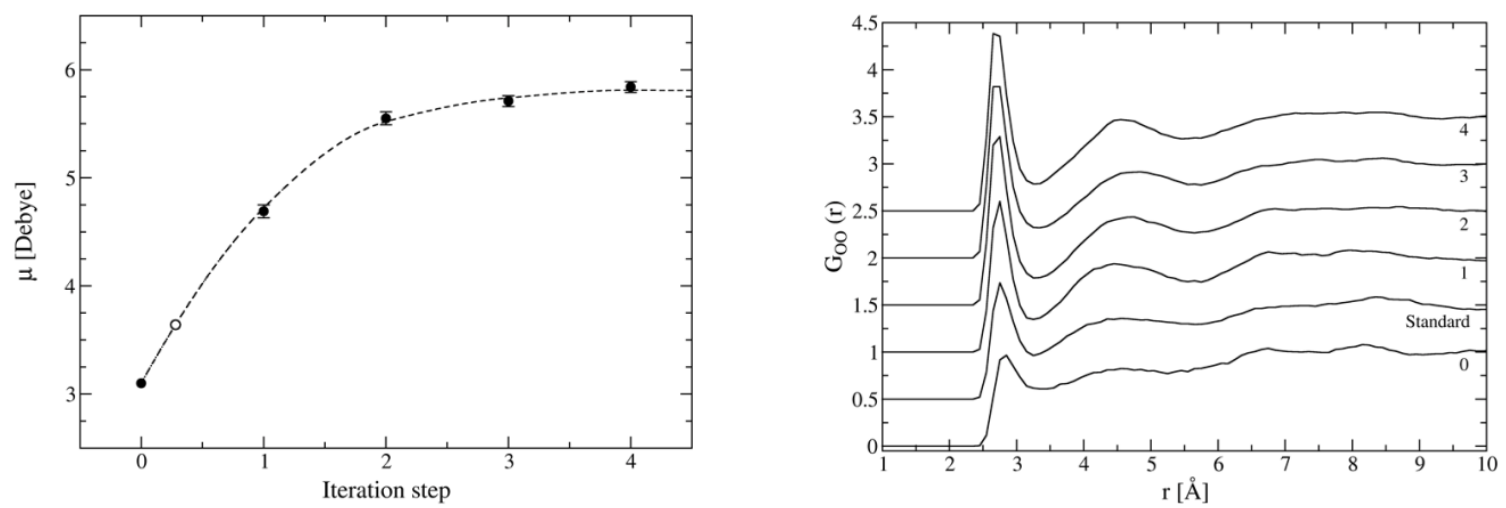

Figura 21: (esquerda) Variação do momento de dipolo da benzofenona em água com o processo de polarização iterativo. O ponto branco representa o dipolo calculado da forma padrão; (direita) Variação da $\mathrm{RDF} G_{O O}(r)$, durante o procedimento de polarização. Gráficos retirados da ref. [40].

$\mathrm{Na}$ direita dessa figura, mostramos como a RDF entre oxigênios da benzofenona e águas, $G_{O O}(r)$, varia ao longo do procedimento de polarização em água. O primeiro pico, por volta de $2.8 \AA$, característica das ligações de hidrogênio, vai crescendo à medida que a benzofenona vai se polarizando, mudando a quantidade de ligações de hidrogênio de 1.3 a 2.3. Isso é um reflexo do aumento da carga atômica no oxigênio da benzofenona (ver parte de cima da Tabela 7). É interessante notar que a reorganização das moléculas de água ao redor da benzofenona é visível à medida que essa se polariza e que, portanto, esse é um efeito importante que não pode ser desprezado.

Repetindo os procedimentos já descritos nos trabalhos anteriores para o cálculo do solvatocromismo obtivemos os resultados mostrados na parte de baixo da Tabela 7. Note que o solvatocromismo da transição $n-\pi^{*}$ muda de $988 \pm 40 \mathrm{~cm}^{-1}$ (não polarizado) para $2045 \pm 40$ $\mathrm{cm}^{-1}$ (polarizado) e a transição $\pi-\pi^{*}$ mais intensa muda $-1009 \pm 40 \mathrm{~cm}^{-1}$ (não polarizado) para $-1943 \pm 40 \mathrm{~cm}^{-1}$ (polarizado). Esses resultados estão em muito bom acordo com os resultados experimentais e mostram como a inclusão da polarização do soluto é relevante. 
Tabela 7: Imagem das tabelas 2 e 4 retiradas da ref. [40] (em cima) com as cargas atômicas e momento de dipolo da benzofenona ao longo do procedimento de polarização em água, e (embaixo) com os valores calculados para o solvatocromismo das 5 primeiras transição eletrônicas da benzofenona em água ao longo do procedimento de polarização.

TABLE II. Evalution of the averaged atomic charges of the carbonyl group and dipole moments ( $\mu$ in Debye) of the benzophenone in aqueous solution during the iteration procedure of its polarization. They are calculated with MP2/6-31++G $(d, p)$ using 100 statistically uncorrelated MC configurations of the solution. The uncertainties are statistical errors (standard deviations are approximately ten times larger). For comparison the values obtained for the gas phase (iteration step 0 ) and for the standard procedure with $\mathrm{HF} / 6-31 \mathrm{G}(d)$ are also shown.

\begin{tabular}{ccccccc}
\hline \hline $\begin{array}{c}\text { Iteration } \\
\text { step }\end{array}$ & 0 & 1 & 2 & 3 & 4 & Standard \\
\hline$q(\mathrm{O})$ & -0.4570 & -0.5712 & -0.6340 & -0.6568 & -0.6636 & -0.5464 \\
$q(\mathrm{C})$ & 0.4021 & 0.4701 & 0.5112 & 0.5186 & 0.5247 & 0.5113 \\
$\mu$ & 3.11 & $4.65 \pm 0.066$ & $5.55 \pm 0.06$ & $5.71 \pm 0.05$ & $5.84 \pm 0.05$ & 3.64 \\
\hline \hline
\end{tabular}

TABLE IV. The evolution of the solvatochromic shifts of the UV-vis spectrum $\left(\mathrm{cm}^{-1}\right)$ of benzophenone in aqueous solution during the iteration procedure of its polarization. The statistical errors associated with the calculated shifts are less than $40 \mathrm{~cm}^{-1}$. The experimental shifts are 2200 and $-1600 \mathrm{~cm}^{-1}$, respectively, for the $n-\pi^{*}$ and the $\pi-\pi^{*}$ bands. See text.

\begin{tabular}{|c|c|c|c|c|c|c|c|}
\hline \multirow{2}{*}{$\begin{array}{l}\text { Iteration } \\
\text { Transition }\end{array}$} & \multirow{2}{*}{$\begin{array}{c}0 \\
\text { Shift }\end{array}$} & \multirow{2}{*}{$\begin{array}{c}1 \\
\text { Shift }\end{array}$} & \multirow{2}{*}{$\begin{array}{c}2 \\
\text { Shift }\end{array}$} & \multirow{2}{*}{$\begin{array}{c}3 \\
\text { Shift }\end{array}$} & \multicolumn{2}{|c|}{4} & \multirow{2}{*}{$\begin{array}{c}\text { Standard } \\
\text { Shift }\end{array}$} \\
\hline & & & & & Shift & Intensity & \\
\hline$n-\pi^{*}$ & 988 & 1656 & 1875 & 1934 & 2045 & 0.003 & 1395 \\
\hline$\pi-\pi^{*}$ & -203 & -225 & -243 & -230 & -244 & 0.021 & -241 \\
\hline$\pi-\pi^{*}$ & -384 & -519 & -541 & -510 & -569 & 0.027 & -428 \\
\hline$\pi-\pi^{*}$ & -1009 & -1653 & -1838 & -1876 & -1943 & 0.257 & -1339 \\
\hline$\pi-\pi^{*}$ & -695 & -1098 & -1256 & -1242 & -1363 & 0.064 & -955 \\
\hline
\end{tabular}

A partir de 2007, os trabalhos que sucederam este, passaram a utilizar a MDDF, devidamente normalizadas, para análise das camadas de solvatação ao redor do soluto.

\subsection{Análise da Delocalização dos Orbitais Moleculares}

Nesta seção serão discutidos 2 trabalhos publicados.

No primeiro trabalho, em colaboração com a aluna de doutorado P. Jaramillo, seus orientadores Profa. P. Pérez e Prof. P. Fuentealba, e Prof. Canuto, fizemos uma análise dos efeitos de solvente nos orbitais de fronteira, HOMO e LUMO, para estudar índices de reatividade globais de 4 solutos em solução aquosa. A aluna P. Jaramillo esteve visitando nosso grupo por 3 meses para dar início no desenvolvimento desse trabalho que foi continuado após seu regresso ao Chile para sua instituição de origem.

No segundo trabalho, em colaboração com Prof. J. V. Ortiz e V. G. Zakrzewski (estudante de seu grupo), Prof. B. J. Cabral e Prof. Canuto, fizemos o estudo do desprendimento eletrônico no ânion de fluoreto em solução aquosa. Em ambos os trabalhos, 
a análise da delocalização dos orbitais moleculares de fronteira foi muito importante e nos ajudou a compor um novo cenário do conceito do orbital molecular num sistema supermolecular.

\subsubsection{Journal of Physical Chemistry B, 113, 4314 (2009)}

Neste trabalho de autoria minha, P. Jaramillo, Profa Pérez, Prof. Fuentealba e Prof. Canuto [41], anexado no Apêndice $H$, apresentamos pela primeira uma análise de delocalização dos orbitais moleculares de fronteira no sistema soluto-solvente para estudar índices de reatividade globais, como potencial químico $(\mu)$, dureza $(\eta)$ e eletrofilia $(\omega)$, de 4 solutos em solução aquosa: duas moléculas neutras, metanol $\left(\mathrm{CH}_{3} \mathrm{OH}\right)$ e metilamina $\left(\mathrm{CH}_{3} \mathrm{NH}_{2}\right)$, um ânion $\left(\mathrm{CH}_{3} \mathrm{O}^{-}\right)$e um cátion $\left(\mathrm{CH}_{3} \mathrm{NH}_{3}^{+}\right)$.

Utilizando conceitos de energia de ionização e de afinidade eletrônica dentro da Teoria de Funcional de Densidade que os relaciona com a energia dos orbitais HOMO, $\varepsilon_{H}$, e energia do LUMO, $\varepsilon_{L}$, respectivamente, é possível escrever esses índices de reatividade como

$$
\mu=\left(\frac{\varepsilon_{L}+\varepsilon_{H}}{2}\right), \quad \eta=\left(\varepsilon_{L}-\varepsilon_{H}\right) \quad \text { e } \quad \omega=\frac{\mu^{2}}{2 \eta} .
$$

Sendo assim, realizando as simulações computacionais desses sistemas em solução aquosa e calculando as energias dos orbitais, $\varepsilon_{H}$ e $\varepsilon_{L}$, em princípio não haveria problema em calcular os índices de reatividade globais mostrados na equação 54. Esse é um procedimento padrão na literatura utilizando modelos contínuo de solventes. Porém, quando se utiliza um método com as moléculas de solventes explicitamente incluídas no cálculo quântico é possível haver a delocalização dos orbitais HOMO e LUMO sobre o sistema supermolecular solutosolvente. Utilizando o método S-QM/MM, inicialmente realizamos simulações de todos os sistemas em solução aquosa, em seguida calculamos o intervalo de correlação estatística e selecionamos 75 configurações estatisticamente descorrelacionadas. Calculamos as RDFs entre centros de massa e definimos as camadas de solvatação. Utilizando as 75 configurações estatisticamente descorrelacionadas para cada sistema, realizamos os cálculos quânticos com o funcional/base, B3LYP/6-31G(d), analisamos a convergência das energias dos orbitais com relação ao número de configurações selecionadas (ver Figura 22) e com relação à quantidade de moléculas de solvente, $N_{s}$, explicitamente incluídas em configurações com envolvimento eletrostático adicional (ver Figura 23).

$\mathrm{Na}$ Figura 22, observamos que as 75 configurações selecionadas são suficientes para termos médias convergidas. 


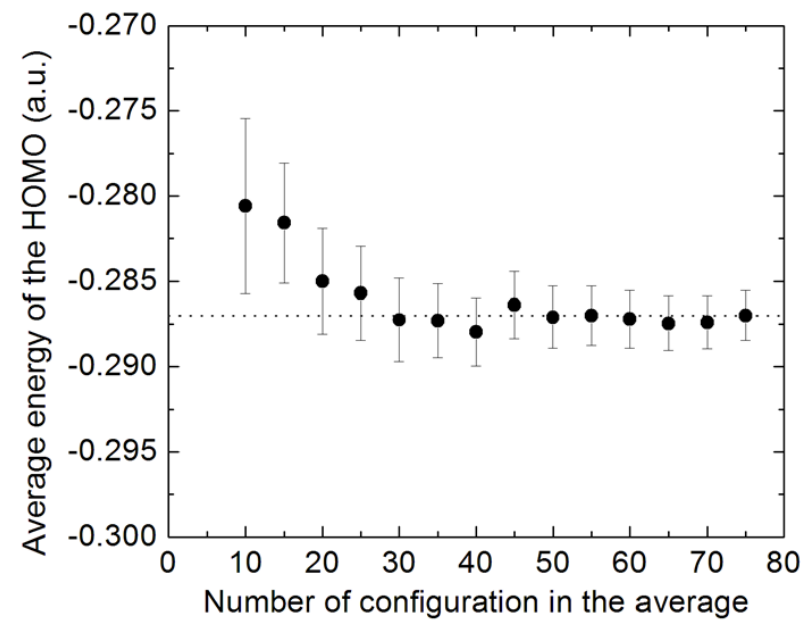

Figura 22: Convergência da energia média do orbital HOMO em relação ao número de configurações incluída na média. Esses dados são para a solução aquosa de metanol. Gráfico retirado da ref. [41].

Na Figura 23 à esquerda, observando que mesmo incluindo a primeira camada de solvatação mais o envolvimento eletrostático não é suficiente para saturar o efeito de solvente na energia dos orbitais HOMO e LUMO. Sendo assim, utilizamos os valores calculados, ajustamos por uma função de saturação do tipo $f\left(N_{s}\right)=a+b \cdot c^{N_{s}}$, que tende ao valor $a$ quando $N_{s}$ tende a infinito e $c$ menor que 1 , e extrapolamos os valores das energias dos orbitais, $\varepsilon_{H}$ e $\varepsilon_{L}$.
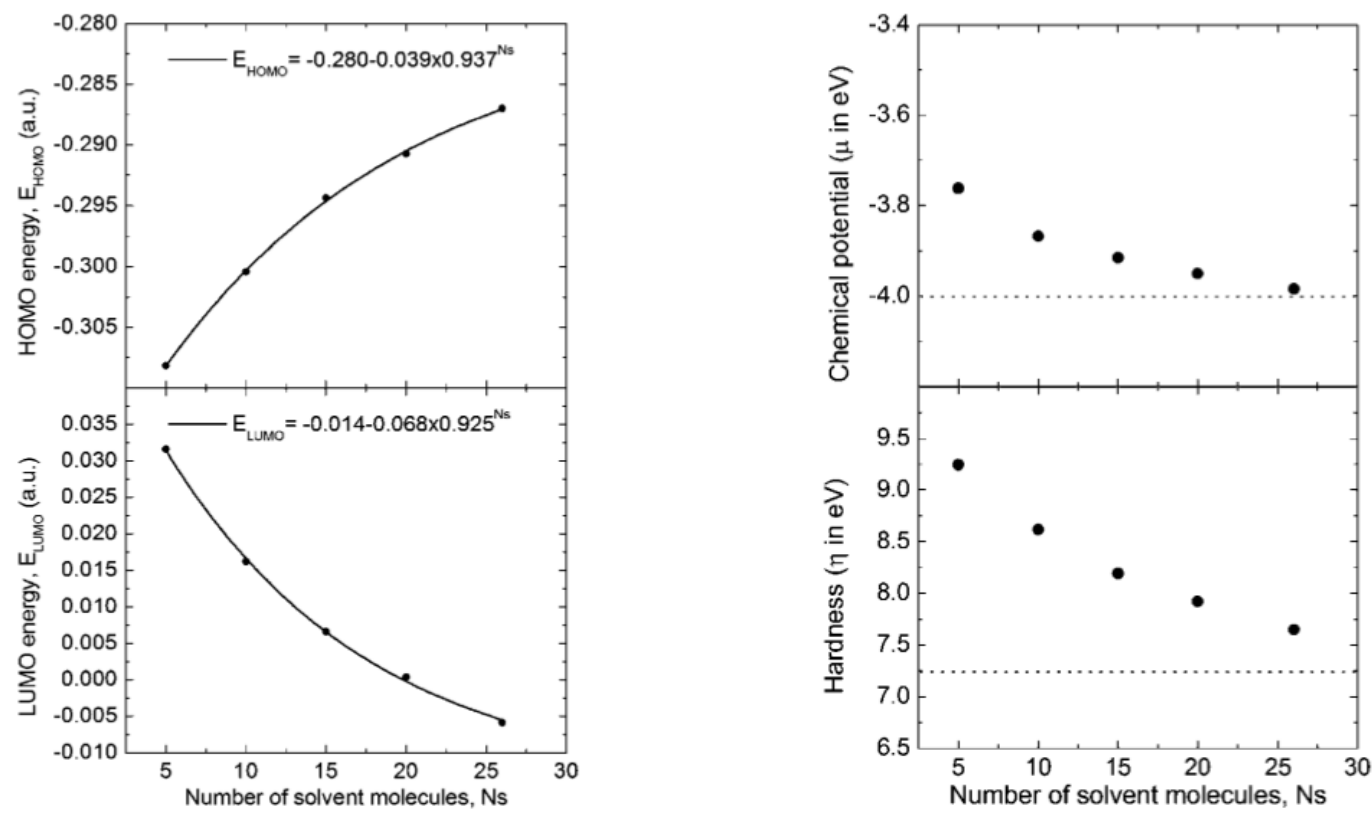

Figura 23: Convergência da energia média dos orbitais HOMO e LUMO (esquerda) e dos índices de reatividade globais (direita) em relação ao número de moléculas explicitamente incluídas em configurações com envolvimento eletrostático adicional. Esses dados são para a solução aquosa de metanol. Gráficos retirados da ref. [41]. 
Usando os valores das energias dos orbitais calculadas e o limite extrapolado, geramos o potencial químico e a dureza através da equação 54 (pontos e linha tracejada, respectivamente). Esses valores estão mostrados na Figura 23 à direita. Note que mesmo não estando com os valores das energias dos orbitais saturadas, os valores dos índices de reatividade estão muito próximos da saturação quando calculados com a primeira camada de solvatação explícita e o envolvimento eletrostático (Sol+1sh+PC). Sendo assim, consideraremos esses últimos resultados como nossos melhores resultados.

Adicionalmente, analisando os coeficientes das contribuições atômicas para a composição dos orbitais moleculares, HOMO e LUMO, observamos que o soluto em média só representa cerca de $8 \%$ desses orbitais (ver Figura 10 à esquerda para representação gráfica do HOMO para solução aquosa de metilamina). Então fica a pergunta: Como o índice de reatividade do soluto pode ser representado por orbitas que têm menos de $10 \%$ de sua participação? Para responder essa pergunta, decidimos analisar o orbital mais alto ocupado com pelo menos $20 \%$ de participação do soluto. Chamamos esse orbitais de HOMO_20Sol. No caso do metanol, esse HOMO_20Sol em geral está no intervalo de HOMO-5 a HOMO-7. De forma geral, analisamos a energia do orbital HOMO_XSol onde variamos X entre 0 e $80 \%$. O resultado dessa análise está mostrado na Figura 24. Note que exigir que o orbital HOMO_XSol tenha pelo menos $10 \%, 20 \%$ e $30 \%$ de contribuição do soluto muda pouquíssimo a energia média desse orbital. Por esse motivo optamos por selecionar o HOMO_20Sol para análises seguintes. Adicionalmente, analisando a participação do soluto no orbital HOMO_20Sol identificamos que cerca de 58\% desse orbital está localizado no soluto. Isso porque quando selecionamos o orbital mais alto ocupado que tem no mínimo $20 \%$ de localização no soluto, esse orbital pode ter qualquer contribuição do soluto maior que $20 \%$ e isso necessariamente compõem uma média superior a $20 \%$.

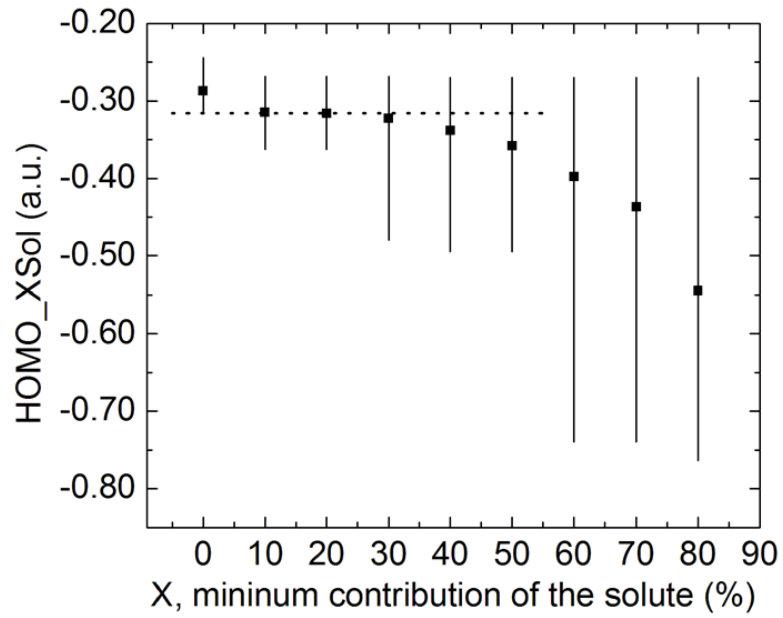

Figura 24: Energia média do orbital molecular que tem pelo menos X\% de contribuição do soluto. Esses dados são para a solução aquosa de metanol. Gráfico retirado da ref. [41]. 
Tabela 8: Imagem da tabela 2 retirada da ref. [41] com o sumário dos resultados das energias dos orbitais e dos índices de reatividade calculados para os solutos isolados e com vários modelos do solvente: $\mathrm{Sol}+\mathrm{PCM}=$ modelo contínuo polarizável, $\mathrm{Sol}+\mathrm{PC}=$ com envolvimento eletrostático, $\mathrm{Sol}+\mathrm{HB}+\mathrm{PC}=$ ligações de hidrogênio explícitas e o envolvimento eletrostático e $\mathrm{Sol}+1 \mathrm{sh}+\mathrm{PC}=$ primeira camada de solvatação explícita e o envolvimento eletrostático. Em parênteses, utilizamos as energias do orbital HOMO_20Sol.

TABLE 2: Calculated Properties of the Solute in Gas Phase and in Solution Using the Continuum Model (PCM) and the Explicit (S-MC/QM) Model ${ }^{a}$

\begin{tabular}{|c|c|c|c|c|c|}
\hline \multirow[b]{2}{*}{ solute and properties } & \multirow[b]{2}{*}{ gas (Sol) } & \multirow[b]{2}{*}{ Sol+PCM } & \multicolumn{3}{|c|}{ S-MC/QM } \\
\hline & & & Sol+PC & $\mathrm{Sol}+\mathrm{HB}+\mathrm{PC}$ & Sol +1 sh + PC \\
\hline \multicolumn{6}{|l|}{$\mathrm{CH}_{3} \mathrm{OH}$} \\
\hline HOMO (au) & -0.262 & -0.260 & -0.277 & $-0.293(-0.301)$ & $-0.287(-0.316)$ \\
\hline LUMO (au) & 0.070 & 0.092 & 0.090 & -0.007 & -0.006 \\
\hline$\mu(\mathrm{eV})$ & -2.61 & -2.29 & -2.54 & $-4.08(-4.19)$ & $-3.99(-4.38)$ \\
\hline$\eta(\mathrm{eV})$ & 9.03 & 9.58 & 9.99 & $7.78(8.00)$ & $7.68(8.45)$ \\
\hline$\omega(\mathrm{eV})$ & 0.38 & 0.27 & 0.32 & $1.07(1.10)$ & $1.04(1.13)$ \\
\hline \multicolumn{6}{|l|}{$\mathrm{CH}_{3} \mathrm{NH}_{2}$} \\
\hline HOMO (au) & -0.224 & -0.224 & -0.248 & $-0.250(-0.251)$ & $-0.246(-0.247)$ \\
\hline LUMO (au) & 0.087 & 0.098 & 0.093 & 0.065 & -0.005 \\
\hline$\mu(\mathrm{eV})$ & -1.86 & -1.71 & -2.11 & $-2.52(-2.53)$ & $-3.41(-3.43)$ \\
\hline$\eta(\mathrm{eV})$ & 8.46 & 8.76 & 9.28 & $8.57(8.60)$ & $6.56(6.58)$ \\
\hline$\omega(\mathrm{eV})$ & 0.21 & 0.17 & 0.24 & $0.37(0.37)$ & $0.89(0.89)$ \\
\hline \multicolumn{6}{|l|}{$\mathrm{CH}_{3} \mathrm{O}^{-}$} \\
\hline HOMO (au) & -0.117 & -0.121 & -0.149 & $-0.215(-0.221)$ & $-0.217(-0.220)$ \\
\hline LUMO (au) & 0.339 & 0.147 & 0.146 & 0.098 & 0.020 \\
\hline$\mu(\mathrm{eV})$ & 3.02 & 0.35 & -0.04 & $-1.59(-1.67)$ & $-2.68(-2.72)$ \\
\hline$\eta(\mathrm{eV})$ & 12.41 & 7.29 & 8.03 & $8.52(8.68)$ & $6.45(6.53)$ \\
\hline$\omega(\mathrm{eV})$ & 0.37 & 0.01 & 0.00 & $0.15(0.16)$ & $0.56(0.57)$ \\
\hline \multicolumn{6}{|l|}{$\mathrm{CH}_{3} \mathrm{NH}_{3}{ }^{+}$} \\
\hline HOMO (au) & -0.629 & -0.439 & -0.468 & $-0.353(-0.430)$ & $-0.341(-0.436)$ \\
\hline LUMO (au) & -0.188 & 0.029 & 0.009 & -0.003 & -0.039 \\
\hline$\mu(\mathrm{eV})$ & -11.12 & -5.58 & -6.24 & $-4.84(-5.89)$ & $-5.17(-6.46)$ \\
\hline$\eta(\mathrm{eV})$ & 12.00 & 12.73 & 12.98 & $9.52(11.62)$ & $8.22(10.80)$ \\
\hline$\omega(\mathrm{eV})$ & 5.15 & 1.22 & 1.50 & $1.23(1.49)$ & $1.63(1.93)$ \\
\hline
\end{tabular}

${ }^{a}$ In the S-MC/QM the quantum calculations are performed for supermolecules formed by the solute (Sol) and the solvent water molecules in three different partitions: (i) with all water molecules until the third solvation shell described as atomic PCs, (ii) with the hydrogen-bonded water molecules (HB) described explicitly and the other as PC, and (iii) with the first solvation shell (1sh) described explicitly and the remaining as PC. All the values were calculated with B3LYP/6-31G(d). The results shown in parenthesis are obtained with the HOMO having at least $20 \%$ of contribution of the solute (see text).

Na Tabela 8 apresentamos um sumário dos resultados obtidos para os vários solutos utilizando vários modelos para o solvente. No artigo publicado existe uma discussão extensa desses resultados e suas interpretações. Aqui, neste texto, chamaremos atenção para algumas conclusões gerais: (i) comparando os resultados da molécula isolada e em solução aquosa existem algumas tendências experimentais que só são observadas corretamente com o modelo Sol+1sh+PC, ou seja, incluindo a primeira camada de solvatação e o envolvimento eletrostático. Exemplos: o potencial químico, $\mu$, dos solutos estudados deve ser negativo em água; e a dureza deve reduzir em solução aquosa. (ii) Os resultados gerados com modelo contínuo polarizável de solventes são ruim tanto qualitativamente quanto quantitativamente. (iii) Os valores dos índices de reatividade gerados com a energia do HOMO_20Sol são muito semelhantes aos gerados pelo HOMO. Este fato está relacionado à nossa observação de que existe uma grande quantidade de orbitais moleculares praticamente degenerados num intervalo muito pequeno de energia próximos do HOMO, ou seja, as configurações supermoleculares soluto-solvente, desses sistemas estudados, gera uma densidade muito grande de orbitais moleculares praticamente degenerados na região do HOMO que são decisivos nas propriedades de reatividade do sistema. Para esses sistemas estudados, existe uma grande contribuição do soluto nesse conjunto denso de orbitais, mas essa não é uma 
regra geral. Eventualmente podem existir sistemas em que esse conjunto de orbitais sejam formados majoritariamente pelo soluto ou pelo solvente ou pela combinação de ambos. Nos casos que estudamos o solvatocromismo, esse conjunto de orbitais de fronteira é composto essencialmente pelo soluto, pois no momento de realizar o experimento são escolhidos naturalmente solventes que não absorvam luz na mesma região do soluto. Desta forma, a diferença de energia HOMO-LUMO do soluto e do solvente são bem distintas, mas isso não impede que o conjunto de um desses orbitais do solvente esteja na mesma região que os orbitais do soluto. Nesses casos no espectro experimental devem aparecer novas bandas com caráter de transferência de cargas soluto-solvente. Nos casos de reações químicas, a situação é diferente. Em geral, escolhem-se os solventes que interfiram na reatividade dos solutos, ou de forma a facilitar o processo reativo ou de forma a impedi-lo. Nessas situações deve existir uma maior mistura dos orbitais do soluto e do solvente e as medidas experimentais podem refletir mais a informação do solvente que do soluto. Esse é um cuidado que tanto os experimentais como os teóricos devem ter.

\subsubsection{Journal of Chemical Physics, 132, 214507 (2010)}

Neste trabalho de autoria minha, V. G. Zakrzewski, Prof. Ortiz, Prof. Cabral e Prof. Canuto [42], anexado no Apêndice I, utilizamos a análise de delocalização dos orbitais moleculares de fronteira no sistema soluto-solvente para estudar a energia vertical de desprendimento eletrônico, VEDE (Vertical Electron Detachment Energy) do sistema aniônico de fluoreto, $F^{-}$, em solução aquosa. Como resultado experimental, estão disponíveis na literatura a quantidade de $3.40-3.45 \mathrm{eV}$ para o desprendimento eletrônico do $F^{-}$e 8.7-9.8 eV para o desprendimento eletrônico do $F^{-}$em solução aquosa. Esses resultados nos chamaram atenção por ser um efeito de solvente muito grande, cerca de 5.3$6.4 \mathrm{eV}$.

Para estudar esse sistema utilizamos o método S-QM/MM. Inicialmente realizamos as simulações de $F^{-}$em água. Em seguida, analisamos a RDF de centros de massa e identificamos 6 molécula de água na primeira camada de solvatação do $F^{-}$(até $3.2 \AA$ ), 19 águas na segunda camada (de $3.2 \AA$ até $5.5 \AA$ ) e 41 águas na terceira camada (de $5.5 \AA$ até $7.6 \AA ̊$ A). Selecionamos as configurações estatisticamente descorrelacionadas e realizamos os subsequentes cálculos quânticos. Neles, para calcular o desprendimento eletrônico do $F^{-}$em solução aquosa, utilizamos diferença de energia total do sistema neutro com o aniônico $\left(\mathrm{VEDE}=E_{q=0}-E_{q=-1}\right)$ com MP2 e B3LYP, e também P3 (perturbação de terceira ordem para resolver a equação de propagadores de Dyson). Para o $F^{-}$isolado obtivemos os seguintes resultados: 3.44, 3.46 e 3.73 eV, respectivamente. Em solução, consideramos a primeira camada de solvatação explicitamente e a segunda ou terceira como envolvimento 
eletrostático, $F^{-}+6 \mathrm{H}_{2} \mathrm{O}+\mathrm{PC}$, obtivemos $8.18 \pm 0.04 \mathrm{eV}$ com B3LYP e $9.41 \pm 0.05 \mathrm{eV}$ com P3, em excelente concordância com os dados experimentais.

Analisando a origem desse efeito de solvente tão grande, identificamos que o orbital HOMO (orbital molecular 35), do qual o elétron é arrancado, tem menos que $1 \%$ de contribuição do $F^{-}$. Sendo assim, calculando a contribuição do $F^{-}$em todos os orbitais moleculares, usando a equação 45, obtivemos o gráfico mostrado na Figura 25. Nota-se claramente que o HOMO está delocalizado nas moléculas de água ao redor do $F^{-}$e os orbitais de valência aquele que tem maior contribuição do $F^{-}$é o HOMO-13 com cerca de $55 \%$. Essa análise nos leva a concluir que o elétron excedente do sistema $F^{-}$hidratado está delocalizado na água e não no $F^{-}$.

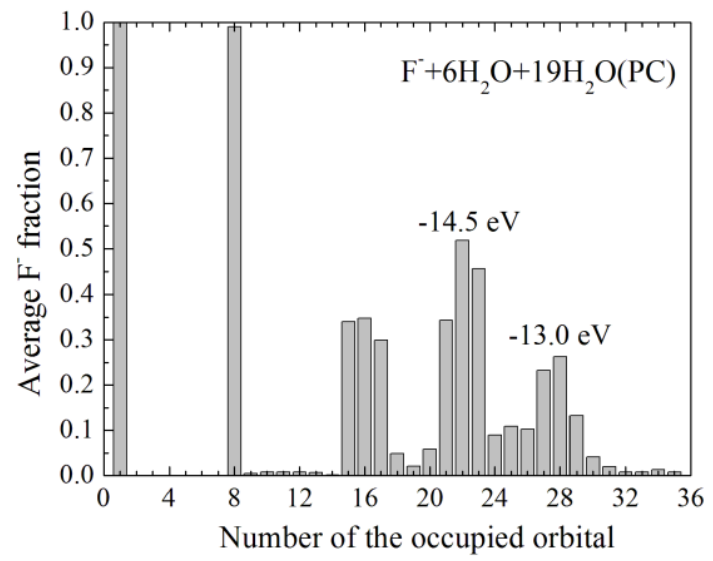

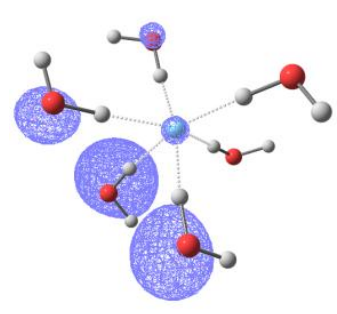

orbital 35 HOMO

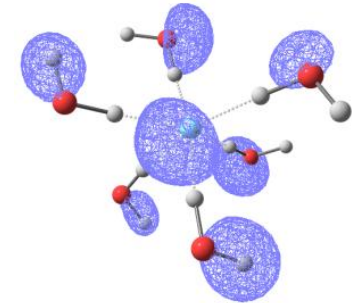

$\mathrm{e}$

orbital 22

HOMO-13

Figura 25: Contribuição do $\mathrm{F}^{-}$para os orbitais moleculares do sistema supermolecular $\mathrm{F}^{-}+6 \mathrm{H}_{2} \mathrm{O}$ e o envolvimento eletrostático de 19 moléculas de água (esquerda) e a ilustração dos orbitais HOMO e HOMO-13 (direita). Gráfico e figuras retiradas da ref. [42].

Calculando a distribuição de cargas no sistema antes e depois da retirada do elétron, $\left[\mathrm{F}+6 \mathrm{H}_{2} \mathrm{O}\right]^{-}$e $\left[\mathrm{F}+6 \mathrm{H}_{2} \mathrm{O}\right]$, obtivemos que para o sistema aniônico existe uma carga efetiva no flúor de cerca de $80 \%$ do elétron e para o sistema neutro de $70 \%$ do elétron (os valores das cargas calculados com vários métodos estão mostrados na Tabela II do artigo). Desta forma, verificamos que o processo vertical de desprendimento eletrônico se dá na seguinte forma

$$
F^{-}+6 \mathrm{H}_{2} \mathrm{O} \rightarrow\left[\mathrm{F}^{-}+6\left(\mathrm{H}_{2} \mathrm{O}\right)^{+}\right]+e^{-}
$$

ou seja, o elétron se desprende do solvente e não do $F^{-}$. Portanto, nossos resultados sugerem que a VEDE medida experimentalmente é basicamente a energia de ionização da água líquida (valores teóricos e experimentais entre 9.9-11.5 eV [106]) sob a perturbação do $F^{-}$. 


\subsection{Configuração Eletrostática Média do Solvente (ASEC)}

Nesta seção será discutido 1 trabalho publicado. Nesse trabalho, em colaboração com o aluno de doutorado H. C. Georg, sob minha orientação, Prof. T. L. Fonseca, Prof. V. Ludwig e Prof. Canuto, fizemos a proposta da configuração eletrostática média do solvente (ASEC), com a finalidade de substituir as $m$ configurações estatisticamente descorrelacionadas do soluto com envolvimento eletrostático. Para testar a ASEC realizamos cálculos do efeito de solvente em várias propriedades.

\subsubsection{Chemical Physics Letters, 437, 148 (2007)}

Neste trabalho de autoria minha, H. C. Georg, Prof. Fonseca, Prof. Ludwig e Prof. Canuto [43], anexado no Apêndice J, apresentamos pela primeira vez a ideia da configuração eletrostática média do solvente (ASEC). Essa ASEC se baseia na ideia de uma única configuração não física representar o campo eletrostático médio de várias configurações estatisticamente descorrelacionadas geradas em simulações computacionais. A descrição detalhada de como gerar a ASEC está apresentada na seção 2.6. Sendo assim, coletamos vários resultados de propriedades previamente calculadas para acetona e aminopurina em solução aquosa com $m$ configurações estatisticamente descorrelacionadas do soluto com envolvimento eletrostático e refizemos esses cálculos com as ASECs geradas para cada sistema. Para acetona em solução aquosa, as propriedades foram: o momento de dipolo polarizado $(\mu)$ usando MP2/aug-cc-pVDZ, o deslocamento solvatocrômico da transição eletrônica $n-\pi^{*}$ usando TD-B3LYP/6-33++G(d,p) e o efeito de solvente na blindagem magnética do ${ }^{13} \mathrm{C}$ e do ${ }^{17} \mathrm{O}$ usando GIAO-B3LYP/6-311++G(2d,2p). Para aminopurina em solução aquosa, as propriedades foram: o momento de dipolo polarizado usando CASSCF(12,10), a energia da transição eletrônica $\pi-\pi^{*}$ usando $\operatorname{CASSCF}(12,10)$ e CASPT2, ambos cálculos com o código MOLCAS [107]. Os resultados estão mostrados na Tabela 9. Podemos ver que os resultados com ASEC reproduzem todos os valores obtidos como média sobre $m$ configurações estatisticamente descorrelacionadas, $m=100$ no caso da acetona e 45 no caso da aminopurina. Portanto, ao invés de realizar $m$ cálculos quânticos para obter as propriedades médias é possível obter esse mesmo valor com apenas 1 cálculo quântico. A desvantagem é a perda da distribuição dos valores. Essa distribuição é interessante, mas em muitos problemas não é fundamental. Entretanto o ganho em tempo computacional é extraordinário, pois para cálculos quânticos com métodos muito sofisticados, como são os cálculos da aminopurina, que levam cerca de 12 horas de processamento, deixamos de gastar cerca de 23 dias nos 45 cálculos para gastar apenas 12 horas em um único cálculo.

Na Figura 26 à esquerda, comparamos a distribuição dos valores obtidos com 100 cálculos quânticos versus o valor obtido com ASEC (linha tracejada) para o efeito de

solvente na blindagem magnética do ${ }^{17} O$ para acetona em solução aquosa. Veja que o valor 
obtido com ASEC corresponde ao valor mais provável. Na Figura 26 à direta, comparamos as médias acumuladas versus o valor obtido com ASEC (linha tracejada) do momento de dipolo polarizado e da energia da transição eletrônica $\pi-\pi^{*}$ para aminopurina em solução aquosa. Veja que o valor obtido com ASEC corresponde à média dos 45 cálculos quânticos.

Tabela 9: Imagem das tabelas 1 e 2 retiradas da ref. [43] com os valores das propriedades calculadas como média sobre $m$ configurações estatisticamente descorrelacionadas, 100 QM e 45 QM, e com ASEC.

Table 1

Average values obtained with the average configuration (ASEC) and with 100 uncorrelated configurations (100 QM) for acetone in water

\begin{tabular}{lllll}
\hline & $\mu$ & $n-\pi^{*}$ shift & $\Delta \sigma^{\text {iso }}\left({ }^{13} \mathrm{C}\right)$ & $\Delta \sigma^{\text {iso }}\left({ }^{17} \mathrm{O}\right)$ \\
\cline { 2 - 5 } & MP2/aug- & TD-B3LYP/6- & B3LYP/6- & \\
& cc-pVDZ & $311++\mathrm{G}(\mathrm{d}, \mathrm{p})$ & $311++\mathrm{G}(2 \mathrm{~d}, 2 \mathrm{p})$ \\
\hline ASEC & 4.79 & 0.31 & -20.5 & 120.5 \\
$100 \mathrm{QM}$ & $4.80 \pm 0.03$ & $0.31 \pm 0.01$ & $-20.5 \pm 0.4$ & $120.3 \pm 2.1$ \\
\hline
\end{tabular}

Dipole in Debye, energy in eV and NMR shieldings in ppm.

Table 2

Average values obtained using the average configuration (ASEC) and 45 uncorrelated configurations (45 QM) for the $\mathrm{N} 9 \mathrm{H}$ tautomer of aminopurine in water

\begin{tabular}{llll}
\hline & $\mu(\mathrm{D}) \mathrm{CASSCF}$ & & $\Delta E(\mathrm{eV})$ CASPT2 \\
\cline { 2 - 4 } & Ground state & Excited state $\pi-\pi^{*}$ & $\pi-\pi^{*}$ transition \\
\hline ASEC & 5.57 & 6.94 & 4.02 \\
$45 \mathrm{QM}$ & $5.60 \pm 0.12$ & $6.92 \pm 0.21$ & $4.02 \pm 0.02$ \\
\hline
\end{tabular}
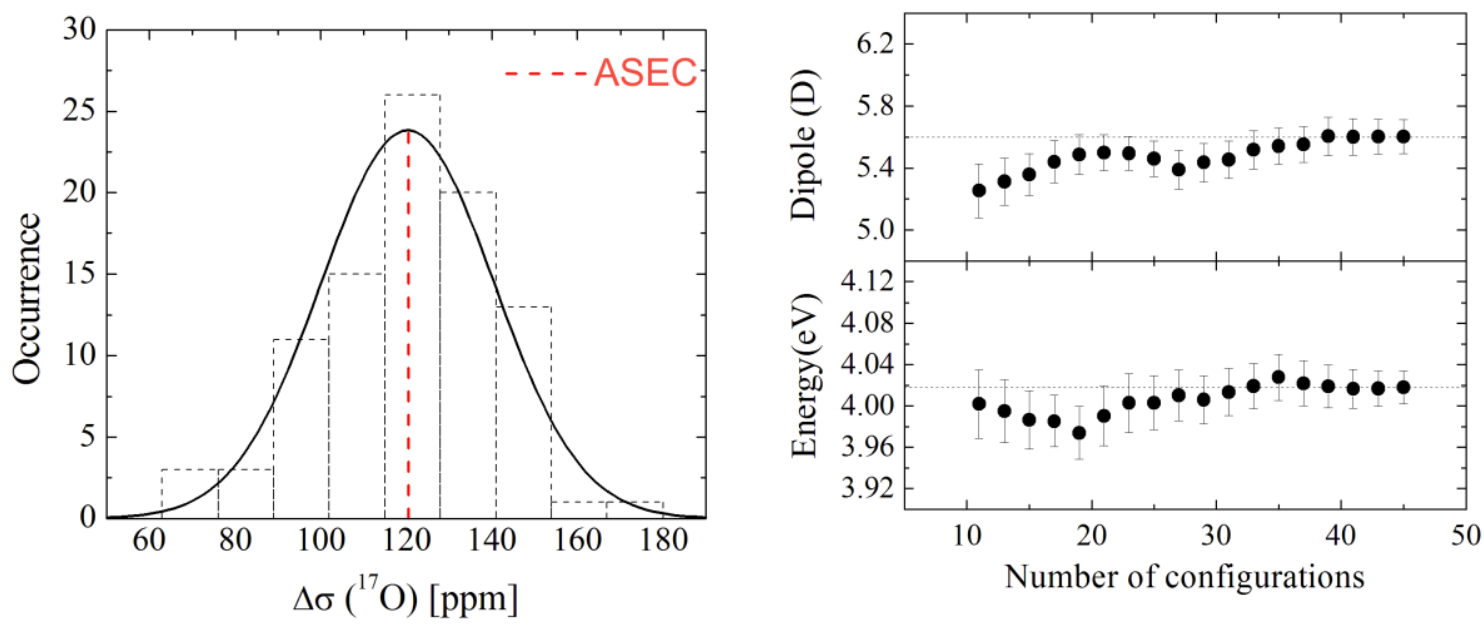

Figura 26: Comparação da distribuição, ou médias acumuladas, de valores obtidos com $m$ cálculos quânticos versus o valor obtido com ASEC (linha tracejada): (esquerda) distribuição dos valores para o efeito de solvente na blindagem magnética do ${ }^{17} O$ para acetona em solução aquosa e (direita) médias acumuladas do momento de dipolo polarizado e da energia da transição eletrônica $\pi-\pi^{*}$ para aminopurina em solução aquosa. Gráficos retirados da ref. [43]. 
Um aspecto importante de chamar atenção é que o ASEC reproduz o valor médio de propriedades calculadas apenas com o envolvimento eletrostático do solvente. Nesse caso, não existem moléculas explícitas do solvente. Portanto, caso seja necessário incluir explicitamente moléculas de solvente a vantagem do ASEC se desfaz e é necessário novamente realizar os $m$ cálculos quânticos.

A partir de 2007, os trabalhos que sucederam este, passaram a utilizar a ASEC para cálculos dos efeitos do campo eletrostático de solventes.

\subsection{Procedimento de Polarização Iterativo}

Nesta seção serão discutidos 2 trabalhos publicados.

No primeiro trabalho, que faz parte da tese de doutorado do aluno H. C. Georg [105] sob minha orientação, apresentamos pela primeira vez a ideia do procedimento de polarização do soluto de forma iterativa com S-QM/MM. Como aplicação desse procedimento, calculamos o momento de dipolo polarizado da acetona em solução aquosa e conferimos os efeitos dessa polarização no cálculo do solvatocromismo da transição $n$ - $\pi^{*}$ dessa molécula.

No segundo trabalho, em colaboração com a pós-doutora C. Vequi-Suplicy, Prof. H. Stassen e W. Nitschke (estudante de seu grupo), utilizamos a polarização da molécula de prodan em diversos ambientes para estudar as interações dessa molécula com uma bicamada lipídica. A polarização da molécula de prodan em diversos solventes foi parte da tese de doutorado da aluna C. Vequi-Suplicy [108], sob minha co-orientação.

\subsubsection{Chemical Physics Letters, 429, 119 (2006)}

Neste trabalho de autoria minha, H. C. Georg e Prof. Canuto [44], anexado no Apêndice $\mathrm{K}$, apresentamos pela primeira vez a ideia do procedimento de polarização de solutos de forma iterativa com S-QM/MM. Essa polarização se baseia em fazer uma sequência de simulações e cálculos quânticos para gerar um conjunto de cargas atômicas polarizadas do soluto que estejam em equilíbrio com a distribuição de solventes ao seu redor e conjuntamente que o solvente esteja em equilíbrio com esse conjunto de cargas polarizadas do soluto. A descrição detalhada desse procedimento está apresentada na seção 2.7. Como aplicação desse procedimento, estudamos a polarização da molécula de acetona devido à presença da solução aquosa. Adicionalmente, estudamos os efeitos dessa polarização na estrutura da água ao redor da acetona e como isso afeta o deslocamento da transição $n$ - $\pi^{*}$ de absorção eletrônica da acetona. A escolha da acetona (soluto polar) se deu por ser uma molécula amplamente utilizada pelos teóricos para testes de novas metodologias. Como 
resultados experimentais, estavam disponíveis as informações que a primeira banda de absorção eletrônica da acetona é do tipo $n-\pi^{*}$ e apresenta um deslocamento devido à presença da água de $1500-1700 \mathrm{~cm}^{-1}$ e o momento de dipolo medido em gás de $2.93 \mathrm{D}$.

O procedimento de polarização iterativo foi aplicado utilizando para cálculo do dipolo e cargas o método ab initio MP2/aug-cc-pVDZ/CHELPG e os principais resultados desse procedimento estão mostrados na Figura 27.
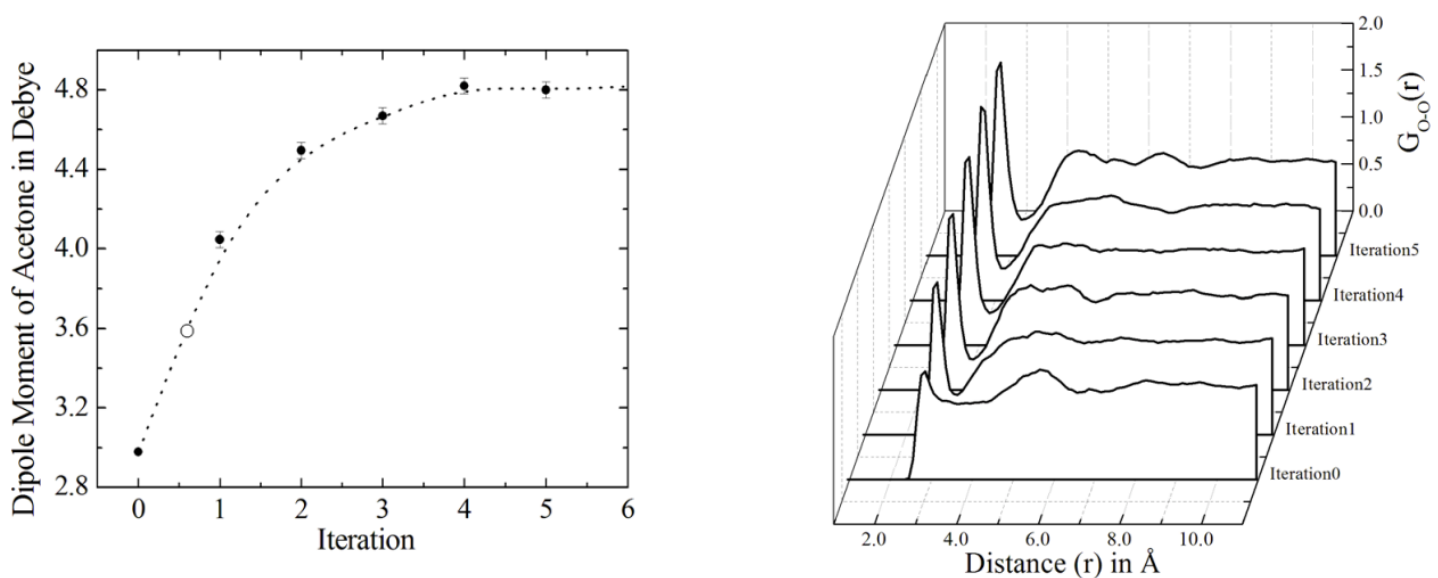

Figura 27: (esquerda) Variação do momento de dipolo da acetona em água durante o procedimento de polarização iterativo. O ponto branco representa o dipolo calculado da forma padrão; (direita) Variação da RDF, $G_{O O}(r)$, durante o procedimento de polarização. Gráficos retirados da ref [44].

Na esquerda, o procedimento é iniciado com o dipolo da molécula isolada de $2.98 \mathrm{D}$ (que está em excelente concordância com o valor experimental) e após a polarização em água se estabiliza em 4.80 D (que também está em boa concordância com os resultados obtidos por outros métodos teóricos entre 4.44 e $4.90 \mathrm{D}$, ver a parte de baixo da Tabela 10). Isso representa um aumento de $61 \%$, bem maior que o $21 \%$ que seria usado devido ao procedimento padrão de cálculos das cargas nos campos de força clássicos $(3.60 \mathrm{D})$. Na direita dessa figura, mostramos como a RDF entre oxigênios da acetona e águas, $G_{O o}(r)$, varia ao longo do procedimento de polarização em água. O primeiro pico, por volta de $2.8 \AA$, que caracteriza das ligações de hidrogênio vai crescendo à medida que a acetona vai se polarizando, mudando a quantidade de ligações de hidrogênio de 1.6 a 2.7. Isso é um reflexo do aumento da carga atômica no oxigênio da acetona (ver na parte de cima da Tabela 7 e da Tabela 10). É interessante notar que a reorganização das moléculas de água ao redor da acetona é visível à medida que essa se polariza e que, portanto, esse é um efeito importante que não pode ser desprezado. O solvatocromismo da transição $n-\pi^{*}$ da acetona muda de 965 $\pm 31 \mathrm{~cm}^{-1}$ (não polarizado) para $1650 \pm 42 \mathrm{~cm}^{-1}$ (polarizado), mostrando como a inclusão da polarização do soluto é relevante para o cálculo correto das propriedades. Os valores calculados para o momento de dipolo da acetona isolada e em água e o solvatocromismo estão mostrados na parte de baixo da Tabela 10, juntamente com os resultados obtidos por 
outros autores com outros métodos. Nossos resultados estão em muito bom acordo com os resultados obtidos por outros métodos.

Tabela 10: Imagem das tabelas 1 e 3 retiradas da ref. [44] (em cima) com as cargas atômicas e momento de dipolo da acetona ao longo do procedimento de polarização em água, e (embaixo) com os valores calculados para o solvatocromismo da transição eletrônicas $n-\pi^{*}$, momento de dipolo em gás e polarizado. Nossos resultados estão comparados com os resultados obtidos com outros métodos.

Table 1

Calculated average values of the atomic charges obtained from CHELPG fitting and dipole moments (in Debye) from MP2/aug-cc-pVDZ calculations using 100 statistically uncorrelated MC configurations

\begin{tabular}{lllllll}
\hline Iteration step & 0 (Gas phase) & 1 (In-solution) & 2 (In-solution) & 3 (In-solution) & 4 (In-solution) & 5 (In-solution) \\
\hline$Q(\mathrm{O})$ & -0.5318 & -0.6562 & -0.6998 & -0.7169 & -0.7226 & -0.7307 \\
$Q(\mathrm{C} 1)$ & 0.6843 & 0.7685 & 0.7866 & 0.7881 & 0.7814 & 0.7953 \\
$Q(\mathrm{C} 2)$ & -0.3378 & -0.3619 & -0.3648 & -0.3641 & -0.3580 & -0.3627 \\
$Q(\mathrm{H} 1)$ & 0.0952 & 0.1036 & 0.1038 & 0.1061 & 0.1006 & 0.1050 \\
$Q(\mathrm{H} 2$ and H3) & 0.0832 & 0.1011 & 0.1088 & 0.1112 & 0.1140 & 0.1127 \\
$\mu$ & 2.98 & $4.05 \pm 0.03$ & $4.50 \pm 0.03$ & $4.67 \pm 0.03$ & $4.82 \pm 0.03$ & $4.80 \pm 0.03$ \\
\hline
\end{tabular}

See Fig. 1 for the atom types. Uncertainties are statistical errors (standard deviations are 10 times larger).

Table 3

Calculated solvatochromic shift of the $n-\pi^{*}$ transition and dipole moments of acetone, isolated and polarized in-water

\begin{tabular}{llllll}
\hline & Present & Ref. [14] & Ref. [18] & Ref. [25] & Experimentals \\
\hline$\Delta E\left(\mathrm{~cm}^{-1}\right)$ & 1650 & 1103 & 2345 & 2016 & $\begin{array}{l}1500-1700 \\
{[26-28]}\end{array}$ \\
& & & & & $2.93[34]$ \\
$\mu_{\text {gas }}(\mathrm{D})$ & 2.98 & 2.92 & 2.90 & 3.08 & - \\
$\mu_{\text {in-solution }}(\mathrm{D})$ & 4.80 & 4.44 & 4.52 & 4.90 & - \\
\hline
\end{tabular}

See text.

É interessante ressaltar aqui que, em cada ponto no processo de polarização (ver Figura 27 à esquerda) foram realizados 100 cálculos quânticos do soluto com envolvimento eletrostático, totalizando 500 cálculos quânticos em todo o processo. Porém após desenvolvermos o procedimento de gerar a configuração eletrostática média do solvente, ASEC, cada um desses 100 cálculos pode ser substituído por um cálculo apenas. Isso faz com que sejam necessários apenas 5 cálculos quânticos e o processo de polarização fica muito mais eficientes. Sendo assim, trabalhos futuros a este, utilizaram a ASEC no procedimento iterativo de polarização.

\subsubsection{Journal of Physical Chemistry B, 116, 2713 (2012)}

Neste trabalho de autoria minha, W. K. Nitschke, C. Vequi-Suplicy e Prof. Stassen [45], anexado no Apêndice L, estudamos como a molécula de prodan, que é uma sonda fluorescente muito utilizada como sensor de bicamadas lipídicas, interagem com a bicamada hidratada de DLPC (dilauroil-fosfatidilcolina) utilizando diferentes conjuntos de distribuição de cargas: não polarizado (CS1), polarizado em ciclohexano (CS2), polarizado em água (CS3) e polarizado em água no primeiro estado excitado (CS4). 
$\mathrm{O}$ processo de polarização do prodan em quatro solventes, ciclohexano $\left(C_{6} H_{12}\right)$, diclorometano $\left(\mathrm{CH}_{2} \mathrm{Cl}\right)_{2}$, acetonitrila $\left(\mathrm{CH}_{3} \mathrm{CN}\right)$ e água $\left(\mathrm{H}_{2} \mathrm{O}\right)$, foi realizado na tese de doutorado da aluna C. Vequi-Suplicy [108], utilizando a MDDF para definir as camadas de solvatação e o procedimento iterativo S-QM/MM para polarização utilizando o envolvimento eletrostático do prodan com ASEC e cálculo das cargas atômicas com MP2/aug-ccpVDZ/CHELPG. Na Figura 28, mostramos à esquerda as MDDFs do prodan nos vários solventes e à direita a variação do momento de dipolo do prodan durante o processo de polarização nos vários solventes. É interessante notar que, como esperado, o dipolo varia pouquíssimo quando a molécula está isolada $(5.8 \mathrm{D})$ e é colocada em solução de ciclohexano (6.1 D). Porém para diclorometano (7.7 D), acetonitrila $(8.0 \mathrm{D})$ e água (10.2 D), já notamos aumentos no momento de dipolo de 33\%, 38\% e 76\%, respectivamente. Esses resultados, com exceção da água que forma ligações de hidrogênio, estão em muito bom acordo com os valores obtidos com o modelo de solvente contínuo polarizável (PCM) [12].
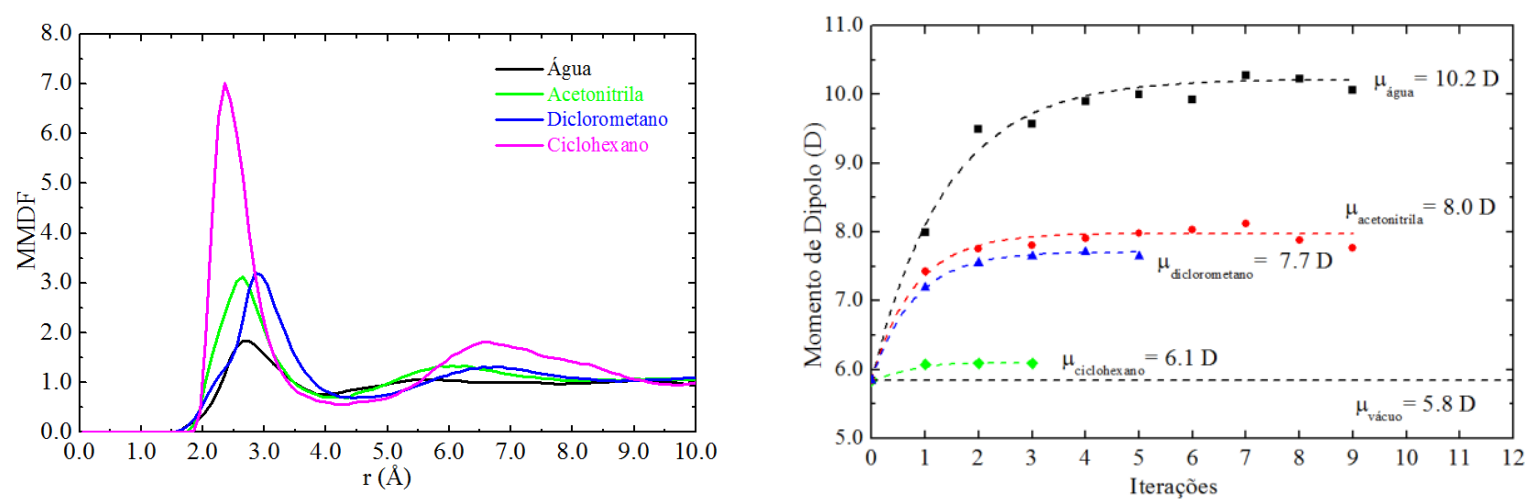

Figura 28: (esquerda) MDDFs e (direita) variação do momento de dipolo durante o processo de polarização da molécula de prodan em vários solventes. Gráficos retirados da ref. [108].

Utilizando essas cargas atômicas da molécula de prodan no campo de força GROMOS57a6, realizamos simulações computacionais do prodan em bicamada hidratada de DLPC com método de dinâmica molecular, programa GROMACS [109]. Na caixa de simulação foram colocadas duas camadas de 13x13 lipídios, totalizando 338 lipídios, 17529 moléculas de água e 2 moléculas de prodan com conjuntos de carga diferentes. As moléculas de prodan foram colocadas em duas posições iniciais, no centro da bicamada e na interface água-lipídio. Os passos de simulação foram 2 fs e no tempo total de cada simulação foi de $100 \mathrm{~ns}$, onde só os últimos 60 ns foram utilizados para análise. Na Figura 29, na parte de cima mostramos a ilustração do sistema simulação (esquerda) e da posição inicial das duas moléculas de prodan no meio da bicamada (direita), na parte central mostramos a ilustração da posição final do prodan com conjunto de cargas não polarizadas, CS1 (esquerda) e polarizado em água, CS3 (direita), e na parte de baixo mostramos os gráficos de densidade eletrônica do sistema todo, das moléculas de água, dos lipídios e da molécula de prodan com 
os diferentes conjuntos de carga (esquerda) e das RDFs entre o oxigênio do prodan e as moléculas de água e alguns grupos funcionais dos lipídios.
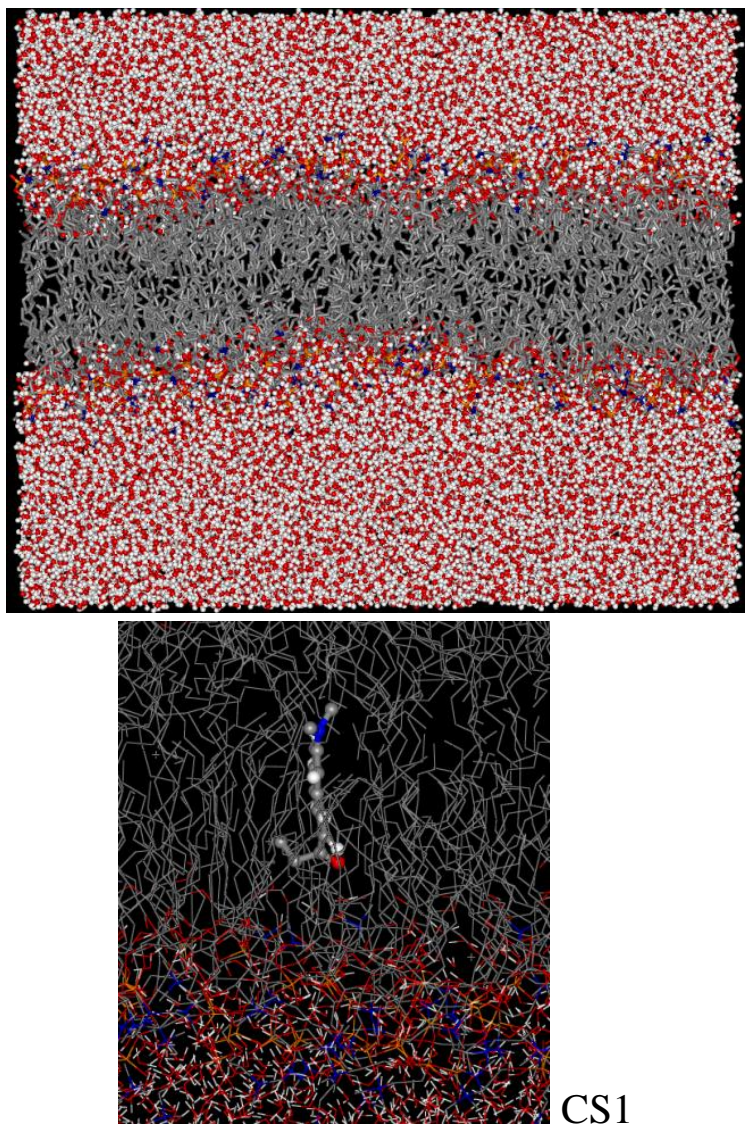

$\varrho_{e l} / \mathrm{e} / \mathrm{nm}^{3}$

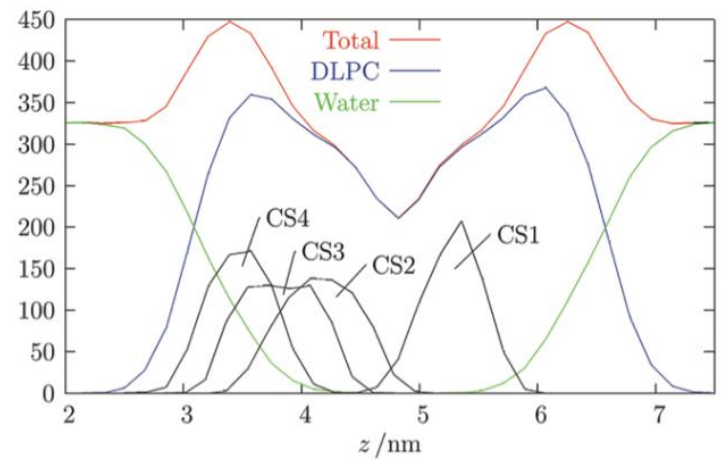

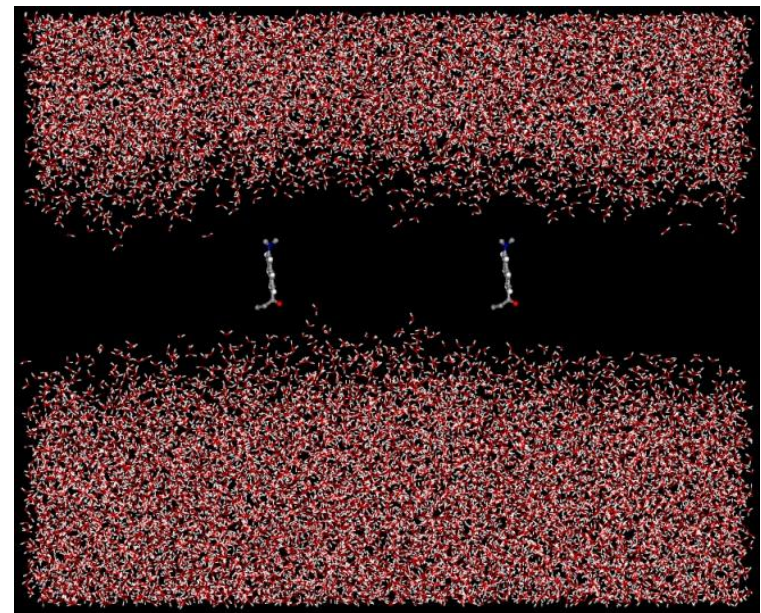

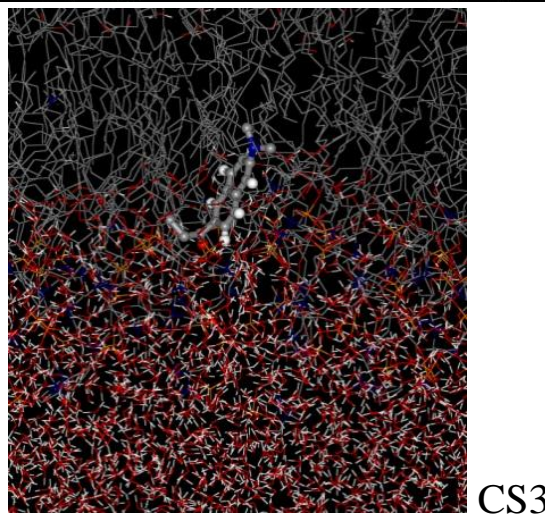

$g(r)$

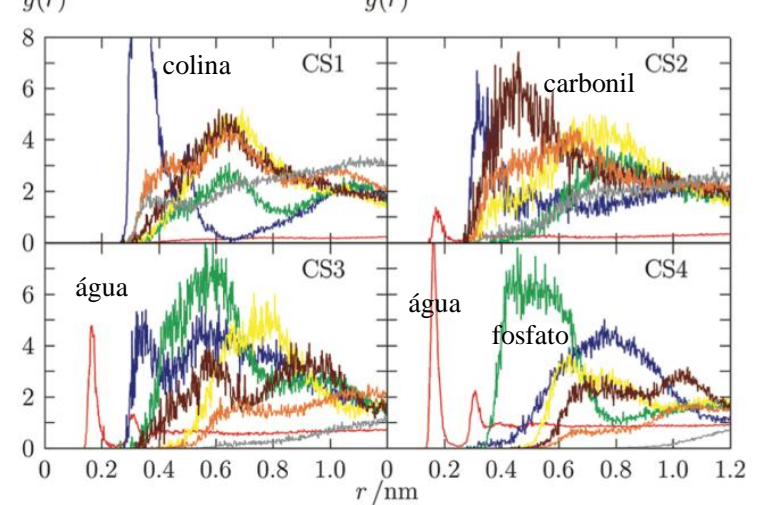

Figura 29: Ilustração da bicamada de DLPC hidratada (em cima esquerda), posicionamento inicial de 2 moléculas de prodan com conjuntos de cargas diferentes (em cima direita), posicionamento final do prodan com conjunto de cardas CS1 (centro esquerda) e CS3 (centro direita), gráficos do perfil de densidade eletrônica total do sistema simulado, das moléculas de água, da bicamada de DLPC e da molécula de prodan com os diferentes conjuntos de cargas (embaixo esquerda) e RDFs entre o oxigênio do prodan e moléculas de água (vermelho) e diferentes grupos funcionais dos DLPCs: colina (azul), fosfato (verde), glicerol (amarelo), carbonil (marrom), primeiros 5 grupos metil da cadeia alifática (laranja) e últimos 6 grupos metil (cinza). Os gráficos retirados da ref. [45]. 
Analisando o gráfico de densidade eletrônica da Figura 29 (embaixo esquerda) podemos perceber que a molécula de prodan escolhe posições diferentes da bicamada dependendo do seu conjunto de cargas. Quando não polarizada, CS1, e polarizada em ciclohexano, CS2, o prodan fica posicionado próximo ao centro da bicamada, imerso nas cadeias alifáticas dos lipídios. Porém quando polarizado em água, tanto do estado fundamental, CS3, como no estado excitado, CS4, o prodan se posiciona próximo às cabeças polares dos lipídios e exposto a hidratação, formando ligações de hidrogênio com as águas, como pode ser vista nas RDFs através dos picos na região inferior a $0.2 \mathrm{~nm}$.

Analisando também as RDFs, na Figura 29 (embaixo direita) podemos verificar que dependendo do conjunto de cargas a molécula de prodan interage mais fortemente com grupos diferentes dos lipídios: prodan com CS1 interage mais proximamente do grupo colina, prodan com CS2 dos grupos colina e carbonil, prodan com CS3 interage mais proximamente das águas e dos grupos colina e fosfato e prodan com CS4 das águas e do grupo fosfato. Sendo assim, mostramos que para sondas sensoras de ambiente, considerar sua polarização com o meio é fundamental e decisivo para compreensão de seu funcionamento e percepção do meio que a envolve.

Atualmente, em nosso grupo, estamos estendendo o procedimento de polarização iterativo com S-QM/MM para meios heterogêneos. De tal forma que possamos analisar a polarização de moléculas como prodan dentro da bicamada lipídica.

\subsection{Cálculos de Variação de Energia Livre}

Nesta seção serão discutidos 4 trabalhos publicados.

No primeiro trabalho, em colaboração com o aluno de doutorado M. Z. Hernandes, seu orientador Prof. R. Longo, e Prof. Canuto, fizemos estudo da transferência intramolecular de carga associado com a rotação do ângulo entre os grupos doador e receptor de cargas da betaina piridium-N-fenóxido em solução aquosa. Nesse trabalho, pela primeira vez utilizamos cálculos de variação de energia livre no estudo de solução. O aluno M. Z. Hernandes esteve visitando nosso grupo por 3 meses para dar início no desenvolvimento desse trabalho que foi continuado após seu regresso ao DQF/UFPE, sua instituição de origem.

No segundo trabalho, em colaboração com Prof. T. L. Fonseca e L. B. A. Oliveira (estudante de seu grupo), e Prof. Canuto, revisitamos o estudo da betaina piridinium-Nfenóxido só que agora incluindo a polarização do soluto devido a presença da água e analisamos os efeitos dessa polarização tanto na transferência intramolecular da carga como em seu deslocamento solvatocrômico. 
No terceiro trabalho, em colaboração com Prof. W. R. Rocha e C. P. Lima (estudante de seu grupo), e Prof. Canuto, fizemos o estudo do processo de tautomerização da molécula de mercaptopirimidina isolada e em solução aquosa.

No quarto trabalho, que faz parte da dissertação de mestrado do aluno M. V. A. Damasceno [110] sob minha orientação, estudamos a estabilidade conformacional cis-trans da molécula de óxido mesitil em solução aquosa e seus efeitos no deslocamento solvatocrômico devido a solução aquosa.

\subsubsection{Physical Chemistry Chemical Physics, 6, 2088 (2004)}

Neste trabalho de autoria minha, M. Z. Hernandes, Prof. R. Longo e Prof. Canuto [46], anexado no Apêndice $M$, fizemos estudo da transferência intramolecular de carga associado com a rotação do ângulo entre os grupos doador e receptor de cargas da betaina piridinium$\mathrm{N}$-fenóxido, também conhecida como orto-betaina, em solução aquosa. Realizando cálculos quânticos da orto-betaina isolada, verificamos que rotacionando o ângulo, $\varphi$, entre os anéis piridinium e fenóxido havia uma considerável mudança no valor do momento de dipolo devido à transferência intramolecular de carga principalmente entre o nitrogênio do piridinium e o oxigênio do fenóxido (ver Figura 30 à esquerda). Nesses cálculos identificamos que a conformação mais estável da orto-betaina isolada é com $\varphi=30^{\circ}$ (ver Figura 30 à direita (a)).
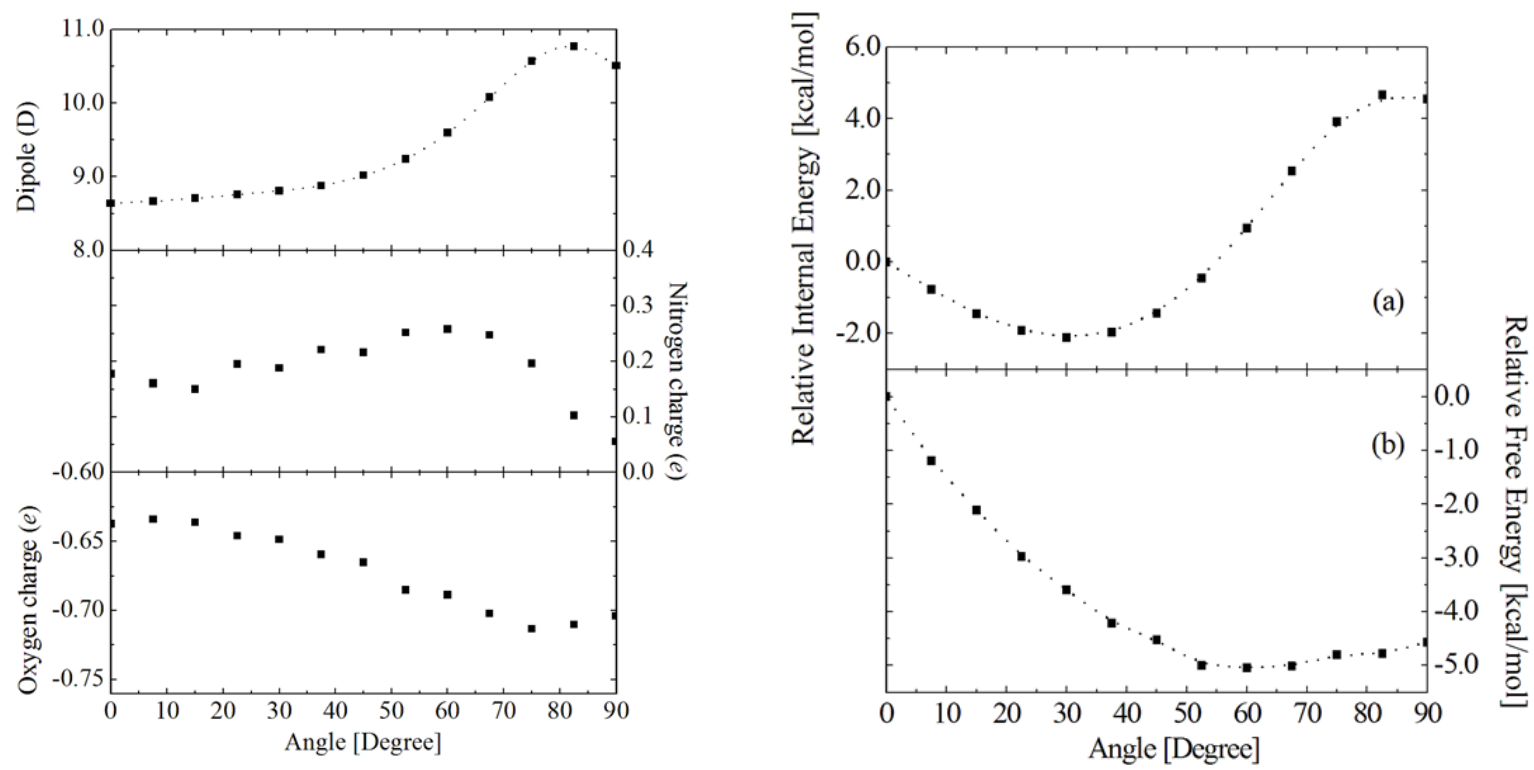

Figura 30: Variação do momento de dipolo e cargas do nitrogênio e oxigênio da orto-betaina isolada (direita) e perfil da energia interna da orto-betaina isolada e da energia livre em solução (esquerda) em relação ao ângulo de torção $\varphi$ entre os anéis piridinium e fenóxido. Gráficos retirados da ref. [46]. 
Como nos campos de força as cargas atômicas são fixas para qualquer geometria, decidimos fazer simulações separadas para cada ângulo de torção com seu respectivo conjunto de cargas, para o posterior cálculo do solvatocromismo com relação ao ângulo de torção. Na Figura 31 mostramos os deslocamentos da transição $n$ - $\pi$ * da orto-betaina isolada e em solução considerando 120 moléculas de água explicitamente incluídas nos cálculos quânticos. Cada ponto sólido nesse gráfico representa a média sobre 61 configurações estatisticamente descorrelacionadas.

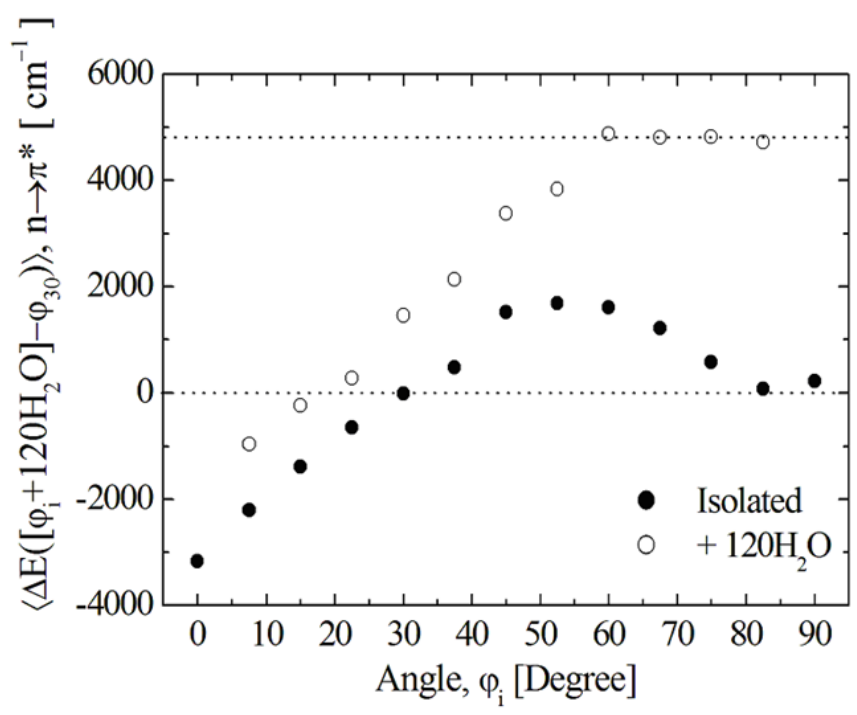

Figura 31: Deslocamento solvatocrômico da transição $n-\pi^{*}$ da orto-betaina isolada e em solução aquosa em relação ao ângulo de torção. Gráfico retirado da ref. [46].

Porém ficou uma questão em aberto: qual deveria ser o ângulo mais estável em solução? Para responder essa pergunta, implementamos o método FEP (ver descrição detalhada na seção 2.8) para cálculos de variação de energia livre em solução. Não utilizamos modelo contínuo de solvente nesse tipo de cálculo devido à formação de ligações de hidrogênio entre o soluto e solvente que não seriam consideradas. Nesse trabalho, então, pela primeira vez utilizamos cálculos de variação de energia livre em solução utilizando FEP. Para isso, realizamos 6 simulações com $\varphi=7.5^{\circ}, 22.5^{\circ}, 37.5^{\circ}, 52.5^{\circ}, 67.5^{\circ}$ e $82.8^{\circ}$, e utilizando a técnica de amostragem dupla e calculamos as diferenças de energia livre para rotacionar o ângulo $\varphi$. Exemplo: na primeira simulação foram calculados $\Delta G\left(7.5^{\circ} \rightarrow 0^{\circ}\right) \mathrm{e}$ $\Delta G\left(7.5^{\circ} \rightarrow 15^{\circ}\right)$. O perfil obtido está mostrado na Figura 30 à esquerda (b). Veja que o perfil mudou, com mínimo em $\varphi=30^{\circ}$ para molécula isolada e mínimo em $\varphi=60^{\circ}$ para molécula em solução aquosa. Considerando essa informação, na Tabela 11 apresentamos um sumário dos resultados encontrados para o deslocamento das transições $n$ - $\pi^{*}$ e $\pi-\pi^{*}$ da ortobetaina devido à mudança conformacional (de $\varphi=30^{\circ}$ para $\varphi=60^{\circ}$ ) e ao efeito do solvente. 
Tabela 11: Imagem da tabela 2 retirada da ref. [46] com o sumário do deslocamento das transições $n$ - $\pi^{*}$ e $\pi-\pi^{*}$ da orto-betaina devido à mudança conformacional e ao efeito do solvente.

Table 2 Transition energies (in $\mathrm{cm}^{-1}$ ) and solvatochromic shift (in $\left.\mathrm{cm}^{-1}\right)$ for the ortho-betaine in the gas phase $\left(\varphi=30^{\circ}\right)$ and aqueous solution $\left(\varphi=60^{\circ}\right)$

\begin{tabular}{|c|c|c|}
\hline \multirow[b]{2}{*}{ Gas phase } & \multicolumn{2}{|l|}{ Transition } \\
\hline & $\pi \rightarrow \pi^{*}$ & $\mathrm{n} \rightarrow \pi^{*}$ \\
\hline Transition energy $\left(\varphi_{30}\right)$ & 15612 & 22798 \\
\hline Transition energy $\left(\varphi_{60}\right)$ & 13626 & 24405 \\
\hline$\Delta E\left(\varphi_{60}-\varphi_{30}\right)$ & -1986 & 1607 \\
\hline \multicolumn{3}{|c|}{$\Delta E=$ transition energy at $60^{\circ}-$ transition energy at $30^{\circ}$} \\
\hline$\left\langle\Delta E\left(\left[\varphi_{60}+\mathrm{HB}\right]-\varphi_{30}\right)\right\rangle^{a}$ & $-1234 \pm 40$ & $3136 \pm 69$ \\
\hline$\left\langle\Delta E\left(\left[\varphi_{60}+30 \mathrm{H}_{2} \mathrm{O}\right]-\varphi_{30}\right)\right\rangle$ & $-162 \pm 107$ & $3456 \pm 114$ \\
\hline$\left\langle\Delta E\left(\left[\varphi_{60}+50 \mathrm{H}_{2} \mathrm{O}\right]-\varphi_{30}\right)\right\rangle$ & $36 \pm 111$ & $4578 \pm 120$ \\
\hline$\left\langle\Delta E\left(\left[\varphi_{60}+120 \mathrm{H}_{2} \mathrm{O}\right]-\varphi_{30}\right)\right\rangle$ & $389 \pm 98$ & $4955 \pm 94$ \\
\hline$\left\langle\Delta E\left(\left[\varphi_{60}+150 \mathrm{H}_{2} \mathrm{O}\right]-\varphi_{30}\right)\right\rangle$ & $483 \pm 80$ & $5230 \pm 85$ \\
\hline$\left\langle\Delta E\left(\left[\varphi_{60} \text { bulk limit }\right]-\varphi_{30}\right)\right\rangle^{b}$ & $1026 \pm 69$ & $6060 \pm 89$ \\
\hline Net solvent effects & $3012 \pm 69$ & $4453 \pm 89$ \\
\hline
\end{tabular}

Nosso melhor resultado para o deslocamento solvatocrômico é $1026 \pm 69 \mathrm{~cm}^{-1}$ para transição $\pi-\pi^{*}$ e $6060 \pm 89 \mathrm{~cm}^{-1}$ para transição $n-\pi^{*}$. O resultado experimental é um deslocamento de $7552 \mathrm{~cm}^{-1}$ comparativamente a mudança do solvente de tolueno para água. Considerando que tolueno é um solvente de baixa polaridade o deslocamento gás-água deve ser muito próximo do tolueno-água. Nossas conclusões foram que: existe uma transferência de carga intramolecular associada à rotação da orto-betaina que tem uma conformação mais estável em $\varphi=30^{\circ}$ para solventes de baixa polaridade e em $\varphi=60^{\circ}$ para água; considerar essa relaxação do soluto (mudança do $\varphi$ ) é muito importante; e com relação ao deslocamento solvatocrômico, na transição $\pi-\pi^{*}$ o efeito de relaxação do soluto tem contribuição contrária $\left(-1986 \mathrm{~cm}^{-1}\right)$ ao efeito da solução aquosa $\left(3012 \pm 69 \mathrm{~cm}^{-1}\right)$, enquanto que na transição $n-\pi^{*}$ ambos os efeitos são positivos $\left(1607 \mathrm{~cm}^{-1}\right.$ e $4453 \pm 89 \mathrm{~cm}^{-1}$, respectivamente).

Nosso resultado só é bom comparativamente ao deslocamento solvatocrômico experimental, se considerarmos o valor calculado para a transição $n-\pi^{*}$, porém é sabido que em geral a transição $n-\pi^{*}$ tem baixa intensidade e a $\pi-\pi^{*}$ tem alta intensidade. Portanto, existe uma grande possibilidade que o experimental esteja observando a transição $\pi$ - $\pi^{*}$ e não a $n-\pi^{*}$. Entramos em contato com o grupo experimental que realizou a medida para nos esclarecer quanto à observação de duas ou uma banda, mas eles não tinham mais o espectro 
disponível, nem a amostra para realizar medidas adicionais. Tentamos o grupo que sintetizou a amostra, mas o professor encarregado havia falecido e a única possibilidade de obter os espectros novamente seria através da rota de síntese publicada. Contatamos um grupo experimental para realizar a síntese, mas após 2 anos de tentativa eles desistiram, pois com a rota publicada falta uma etapa que não permite estabilizar o composto. Sendo assim, ficamos com essa questão em aberto com relação a esse sistema.

\subsubsection{Chemical Physics Letters, 514, 251 (2011)}

Neste trabalho de autoria minha, L. B. A. Oliveira, Prof. T. L. Fonseca e Prof. Canuto [47], anexado no Apêndice N, revisitamos o estudo da betaina piridium-N-fenóxido (ortobetaina) só que agora com métodos $a b$ initio, TD-DFT, para cálculo do deslocamento solvatocrômico e incluindo polarização na orto-betaina devido a presença da água. A polarização da orto-betaina em solução aquosa foi obtida através do procedimento iterativo S-QM/MM (ver seção 2.7 para descrição detalhada) utilizando o envolvimento eletrostático com ASEC e método MP2/cc-pVDZ/CHELPG para os vários ângulos $\varphi$. Na Figura 32 mostramos a variação do momento de dipolo não polarizado e polarizado da orto-betaina variando com o ângulo $\varphi$. É interessante notar que o dipolo polarizado é bastante grande ( 12 D) mesmo para ângulos $\varphi$ pequenos e a sua variação com o ângulo $\varphi$ é pequena (de 11.6 a 12.4 D) após considerar o processo de polarização do soluto. Isso mostra que a presença da água gera uma grande separação de carga na molécula de orto-betaina independentemente do valor do ângulo $\varphi$, assumido por ela.
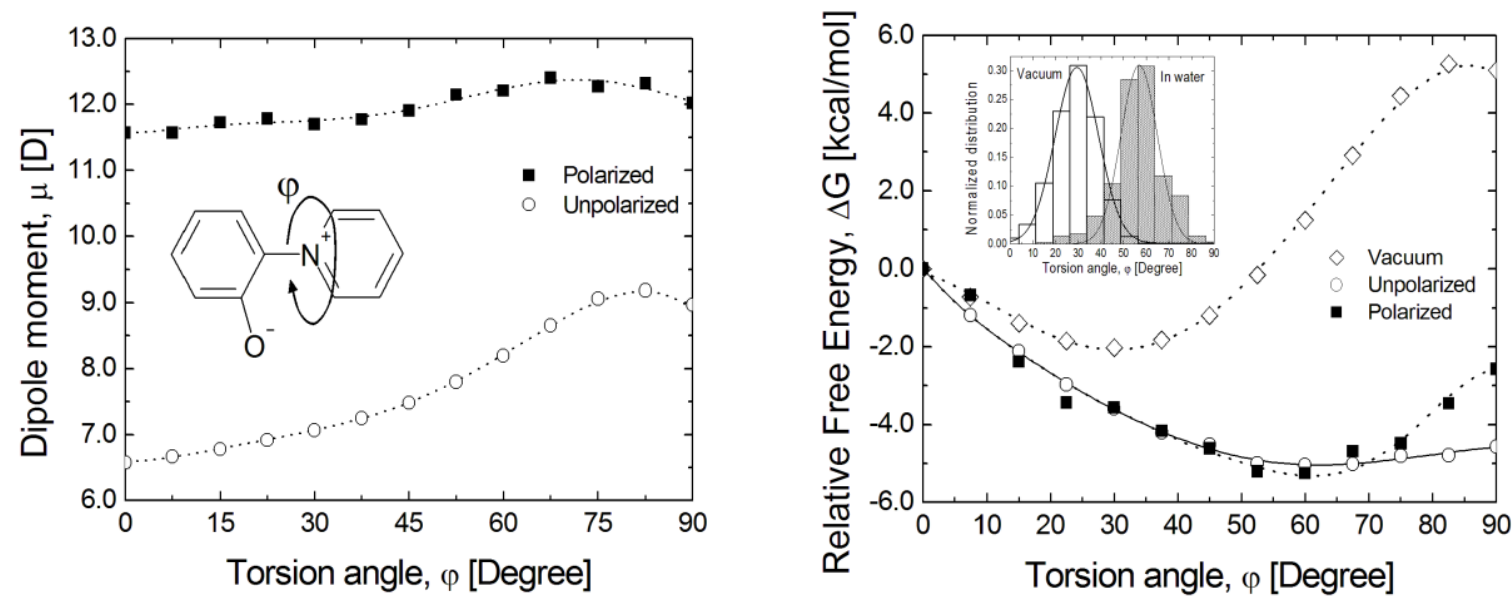

Figura 32: Variação do momento de dipolo não polarizado e polarizado da orto-betaina (esquerda) e perfil da energia interna (vácuo) e da energia livre com a orto-betaina não polarizada e polarizada (direita) variando com o ângulo $\varphi$. Gráficos retirados da ref. [47]. 
Considerando os conjuntos de cargas atômicas polarizadas, realizamos os cálculos das variações de energia livre de forma análoga ao do trabalho anterior [46]. O perfil de energia livre obtido está mostrado na Figura 32 (direita). Note que o único efeito da polarização no perfil de energia livre é produzir um vale mais profundo em torno de $\varphi=60^{\circ}$ através do aumento da barreira próxima de $\varphi=90^{\circ}$. Desta forma, a orto-betaina fica confinada num ângulo próximo de $60^{\circ}$, enquanto que sem a polarização ela ficava livre para visitar ângulos entre $60^{\circ}$ e $90^{\circ}$. Esse novo resultado está em concordância com outro resultado teórico obtido com dinâmica de Car-Parrinello combinada com simulação computacional (CP-QM/MM). Com relação às transições $\pi-\pi^{*}$ e $n-\pi^{*}$ da orto-betaina, testamos os seguintes funcionais: B3LYP, PBE1PBE, BHandHLYP, CAM-B3LYP e LC-wPBE, para molécula isolada e em água. Comparando os valores calculados com os valores experimentais obtidos em solução de benzeno e extrapolado para vácuo, e em solução aquosa, concluímos que o funcional BHandHLYP é o que melhor descreve essas transições e em segundo lugar com resultados não muito bons vem o funcional B3LYP. Na Tabela 12 mostramos os valores da transição $\pi$ $\pi^{*}$, para os funcionais BHandHLYP e B3LYP, variando com o ângulo $\varphi$, de $15^{\circ}$ a $45^{\circ}$ para a orto-betaina isolada e de $52.5^{\circ}$ a $82.5^{\circ}$ em solução aquosa. Adicionalmente, nas duas últimas colunas dessa tabela também é mostrado o deslocamento solvatocrômico. Consideramos como nosso melhor resultado, fazendo a relaxação da geometria de $\varphi=30^{\circ}$ em vácuo para $\varphi$ $=60^{\circ} \mathrm{em}$ água e usando o funcional BHandHLYP, o valor de $0.90 \pm 0.14 \mathrm{eV}(=7260 \pm 1130$ $\mathrm{cm}^{-1}$ ) em muito bom acordo com o resultado experimental de $0.93 \mathrm{eV}\left(=7500 \mathrm{~cm}^{-1}\right) \mathrm{de}$ benzeno para água e $0.99 \pm 0.14 \mathrm{eV}\left(=7980 \pm 1130 \mathrm{~cm}^{-1}\right)$ de vácuo para água.

Tabela 12: Imagem da tabela 2 retirada da ref. [47] com os valores da transição $\pi-\pi^{*}$, para os funcionais BHandHLYP e B3LYP, variando com o ângulo $\varphi$, de $15^{\circ}$ a $45^{\circ}$ para a orto-betaina isolada e de $52.5^{\circ}$ a $82.5^{\circ}$ em solução aquosa. $\mathrm{O}$ deslocamento solvatocrômico é mostrado nas últimas duas colunas.

\begin{tabular}{|c|c|c|c|c|c|c|}
\hline \multirow[t]{2}{*}{$\varphi\left(^{\circ}\right)$} & \multicolumn{2}{|c|}{ Vacuum } & \multicolumn{2}{|c|}{ In water } & \multicolumn{2}{|c|}{ Vacuum-water shift } \\
\hline & B3LYP & BHandHLYP & B3LYP & BHandHLYP & B3LYP & BHandHLYP \\
\hline 15.0 & 2.17 & 2.56 & & & & \\
\hline 22.5 & 2.09 & 2.51 & & & & \\
\hline 30.0 & 2.02 & 2.46 & & & & \\
\hline 37.5 & 1.94 & 2.39 & & & & \\
\hline 45.0 & 1.84 & 2.31 & 2.59 & 3.28 & $0.57 \pm 0.17$ & $0.82 \pm 0.14$ \\
\hline 52.5 & & & 2.57 & 3.33 & $0.55 \pm 0.17$ & $0.87 \pm 0.14$ \\
\hline 60.0 & & & 2.54 & 3.36 & $0.52 \pm 0.17$ & $0.90 \pm 0.14$ \\
\hline 67.5 & & & 2.48 & 3.37 & $0.46 \pm 0.17$ & $0.91 \pm 0.14$ \\
\hline 75.0 & & & 2.43 & 3.36 & $0.41 \pm 0.17$ & $0.91 \pm 0.14$ \\
\hline 82.5 & & & 2.45 & 3.44 & $0.43 \pm 0.17$ & $0.98 \pm 0.14$ \\
\hline Exp. $^{a}$ & \multicolumn{2}{|c|}{$\begin{array}{c}2.35 \text { in benzene } \\
2.29 \pm 0.16 \text { in vacuum }\end{array}$} & \multicolumn{2}{|c|}{3.28} & \multicolumn{2}{|c|}{$\begin{array}{c}0.93 \\
0.99 \pm 0.16\end{array}$} \\
\hline
\end{tabular}

${ }^{a}$ Experimental absorptions (in eV) from Ref. [8]. 
Portanto, conseguimos ter uma boa descrição do deslocamento solvatocrômico da transição $\pi-\pi^{*}$ da orto-betaina devido a presença da água considerando o efeito de polarização do soluto na solução aquosa. Essa polarização em água não muda muito o perfil de energia livre em relação ao ângulo de torção entre os anéis piridinium e fenóxido, mas provoca uma grande estabilização a separação de carga entre os dois anéis. Sendo assim, consideramos que a inclusão da polarização eletrônica do soluto é decisiva na correta descrição do efeito do solvente no processo de absorção de luz da betaina piridium-Nfenóxido.

\subsubsection{Journal of Physical Chemistry A, 110, 7253 (2006)}

Neste trabalho de autoria minha, C. P. Lima, Prof. W. R. Rocha e Prof. Canuto [48], anexado no Apêndice $\mathrm{P}$, fizemos o estudo do processo de tautomerização da molécula de mercaptopirimidina isolada e em solução aquosa. A tautomerização é um processo de transferência do átomo de hidrogênio dentro da mesma molécula. Sendo assim, esse processo envolve reações químicas com quebra e formação de ligações químicas. Estudamos esse processo por duas rotas: a intramolecular direta, onde o hidrogênio deixa de se ligar ao enxofre e passa a se ligar ao nitrogênio, e o auxiliado pelo solvente, onde o hidrogênio deixa de se ligar ao enxofre para se ligar a uma molécula de água próxima e essa molécula libera outro hidrogênio para se ligar ao nitrogênio. Essas duas rotas foram inicialmente estudadas em vácuo através de cálculos quânticos (ver Figura 33 à esquerda).
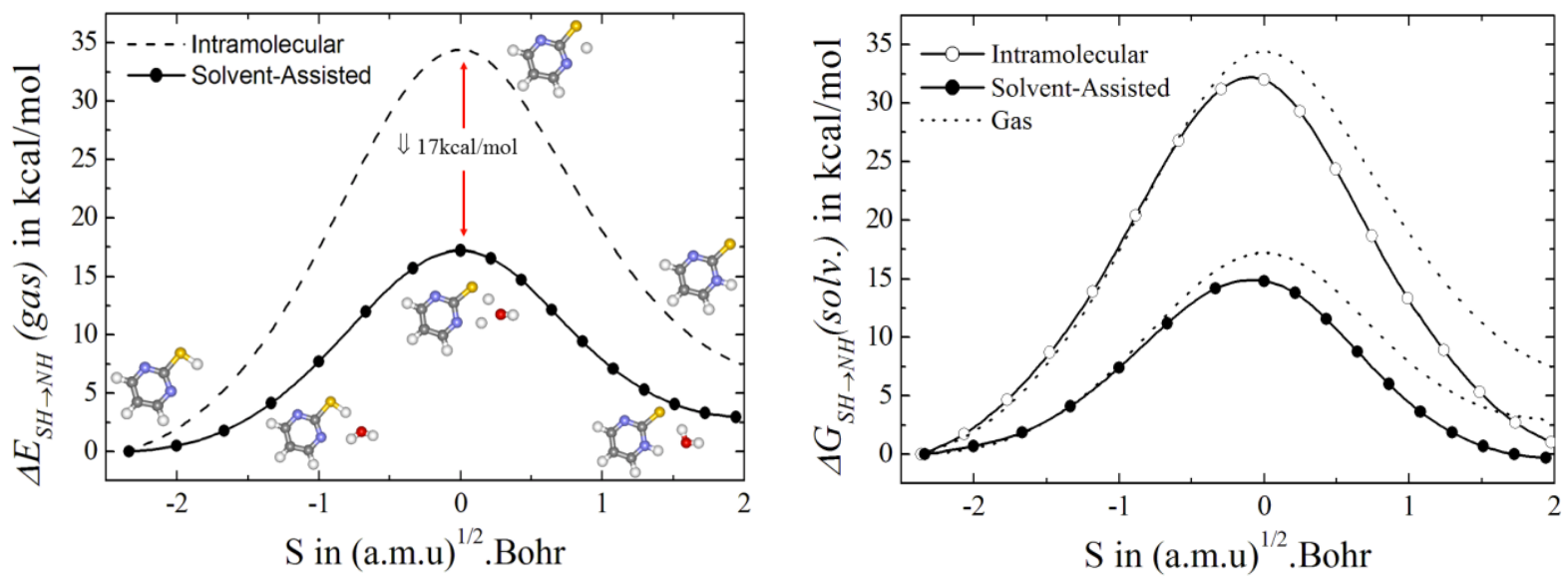

Figura 33: Perfil de energia ao longo do processo de tautomerização da mercaptopirimidina em vácuo (esquerda) e perfil de energia livre em solução aquosa (direita). As linhas tracejadas mostram os resultados em vácuo apenas para comparação. Gráficos modificados da ref. [48]. 
Observa-se que a forma tiol (com o hidrogênio ligado ao enxofre) é mais estável que a forma tione (com o hidrogênio ligado ao nitrogênio) e que o processo auxiliado pela água funcional como catalizador do processo, pois abaixa consideravelmente a barreira. A inclusão de apenas uma molécula de água no processo não é suficiente para estabilizar a forma tione, como é esperado experimentalmente. Ao longo da coordenada de reação geramos 17 geometrias e seus respectivos conjuntos de cargas atômicas para cada rota. Em seguida, utilizamos essas 17 geometrias e conjuntos de cargas para realizamos 8 simulações com dupla amostragem para cálculos das variações de energia livre ao longo da coordenada de reação.

Na Figura 33 (direita) mostramos as curvas de energia livre que obtivemos para ambas as rotas. Nota-se que para o processo auxiliado pelo solvente (pontos sólidos) a forma tione passa a ser mais estável por $\Delta G_{S H \rightarrow N H}(s o l v)=-0.3 \pm 0.9 \mathrm{kcal} / \mathrm{mol}$. Sendo assim, esse resultado é inconclusivo.

Para termos resultados confiáveis, ao invés de calcularmos o $\Delta G_{S H \rightarrow N H}($ solv $)$ diretamente, através do caminho de reação, utilizamos o ciclo termodinâmico ilustrado na Figura 13 e realizamos o cálculo de $\Delta G_{S H \rightarrow N H}(\operatorname{solv})$ utilizando a equação 53, ou seja, através do solvatação diferencial das formas tiol, $\mathrm{SH}$, e tione, $\mathrm{NH}$. Na parte de cima da Tabela 13 mostramos todas as etapas do procedimento perturbativo utilizado para calcular a energia livre de solvatação de cada forma, SH e NH. No total foram realizadas 5 simulações com amostragem dupla: 3 para aniquilar as cargas, 1 para reduzir o parâmetro $\varepsilon$ do potencial Lennard-Jones e 1 para aniquilar o potencial Lennard-Jones. Ao final obtivemos que a forma tione, que tem maior momento de dipolo, é a que solvata melhor em solução aquosa por $\Delta G_{N H}($ solv $)=-21.74 \pm 0.47 \mathrm{kcal} / \mathrm{mol}$, enquanto que a solvatação da forma tione é de $\Delta G_{N H}($ solv $)=-11.58 \pm 0.56 \mathrm{kcal} / \mathrm{mol}$. Na parte de baixo da Tabela 13 mostramos o sumário dos resultados obtidos com esse procedimento. Observa-se que esse procedimento mostra a forma tione como mais estável em solução aquosa por $\Delta G_{S H \rightarrow N H}($ solv $)=-1.86 \pm$ $1.03 \mathrm{kcal} / \mathrm{mol}$. Esse resultado é coerente com a observação experimental, mas não há dados numéricos para uma comparação quantitativa.

Atualmente, acreditamos que esse valor obtido de $\Delta G_{S H \rightarrow N H}(\operatorname{solv})=-1.86 \pm 1.03$ $\mathrm{kcal} / \mathrm{mol}$ é um limite inferior, pois se polarizarmos as formas tiol e tione em solução aquosa, vamos ver um maior efeito de polarização na forma tione, devido a seu maior momento de dipolo. Desta forma, a forma tione teria uma energia livre de solvatação ainda mais estabilizada. 
Tabela 13: Imagem das tabelas 5 e 8 retiradas da ref. [48] com as etapas do processo perturbativo para o cálculo da energia livre de solvatação das formas tiol, $\mathrm{SH}$, e tione, $\mathrm{NH}$, (em cima) e o sumário dos resultados obtidos através do ciclo termodinâmico de solvatação (embaixo).

TABLE 5: Gibbs Free Energy of Solvation (kcal/mol) for the Two Tautomeric Species Thiol and Thione in Aqueous Solution at $25^{\circ} \mathrm{C}$ and 1 atm

\begin{tabular}{|c|c|c|c|}
\hline \multirow[b]{2}{*}{$\lambda_{i}$ in $q$} & \multirow[b]{2}{*}{$\lambda_{j}$ in $q$} & \multicolumn{2}{|c|}{$\Delta G_{\lambda_{i} \rightarrow \lambda_{j}}$ (solv) } \\
\hline & & Pym-SH & Pym-NH \\
\hline 1.0 & 0.9 & 0.889 & 2.923 \\
\hline 0.9 & 0.8 & 0.772 & 2.587 \\
\hline 0.8 & 0.6 & 1.172 & 3.799 \\
\hline 0.6 & 0.4 & 0.804 & 2.722 \\
\hline 0.4 & 0.2 & 0.449 & 1.582 \\
\hline 0.2 & 0.0 & 0.162 & 0.616 \\
\hline \multicolumn{2}{|c|}{ total of stage 1} & 4.248 & 14.230 \\
\hline & & \multicolumn{2}{|c|}{$\Delta G_{\lambda_{i} \rightarrow \lambda_{j}}($ solv $)$} \\
\hline$\lambda_{i}$ in $\epsilon$ & $\lambda_{j}$ in $\epsilon$ & with $q=0$ & with $q=0$ \\
\hline 1.0 & 0.5 & 3.669 & 3.715 \\
\hline 0.5 & 0.01 & 5.980 & 6.100 \\
\hline \multicolumn{2}{|c|}{ total of stage 2} & 9.649 & 9.815 \\
\hline & & \multicolumn{2}{|c|}{$\Delta G_{\lambda_{i} \rightarrow \lambda_{j}}$ (solv) } \\
\hline$\lambda_{i}$ in $\sigma$ & $\lambda_{j}$ in $\sigma$ & $\begin{array}{l}\text { with } q=0 \text { and } \\
\qquad \epsilon=1 \%\end{array}$ & $\begin{array}{c}\text { with } q=0 \text { and } \\
\epsilon=1 \%\end{array}$ \\
\hline 1.0 & 0.0 & -2.315 & -2.305 \\
\hline $\begin{array}{l}\text { total } \Delta G_{X-0}( \\
\Delta G_{X}(\text { solv })\end{array}$ & & $\begin{array}{r}11.58 \pm 0.56 \\
-11.58 \pm 0.56\end{array}$ & $\begin{array}{r}21.74 \pm 0.47 \\
-21.74 \pm 0.47\end{array}$ \\
\hline
\end{tabular}

TABLE 8: Summary of the Calculated Relative Gibbs Free Energies and Activation Barriers $(\mathrm{kcal} / \mathrm{mol})$ As Obtained from the ab Initio MP4//MP2/6-31++G(d,p) and Monte Carlo Simulations

\begin{tabular}{|c|c|c|c|c|}
\hline & & gas & \multicolumn{2}{|c|}{ solution } \\
\hline$\Delta H_{\mathrm{SH} \rightarrow \mathrm{NH}}$ & & 8.6 & \multicolumn{2}{|c|}{$-1.71 \pm 0.52$} \\
\hline$\Delta G_{\mathrm{SH} \rightarrow \mathrm{NH}}$ & & 8.3 & \multicolumn{2}{|c|}{$-1.86 \pm 1.03$} \\
\hline & \multicolumn{4}{|c|}{ Transition State (Activation Barrier) ${ }^{a}$} \\
\hline & \multicolumn{2}{|c|}{ gas } & \multicolumn{2}{|c|}{ solution } \\
\hline & $\mathrm{IM}$ & WA & IM & WA \\
\hline$\Delta G_{\mathrm{SH} \rightarrow \mathrm{TS}}$ & 34.4 & 17.2 & 32.0 & 14.8 \\
\hline
\end{tabular}

${ }^{a} \mathrm{IM}$ stands for intramolecular and WA for the water-assisted mechanisms.

3.6.4. Theoretical Chemistry Accounts, 131, 1214 (2012)

Neste trabalho de autoria minha, M. V. A. Damasceno e Prof. Cabral [49], anexado no Apêndice Q, estudamos a estabilidade conformacional cis-trans da molécula de óxido mesitil 
(MOx) em solução aquosa e seus efeitos no deslocamento solvatocrômico devido a presença da solução aquosa.

Inicialmente realizamos os estudos da molécula de MOx isolada com cálculos quânticos utilizando vários métodos/bases. Identificamos que a forma syn (ou cis) é mais estável que a forma anti (ou trans) por cerca de $2.0 \mathrm{kcal} / \mathrm{mol}$. Após as simulações e o procedimento iterativo de polarização do soluto, realizamos cálculos da energia livre de solvatação das formas syn e anti em água, utilizando o método FEP. Identificamos que a forma anti é a mais estável em solução aquosa por cerca de $2.8 \mathrm{kcal} / \mathrm{mol}$. Sendo assim, nossa principal conclusão foi que o MOx apresenta estabilidade conformacional dependente do solvente. Em fase gasosa ou em solventes de polaridade baixa o MOx existe predominantemente na forma syn e em solução aquosa na forma anti. A consideração da polarização em água do MOx foi muito importante para descrever corretamente a interação eletrostática soluto-solvente.

Em seguida, após analisarmos as camadas de solvatação com MDDF, selecionamos 75 configurações estatisticamente descorrelacionadas e realizamos os cálculos quânticos, nosso melhor resultado para o solvatocromismo da transição $\pi-\pi^{*}$ do MOx devido a presença da água é um deslocamento de $-2520 \pm 90 \mathrm{~cm}^{-1}$, em excelente concordância com o valor experimental extrapolado de $-2410 \pm 90 \mathrm{~cm}^{-1}$. Esse deslocamento de cerca de $-2500 \mathrm{~cm}^{-1}$ pode ser dividido em duas contribuições distintas e opostas. Uma contribuição está relacionada com a mudança conformacional syn $\rightarrow$ anti que produz um deslocamento da transição de cerca de $+1700 \mathrm{~cm}^{-1}$. A outra contribuição é o efeito do solvente sobre a estrutura eletrônica do MOx que produz um deslocamento da transição de cerca de -4200

$\mathrm{cm}^{-1}$. Além disso, analisando nossos resultados podemos mostrar que esse deslocamento causado pelo efeito solvente sobre a estrutura eletrônica do MOx pode ser decomposto em três contribuições: $10 \%$ devido à inclusão explícita das moléculas de água que formam ligações de hidrogênio com o MOx, 30\% devido à inclusão explícita das moléculas de água da primeira camada de solvatação e $60 \%$ devido ao efeito eletrostático do bulk.

Essa aplicação nos mostra a versatilidade da combinação do método S-QM/MM com os cálculos de variação de energia livre de forma perturbativa nas simulações computacionais.

\section{Conclusões}

Analisando minha atividade científica, percebe-se que meu foco está na parte de desenvolvimento de métodos, técnicas e algoritmos no tema de efeitos de solventes, ou efeitos do ambiente de forma mais ampla, em propriedades moleculares, no qual venho continuamente trabalhando nos últimos 15 anos. 
Com base nos resultados dos nossos artigos publicados, e parte deles aqui discutidos, podemos afirmar que nossa proposta pioneira do método sequencial com mecânica quântica e mecânica molecular, S-QM/MM, e em seguida associado aos cálculos de variação de energia livre com métodos perturbativos nas simulações, compõem uma ferramenta teórica bastante poderosa na área de modelagem molecular. Esperamos dar continuidade nessa linha, ampliando os sistemas estudados para uma maior interface com sistemas biológicos e biosensores.

\section{Referências}

[1] K. Coutinho, "Modelo Discreto de Solvente. Solvatocromismo no Espectro de Absorção Molecular", Tese de doutorado, Instituto de Física da Universidade de São Paulo (1997).

[2] S. Canuto, K. Coutinho, Adv. Quantum Chem., 28, 89 (1997).

[3] K. Coutinho, M. J. de Oliveira, S. Canuto, Int. J. Quantum Chem., 66, 249 (1998).

[4] K. Coutinho, S. Canuto, M. C. Zerner, Int. J. Quantum Chem., 65, 885 (1997).

[5] K. Coutinho, S. Canuto, "DICE(v1.0): A Monte Carlo program for molecular liquid simulation in NVT ensemble", University of São Paulo, Brazil (1997); "DICE(v2.0): includes NPT ensemble" (2000); "DICE (v2.8): includes preferential sampling technique" (2001); "DICE (v2.9): includes Thermodynamic Perturbation Theory" (2003); "DICE(v2.9c): actual version" (2011).

[6] C. Reichardt, "Solvents and solvent effects in organic chemistry", 3rd edn., WileyVCH (2003).

[7] S. Canuto (Ed.), "Solvation Effects on Molecules and Biomolecules Computational Methods and Applications Series: Challenges and Advances in Computational Chemistry and Physics", Springer, vol. 6 (2008).

[8] L. Onsager, J. Am. Chem. Soc., 58, 1486 (1936).

[9] J. G. Kirkwood, J. Chem. Phys. 2, 351 (1934).

[10] O. Tapia, O. Goscinski, Mol. Phys., 29, 1653 (1975).

[11] D. Rinaldi, J. L. Rivail; Theor. Chim. Acta., 32, 57 (1973); J. L. Rivail, D. Rinaldi; Chem. Phys., 18, 233 (1976).

[12] S. Miertus, E. Scrocco, J. Tomasi, Chem. Phys., 55, 117 (1981); J. Tomasi, M. Persico, Chem. Rev. 94, 2027 (1994); V. Barone, M. Cossi, J. Tomasi, J. Chem. Phys. 107, 3210 (1997); J. Tomasi, Theor. Chem. Acc., 112, 184 (2004). J. Tomasi, B. Mennucci, R. Cammi, Chem. Rev. 105, 2999 (2005).

[13] M. P. Allen, D. J. Tildesley, "Computer Simulation of Liquids", Oxford Press (1987); A. R. Leach, "Molecular Modelling: Principles and Applications", $2^{\text {nd }}$ ed., Pearson Education (2001); D. Frenkel, B. Smit, "Understanding Molecular Simulation: From Algorithms to Applications", $2^{\text {nd }}$ ed., Academic Press (2002). 
[14] D. Marx, J. Hutter "Ab Initio Molecular Dynamics: Basic Theory and advanced methods", Cambridge University Press (2009).

[15] R. Car, M.Parrinello, Phys. Rev. Lett. 55 , 2471 (1985).

[16] T. Helgaker, E. Uggerud, H. J. A. Jensen, Chem. Phys. Lett., 173, 145 (1990).

[17] D. K. Remler, P. A. Madden, Mol. Phys., 70, 921 (1990).

[18] A Pérz, M. E. Tuckerman, M. H. Müser, J. Chem. Phys., 130, 184105 (2009).

[19] L.D. Schuler, X. Daura, W. F. van Gunsteren, J. Comput. Chem., 22, 1205 (2001).

[20] W. D. Cornell, P. Cieplak, C. I. Bayly, I. R. Gould, K. M. Merz Jr., D. M. Ferguson, D. C. Spellmeyer, T. Fox, J. W. Caldwell, P. A. Kollman, J. Am. Chem. Soc., 117, 5179 (1995).

[21] B. R. Brooks, R. E. Bruccoleri, B. D. Olafson, D. J. States, S. Swaminathan, M. Karplus, J. Comp. Chem. 4, 187 (1983).

[22] W. L. Jorgensen, D. S. Maxwell, J. Tirado-Rives, J. Am. Chem. Soc., 118, 11225 (1996).

[23] A. K. Rappe, C. J. Casewit, K. S. Colwell, W. A. Goddard III, W. M. Skiff, J. Am. Chem. Soc. 114, 10024 (1992).

[24] J. L. Gao, in: K. B. Lipkowitz, D. B. Boyd (Eds.), Reviews of Computational Chemistry, vol 7, p. 119 (1996).

[25] M. F. Ruiz-López (Ed.), J. Mol. Struct. (Theochem) 632, special issue on Combined QM/MM calculations in chemistry and biochemistry (2003).

[26] A. Warshell, M. Levitt, J. Mol. Biol., 103, 227 (1976).

[27] M. Orozco, F. J. Luque, Chem. Rev., 100, 4187 (2000).

[28] C. J. Cramer, "Essentials of computational chemistry: Theories and models", 2nd edn., Wiley (2004).

[29] H. Lin, D. G. Truhlar, Theor. Chem. Acc., 117, 185 (2007).

[30] M. J. Field, P. A. Bash, M. Karplus, J. Comput. Chem., 11, 700 (1990).

[31] J. L. Gao, F. J. Luque, M. Orozco, J. Chem. Phys., 98, 2975 (1993).

[32] N. Reuter, A. Dejaegere, B. Maigret, M. Karplus, J. Phys. Chem. A, 104, 1720 (2000).

[33] J. T. Blair, K. Krogh-Jespersen, R. M. Levy, J. Am. Chem. Soc., 111, 6948 (1989); R. M. Levy, D. B. Kitchen, J. T. Blair, K. Krogh-Jespersen, J. Phys. Chem., 94, 4470 (1990); J. T. Blair, R. M. Levy, K. Krogh-Jespersen, Chem. Phys. Lett., 166, 429 (1990).

[34] J. Zeng, N. S. Hush, J. R. Reimers, J. Chem. Phys., 99, 1508 (1993); J. Zeng, J. S. Craw, N. S. Hush, J. R. Reimers, J. Phys. Chem., 98, 11075 (1994).

[35] K. Coutinho, S. Canuto, J. Mol. Structure (Theochem), 287, 99 (1993); K. Coutinho, S. Canuto; Química Nova, 17, 480 (1994).

[36] K. Coutinho, S. Canuto, M. C. Zerner, J. Chem. Phys., 112, 9874 (2000).

[37] S. Canuto, K. Coutinho, Int. J. Quantum Chem., 77, 192 (2000).

[38] K. Coutinho, S. Canuto, J. Chem. Phys., 113, 9132 (2000). 
[39] S. Canuto, K. Coutinho, D. Trzesniak, Adv. Quantum Chem., 41, 161 (2002).

[40] H. C. Georg, K. Coutinho, S. Canuto, J. Chem. Phys. 126, 34507-1 (2007).

[41] P. Jaramillo, P. Pérez, P. Fuentealba, S. Canuto, K. Coutinho, J. Phys. Chem. B, 113, 4314 (2009).

[42] S. Canuto, K. Coutinho, B. J. C. Cabral, V. G. Zakrzewski, J. V. Ortiz, J. Chem. Phys., 132, 214507 (2010).

[43] K. Coutinho, H. C. Georg, T. L. Fonseca, V. Ludwig, S. Canuto, Chem. Phys. Lett., 437, 148 (2007).

[44] H. C. Georg, K. Coutinho, S. Canuto, Chem. Phys. Lett., 429, 119 (2006).

[45] W. Nitschke, C. Vequi-Suplicy, K. Coutinho, H. Stassen, J. Phys. Chem. B, 116, 2713 (2012).

[46] M. Z. Hernandes, R. Longo, K. Coutinho, S. Canuto, Phys. Chem. Chem. Phys., 6, 2088 (2004).

[47] L. B. A. Oliveira, T.L. Fonseca, K. Coutinho, S. Canuto, Chem. Phys. Let., 514, $251(2011)$.

[48] M. C. P. Lima, K. Coutinho, W. R. Rocha and S. Canuto, J. Phys. Chem. A, 110, 7253 (2006).

[49] M. V. A. Damasceno, B. J. C. Cabral, K. Coutinho, Theor. Chem. Acc., 131, 1214 (2012).

[50] P. Ehrenfest, T. Ehrenfest, "The Conceptual Foundations of the Statistical Approach in Mechanics", M. J. Moravicsik (Trad.), Cornell U. P. (1959).

[51] K. Coutinho; "ORDER (v1.0): Performs structural analysis in the liquid conformations", University of São Paulo, Brazil, (2001); “ORDER (v2.0): includes hydrogen bonds analysis between solute and solvent" (2004); "ORDER (v2.5): generates the average solvent electrostatic configuration, ASEC", (2006); "ORDER (v2.6): includes hydrogen bonds analysis between solute and heterogeneous solvent an between solvent and solvent, ASEC", (2011).

[52] K. Coutinho, "CORRELATION (v1.0): "Generates de normalized auto-correlation function and the statistical inefficiency of several properties generated during the simulação", University of São Paulo, Brazil, (1997);

[53] K. Coutinho, "DiceWin (v3.0): Graphic interface for the DICE and ORDER programs", University of São Paulo, Brazil (2004).

[54] http://fig.if.usp.br/ kaline/

[55] N. Metropolis, A. W. Rosenbluth, M. N. Rosenbluth, A. H. Teller, E. Teller; J. Chem. Phys., 21, 1087 (1953).

[56] S. R. Elliott, S. R., "Physics of Amorphous Materials", 2nd ed., New York, Longman Scientific (1990).

[57] N. S. Gingrich, Rev. Mod. Phys., 15, 90 (1943).

[58] A. Guinier, G. Fournet, C. B. Walker, K. L. Yudowitch; "Small Angle Scattering of X-Ray”, Wiley, New York, (1955). 
[59] K. J. Almeida, K. Coutinho, W. B. Almeida, W. R. Rocha, S. Canuto, Phys. Chem. Chem. Phys., 3, 1583 (2001).

[60] T. Malaspina, K. Coutinho and S. Canuto, J. Chem. Phys. 117, 1692 (2002).

[61] M. G. Kendal, "Time Series", Griffin, (1973); C. Chatfield, "The Analysis of Time Series. An Introduction", Chapman and Hall (1984).

[62] R. Krätschmer, K. Binder, D. Stauffer, J. Stat. Phys. 15, 267 (1976); A. Caprihan, J. D. Seymour, J. Mag. Res. 144, 96 (2000).

[63] H. Müller-Krumbhaar, K. Binder, J. Stat. Phys., 8, 1 (1973); S. Tang, D. P. Landau, Phys. Rev. B, 36, 567 (1987).

[64] K. Coutinho, R. Rivelino, H. C. Georg, S. Canuto, in "Solvation Effects on Molecules and Biomolecules Computational Methods and Applications", S. Canuto (Ed.), Series: Challenges and Advances in Computational Chemistry and Physics, Springer, vol. 6, cap. 7, 159-189 (2008). ISBN: 978-1-4020-8269-6.

[65] R. Friedberg, J. E. Cameron, J. Chem. Phys., 52, 6049 (1970).

[66] K. Coutinho, T. L. Fonseca, S. Canuto, in "Approximate Molecular Orbital Methods", E. A. Boudreaux (Ed.), Transworld Research Network, chapter 2, pp. 6384 (2010).

[67] M. J. Frisch, G. W. Trucks, H. B. Schlegel, G. E. Scuseria, M. A. Robb, J. R. Cheeseman, J. A. Montgomery, Jr., T. Vreven, K. N. Kudin, J. C. Burant, J. M. Millam, S. S. Iyengar, J. Tomasi, V. Barone, B. Mennucci, M. Cossi, G. Scalmani, N. Rega, G. A. Petersson, H. Nakatsuji, M. Hada, M. Ehara, K. Toyota, R. Fukuda, J. Hasegawa, M. Ishida, T. Nakajima, Y. Honda, O. Kitao, H. Nakai, M. Klene, X. Li, J. E. Knox, H. P. Hratchian, J. B. Cross, V. Bakken, C. Adamo, J. Jaramillo, R. Gomperts, R. E. Stratmann, O. Yazyev, A. J. Austin, R. Cammi, C. Pomelli, J. W. Ochterski, P. Y. Ayala, K. Morokuma, G. A. Voth, P. Salvador, J. J. Dannenberg, V. G. Zakrzewski, S. Dapprich, A. D. Daniels, M. C. Strain, O. Farkas, D. K. Malick, A. D. Rabuck, K. Raghavachari, J. B. Foresman, J. V. Ortiz, Q. Cui, A. G. Baboul, S. Clifford, J. Cioslowski, B. B. Stefanov, G. Liu, A. Liashenko, P. Piskorz, I. Komaromi, R. L. Martin, D. J. Fox, T. Keith, M. A. Al-Laham, C. Y. Peng, A. Nanayakkara, M. Challacombe, P. M. W. Gill, B. Johnson, W. Chen, M. W. Wong, C. Gonzalez, and J. A. Pople, Gaussian 03, Revision D.01, Gaussian, Inc., Wallingford CT, (2004); M. J. Frisch, G. W. Trucks, H. B. Schlegel, G. E. Scuseria, M. A. Robb, J. R. Cheeseman, G. Scalmani, V. Barone, B. Mennucci, G. A. Petersson, H. Nakatsuji, M. Caricato, X. Li, H. P. Hratchian, A. F. Izmaylov, J. Bloino, G. Zheng, J. L. Sonnenberg, M. Hada, M. Ehara, K. Toyota, R. Fukuda, J. Hasegawa, M. Ishida, T. Nakajima, Y. Honda, O. Kitao, H. Nakai, T. Vreven, J. A. Montgomery, Jr., J. E. Peralta, F. Ogliaro, M. Bearpark, J. J. Heyd, E. Brothers, K. N. Kudin, V. N. Staroverov, R. Kobayashi, J. Normand, K. Raghavachari, A. Rendell, J. C. Burant, S. S. Iyengar, J. Tomasi, M. Cossi, N. Rega, J. M. Millam, M. Klene, J. E. Knox, J. B. Cross, V. Bakken, C. Adamo, J. Jaramillo, R. Gomperts, R. E. Stratmann, 
O. Yazyev, A. J. Austin, R. Cammi, C. Pomelli, J. W. Ochterski, R. L. Martin, K. Morokuma, V. G. Zakrzewski, G. A. Voth, P. Salvador, J. J. Dannenberg, S. Dapprich, A. D. Daniels, Ö. Farkas, J. B. Foresman, J. V. Ortiz, J. Cioslowski, D. J. Fox, Gaussian 09, Revision A.1, Gaussian, Inc., Wallingford CT, (2009).

[68] M. C. Zerner, "ZINDO: a semi-empirical program package”, University of Florida, Gainesville, FL/USA, (1996).

[69] A. Szabo, N. S. Ostlund, "Modern Quantum Chemistry: Introduction to Advanced Electronic Structure Theory", 1st Ed. Revised, McGraw-Hill Publishing Company (1989); I. N. Levine, "Quantum Chemistry", 5th Ed., Prentice Hall (2000); C. J. Cramer, "Essentials of Computational Chemistry", John Wiley \& Sons, pp. 191-232 (2002).

[70] J. D. M. Vianna, A. Fazzio, S. Canuto, “Teoria Quântica de Moléculas e Sólidos Simulação Computacional”, Editora Livraria da Física (2004).

[71] N. H. Morgon, K. Coutinho (Eds), "Métodos de Química Teórica e Modelagem Molecular", Editora Livraria da Física (2007).

[72] R. G. Parr, W. Yang, "Density functional theory of atoms and 804 molecules", Oxford Science Publications (1994).

[73] A. D. Becke, J. Chem. Phys., 98, 5648 (1993); Y. Imamura, T. Otsuka, H. Nakai, J. Comput. Chem., 28, 2067 (2007).

[74] C. Møller C, M. S. Plesset, Phys. Rev., 46, 618 (1934); R. Krishnan, J. A. Pople, Int. J. Quantum Chem., 14, 91 (1978).

[75] D. Ditchfield, W. J. Hehre, J. A. Pople, J. Chem. Phys., 54, 724 (1971).

[76] T. H. Dunning Jr, J. Chem. Phys., 90, 1007, (1987).

[77] M. C. Zerner, in "Reviews of Computational Chemistry", K. B. Lipkowitz, D. B. Boyd (Eds.), VCH, vol. 2, pp. 313-366 (1991).

[78] C. D. Sherrill, H. F. Schaefer III, Adv. Quantum Chem., 34, 143 (1999).

[79] J. Ridley, M. C. Zerner, Theor. Chim. Acta, 32, 111 (1973).

[80] C. Fiolhais, F. Nogueira, M. Marques (Eds), "A primer in density functional theory", chapter 4, Springer, New York (2003).

[81] J. F. Stanton, R. J. Bartlett, J. Chem. Phys., 98, 7029 (1993).

[82] C. M. Breneman, K. B. Wiberg, J. Comput. Chem. 11, 361 (1990).

[83] H. C. Georg, K. Coutinho, S. Canuto, J. Chem. Phys., 123, 124307 (2005).

[84] A. C. Borin, L. Serrano-Andrés, V. Ludwig, K. Coutinho, S. Canuto, Int. J. Quantum Chem., 106, 2564 (2006).

[85] M. L. Sánchez, M. A. Aguilar, F. J. Olivares Del Valle, J. Comput. Chem., 18, 313 (1997); M. L. Sánchez, M. A. Aguilar, F. J. Olivares Del Valle, J. Mol. Struct. (Theochem) 426, 181 (1998); M. E. Martin, M. L. Sánchez, F. J. Olivares Del Valle, M. A. Aguilar, J. Chem. Phys. 113, 6308 (2000).

[86] N. A. McDonald, H. A. Carlson, W. L. Jorgensen, J. Phys. Org. Chem., 10, 563 (1997). 
[87] C. J. R. Illingworth, S. R. Gooding, P. J. Winn, G. A. Jones, G. G. Ferenczy, C. A. Reynolds, J. Phys. Chem. A 110, 6487 (2006); K. Aidas, J. Kongsted, A. Osted, K. V. Mikkelsen, O. Christiansen, J. Phys. Chem. A, 109, 8001 (2005); L. Jensen, P. Th. van Duijnen, J. G. Snijders, ibid. 119, 3800 (2003); J. Kongsted, A. Osted, K. V. Mikkelsen, O. Christiansen, J. Chem. Phys., 118, 1620 (2003); T. D. Poulsen, P. R. Ogilby, K. V. Mikkelsen, J. Chem. Phys., 115, 7843 (2001); S. Chalmet, M. F. RuizLópez, J. Chem. Phys. 115, 5220 (2001); P. L. Silvestrelli, M. Parrinello, Phys. Rev. Lett. 82, 3308 (1999); K. Naka, A. Morita S. Kato, J. Chem. Phys., 111, 481 (1999); J. Gao, X. Xia, Science, 258, 631 (1992).

[88] W. L. Jorgensen (Ed.), J. Chem. Theor. Comput., 3, 1877-2145 (2007); W. D. Cornell, P. Cieplak, C. I. Bayly, I. R. Gould, K. M. Merz, Jr., D. M. Ferguson, D. C. Spellmeyer, T. Fox, J. W. Caldwell, P. A. Kollman, J. Am. Chem. Soc. 117, 5179 (1995); C.J. Cramer, D.G. Truhlar, Science, 256, 213 (1992); J. Pranata, S. G. Wierschke, W. L. Jorgensen, J. Am. Chem. Soc., 113, 2810 (1991).

[89] K. Coutinho, R. C. Guedes, B. J. Costa Cabral, S. Canuto, Chem. Phys. Lett. 369, 345 (2003); R. Rivelino, B. J. C. Cabral, K. Coutinho, S. Canuto, Chem. Phys. Lett. 407, 13 (2005).

[90] T. Ohba, S. Ikawa, Mol. Phys. 73, 985 (1991).

[91] T. Fonseca, H. C. Georg, K. Coutinho, S. Canuto, J. Phys. Chem. A, 113, 5112 (2009).

[92] P. R. Schleyer (Ed.), "Encyclopedia of Computational Chemistry", vol. 2, 10361089, John Wiley and Sons (1998).

[93] A. E. Mark, in "Encyclopedia of Computational Chemistry", P. R. Schleyer (Ed.), vol. 2, 1070-1083, John Wiley and Sons (1998).

[94] C. H. Bennett, J. Comp. Phys., 22, 245 (1976); W. L. Jorgensen, C. Ravimohan, J. Chem. Phys., 83, 3050 (1985).

[95] W. L. Jorgensen, J. K. Buckner, S. Boudon, J. Tirado-Rives J. Chem. Phys., 89. 3742 (1988)

[96] H. Pasalic, A. J. A. Aquino, D. Tunega, G. Haberhauer, M. H. Gerzabek, H. C. Georg, T. F. Moraes, K. Coutinho, S. Canuto, H. Lischka, J. Comp. Chem., 31, 2046 (2010); P. Jaramillo, K. Coutinho, S. Canuto, J. Phys. Chem. A, 113, 12485 (2009); H. C. Georg, K. Coutinho, S. Canuto, Chem. Phys. Lett., 413, 16 (2005); R. C. Guedes, K. Coutinho, B. J. C. Cabral, S. Canuto, C. F. Correia, R. M. B. dos Santos, J. A. M. Simões, J. Phys. Chem. A, 107, 9197 (2003); R. C. Guedes, K. Coutinho, B. J. C. Cabral, S. Canuto, J. Phys. Chem. B, 107, 4304 (2003).

[97] A. R. Cunha, "Estudos Teóricos de Propriedades Estruturais e Eletrônicas da Molécula Emodina em Solução", Tese de doutorado, Instituto de Física da Universidade de São Paulo (2009).

[98] N. Rösch, M. C. Zerner, J. Phys. Chem. 98, 5817 (1994).

[99] S. M. Urahata, K. Coutinho, S. Canuto, Chem. Phys. Lett., 274, 269 (1997). 
[100] S. Canuto, K. Coutinho, M. C. Zerner, J. Chem. Phys., 112, 7293 (2000).

[101] K. Coutinho, N. Saavedra, S. Canuto, Theochem J. Mol. Structure, 466, 69 (1999).

[102] K. Coutinho, N. Saavedra, A. Serrano, S. Canuto, Theochem J. Mol. Struct., 539, 171 (2001).

[103] W. R. Rocha, K. J. de Almeida, K. Coutinho, S. Canuto, Chem. Phys. Let., 345, 171 (2001).

[104] W. R. Rocha, K. Coutinho, W. B. de Almeida, S. Canuto, Chem. Phys. Lett., 335, 127 (2001).

[105] H. C. Georg "Efeitos do Meio em Propriedades Conformacionais e Eletrônicas de Moléculas". Tese de doutorado, Instituto de Física da Universidade de São Paulo (2006).

[106] P. C. Couto, B. J. C. Cabral, S. Canuto, Chem. Phys. Lett., 429, 129 (2006).

[107] K. Andersson, M. Barysz, A. Bernhardsson, M.R.A. Blomberg, D. L. Cooper, T. Fleig, M. P. Fülscher, C.Graaf, B. A. Hess, G. Karlström, R. Lindh, P.-Å. Malmqvist, P. Neogrády, J. Olsen, B. O. Roos, A. J. Sadlej, M. Schütz, B. Schimmelpfennig, L. Seijo, L. Serrano-Andrés, P. E. M. Siegbahn, J. Stålring, T. Thorsteinsson, V. Veryazov, P.-O. Widmark, MOLCAS Version 5, Lund University, Sweden (2000).

[108] C. Vequi-Suplicy, "Estudos experimentais e teóricos dos espectros eletrônicos das sondas fluorescentes Prodan e Laurdan em solventes e bicamadas lipídicas" Tese de doutorado, Instituto de Física da Universidade de São Paulo (2010).

[109] E. Lindahl, B. Hess, D. van der Spoel, J. Mol. Model., 7, 306 (2001).

[110] M. V. A. Damasceno, "Estudos Teóricos dos Efeitos de Solvente no Espectro Eletrônico de Absorção da Molécula Óxido Mesitil" Dissertação de mestrado, Instituto de Física da Universidade de São Paulo (2009). 
Síntese Crítica - Kaline Rabelo Coutinho

6. Apêndices 